\title{
Novel Molten Salts Thermal Energy Storage for Concentrating Solar Power Generation
}

\author{
Performing Organizations \\ The University of Alabama (UA), Tuscaloosa, Alabama \\ Funding Opportunity Announcement Number \\ DE-PS36-08G098032 \\ Funding Organization \\ DOE EERE SETP CSP \\ Contract Number \\ DE-FG36-08GO18153 \\ DOE Contact: \\ DOE Award Administrator: Uriel Trujillo \\ DOE Project Officer: Thomas L. Rueckert
}

Key Technical Contact:

Dr. Ramana G. Reddy

ACIPCO Endowed Professor

Department of Metallurgical and Materials Engineering

P.O. Box 870202

The University of Alabama, Tuscaloosa, AL 35487-0202

Tel: (205) 348-4246

E-mail: rreddy@eng.ua.edu

October 2013 


\section{Authorized Distribution Limitation Notice:}

All information submitted in this report is public information. This report may be posted on the appropriate sub-program website, minus budget information. 


\section{Executive Summary}

\section{(i) How the research adds to the understanding of the area investigated:}

There are three steps involved in accomplishing the final goal of "Development of low melting point molten salt thermal energy storage". They are:

1. Development of lower melting point (MP) compared to current salts $\left(<222^{\circ} \mathrm{C}\right)$

2. Development of higher energy density compared to current salts $\left(>300-756^{*} \mathrm{MJ} / \mathrm{m}^{3}\right)$

3. Development of lower power generation cost compared to current salt

In each and every step of the process, more than one process variable has been examined. In the dissolution step, the effect of temperature, time and the amount of metal oxide has been estimated. The effect of changing the working electrode has been tested while determining the reduction potential using CV. Last but not the least, the effect of stirring, reduction potential, time, temperature, and the amount of metal oxide dissolved on the current efficiency and energy consumption of the process has been investigated. The final products obtained were characterized using X-ray diffraction (XRD) for phases present and scanning electron microscopy (SEM) equipped with energy dispersive spectrometer (EDS) for the determination of morphological features and elemental analysis.

\section{(ii) Technical effectiveness and economic feasibility of the methods or techniques investigated or demonstrated:}

Concentrating solar power (CSP) technologies are seen as the Solar Program's most attractive option for meeting utility-scale needs in the U.S. southwest. The research and development activities conducted in University of Alabama will reduce the cost of CSP plants and facilitate their implementation. Two key opportunities for cost reduction are the development of improved heat transfer fluids and improved methods for thermal storage.

In terms of lower power costs, the findings in this project reduce the cost of Thermal Energy Storage (TES) to less than $\$ 15 / \mathrm{kWh}$-th and achieve round trip efficiencies greater than $93 \%$.

\section{(iii) How the project is otherwise of benefit to the public:}

The public will directly benefit from this proposed technique by the low cost energy generation and storage system. Indirect benefit is the reduction of required amount of HTF in the CSP generation system due to the high energy storage density of the novel low melting point molten salt systems, which also, to some extent, decreases the emission of chemical wastes. In summary, the method of energy storage using low melting point molten salt is not only cost effective, but also environment friendly. 
Acknowledgment: "This report is based upon work supported by the U. S. Department of Energy under DE-FG36-08GO18153".

Disclaimer: "Any findings, opinions, and conclusions or recommendations expressed in this report are those of the author(s) and do not necessarily reflect the views of the Department of Energy" 


\section{Table of Contents}

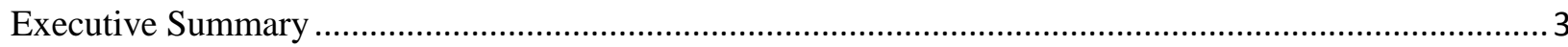

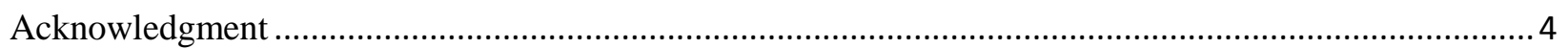

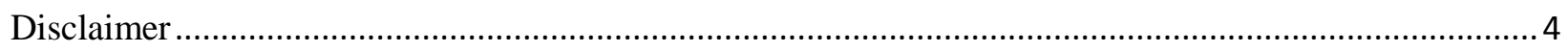

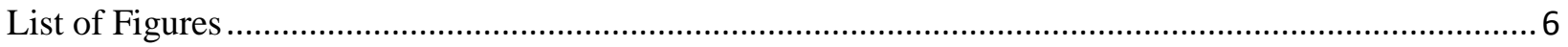

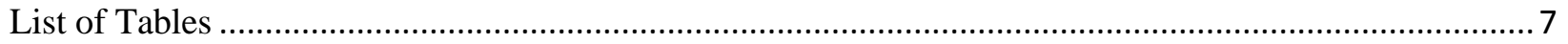

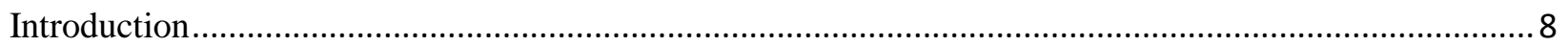

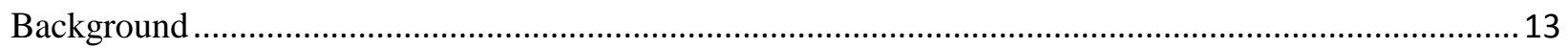

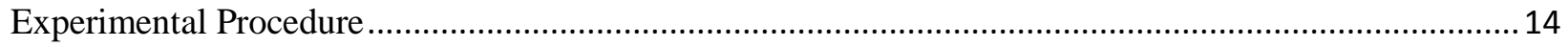

Materials and Preparation .......................................................................................................

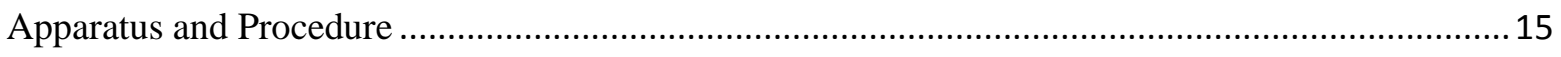

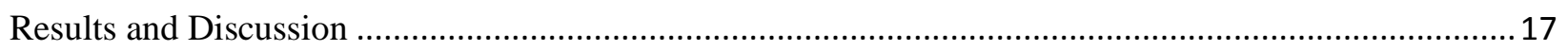

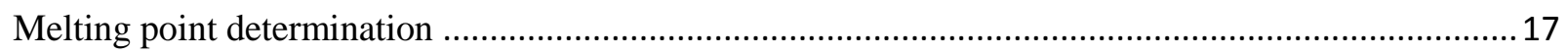

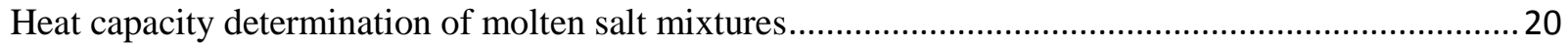

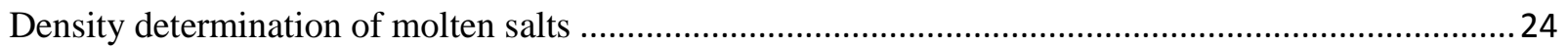

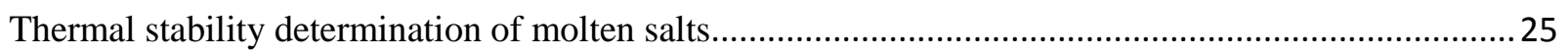

Thermal conductivity determination of salt mixtures in solid state ......................................................3

Determination of corrositivity of Low melting point (LMP) molten salts............................................ 42

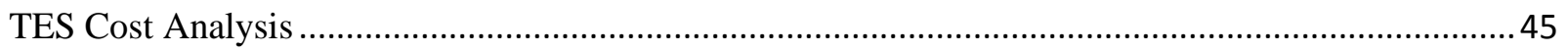

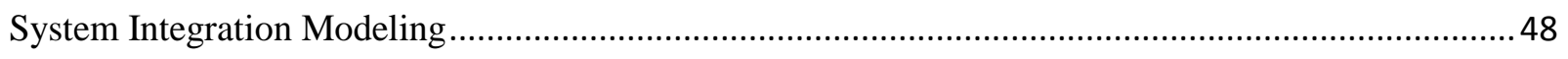

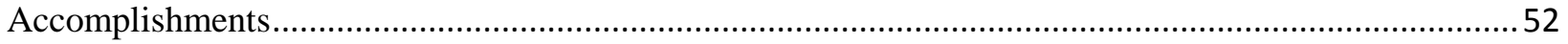

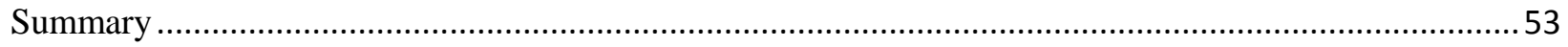

Products developed and technology transfer activities: …………………………………………..... 54

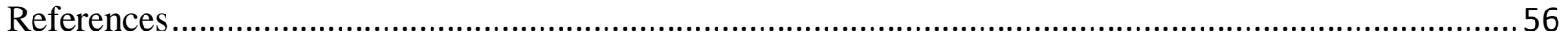




\section{List of Figures}

Fig. 1 Theoretical and engineering energy conversion efficiency as function of temperature .................. 10

Fig. 2 Gravimetric storage density for different energy storage systems as function of temperature..........12

Fig. 3 Melting point determination of LiNO3-NaNO3-KNO3 ternary system........................................ 18

Fig. 4 Representative DSC heat flow curve for the melting point determination of LiF-Na2CO3-K2CO3

eutectic ternary system in argon atmosphere

Fig. 5 DSC heat flow curves for the melting point determination of LiF-Na2CO3-K2CO3 eutectic ternary

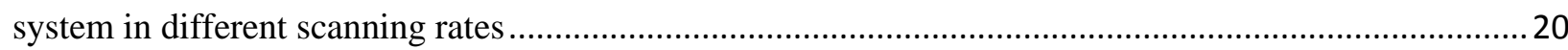

Fig. 6 Heat capacity data plot of LiNO3-NaNO3-KNO3 ternary system as function of temperature ........ 21

Fig. 7 Heat capacity of LiF-Na2CO3-K2CO3 eutectic ternary system as function of temperature ............23

Fig. 8 Weight loss of the eutectic mixture of LiNO3-NaNO3-KNO3 ternary system as function of temperature in cyclic short-term thermal stability experiment. ..............................................................26

Fig. 9 Heat flow curves using DSC for 20-cycle thermal reliability measurement of the eutectic mixture of

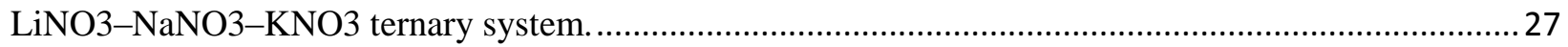

Fig. 10 60hrs long-term thermal stability measurement of LiNO3-NaNO3-KNO3 ….............................. 29

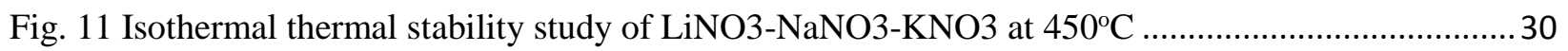

Fig. 12 Weight change of LiF-Na2CO3-K2CO3 system as function of temperature in argon atmosphere31 Fig. 13 Weight change of LiF-Na2CO3-K2CO3 system as function of temperature in carbon dioxide

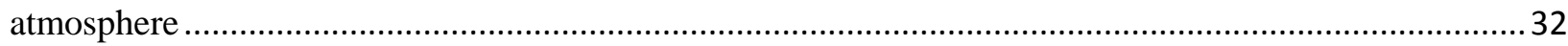

Fig. 14 Thermal gradient of cylindrical sample along the radial direction ............................................... 36

Fig. 15 Thermal conductivity of HITEC $®$ salt measured as a function of temperature ............................37

Fig. 16 (a) Comparison of extrapolated and literature data of thermal conductivity of HITEC@ salt near melting point, (b) linear variation of experimental thermal conductivity in the temperature range of 90 -

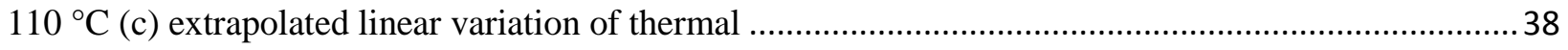

Fig. 17 Thermal conductivity of LiNO3-NaNO3-KNO3 ternary system. ................................................ 39

Fig. 18 Thermal conductivity of Li2CO3-Na2CO3-K2CO3 ternary system........................................... 40

Fig. 19 Polarization curve for LiNO3-NaNO3-KNO3 at $450{ }^{\circ} \mathrm{C}$......................................................... 42

Fig. 20 Variation of corrosion rate as a function of temperature for LiNO3-NaNO3-KNO3 salt..............43

Fig. 21 Variation of corrosion rate as a function of temperature for Salt \# LiNO3-NaNO3-KNO3-MgKN

Fig. 22 Variation of corrosion rate as a function of temperature for Salt \# LiNO3-NaNO3-KNO3-NaNO2

Fig. 23 Variation of corrosion rate as a function of temperature for LiNO3-NaNO3-KNO3-NaNO2$\mathrm{KNO} 2$.

Fig. 24 TES Calculations using 2009 EPRI Baseline (from Phase I report). Blue bars assume full delta T and linear equipment scaling; red bars assume average properties at $350{ }^{\circ} \mathrm{C}$ and 0.7 power scaling. ........47 Fig. 25 Oil based HTF system - 2 Tank "Indirect” TES - Baseline Case 1 ........................................... 49

Fig. 26 Molten Salt based HTF system - 2 Tank "Direct” TES - Case 2 ................................................ 49 Fig. 27 Molten Salt based HTF system - 2 Tank "Direct" TES with salt heating all FWH (except FWH3 which is a deaerator) - Case 5 .50 


\section{List of Tables}

Table 1 Experimental determined and predicted melting points of molten salt systems ..........................17

Table 2 Heat capacities of molten LMP systems ............................................................................... 21

Table 3 Heat capacities of molten HMP systems............................................................................ 24

Table 4 Coefficient A and B for density determination of LMP salt systems .......................................24

Table 5 Weight loss of the eutectic mixture of LiNO3-NaNO3-KNO3 ternary system at different cycles

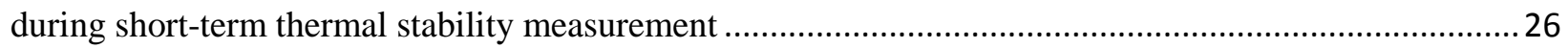

Table 6 Short-term thermal stability of LMP molten salt systems ........................................................28

Table 7 Upper limit of thermal stability and weight loss of LMP molten salt systems at $500^{\circ} \mathrm{C}$ after $20 \mathrm{hrs}$

Table 8 Upper limit temperature of thermal stability under carbon dioxide atmosphere ........................32

Table 9 Isothermal range along Z-axis of different solid samples with $75 \mathrm{~mm}$ cylinder length.................34

Table 10 Thermal conductivity of LMP and HMP molten salt systems at melting point......................... 41

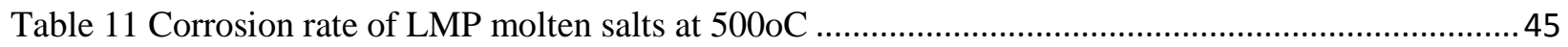

Table 12 Cost Model Baseline Cost Comparisons........................................................................... 46

Table 13 TES cost estimates based upon EPRI System as a baseline ...................................................... 46

Table 14 . Oil vs. Salt - Solar Field Size, HTF Flow Rates and Comparative Pressure Drops .................. 48 Table 15 Modeling Results from Expanded Molten Salt Energy Use - Cases Using $\mathrm{LiNO}_{3}-\mathrm{NaNO}_{3}-\mathrm{KNO}_{3}$

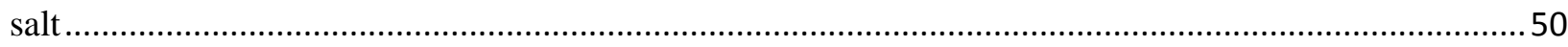

Table 16 Key Metric Comparison for All Cases and All Salts ............................................................ 51

Table 17 Comparison of the actual accomplishments with the goals and objectives of the project ...........52 


\section{Introduction}

Renewable energy sources such as wind, solar, water power, geothermal and biomass are playing more and more significant role in our energy supply. Because the cheap cost and infinite amount of energy storage inside the resource, solar energy is emphasized since $20^{\text {th }}$ century and viewed as promising alternative method to satisfy the large energy consuming every day in the world, reduce the emission of carbon and strengthen the economy.

The wind energy was used as a clean energy to generate electricity back to late $19^{\text {th }}$ century. However, this renewable energy source was not emphasized due to the cheap price of fossil fuel. The re-emergence happened in mid 1950s when the amount of traditional energy source was found apparently decrease. The development of wind energy usage continued and in 1990 the first megawatt wind turbine was launched, which was viewed as a symbol of shift to large scale wind energy utilization [1-2]. The modern application of wind energy mainly relies on wind turbine. On the basis of aerodynamic, wind turbine generates certain net positive torque on rotating shaft and then converts the mechanical power to electrical power. As an electrical power generator, wind turbine are connected some electrical network to transport the electricity to battery charging utilities, residential power systems and large scale energy consuming systems. In general, most of wind turbines are small scale and can only generate $10 \mathrm{KW}$ electrical power. Only few of the wind turbine systems operate with capacity as large as 5MW. Although the usage of wind energy can reduce the emission of carbon oxide, the noise pollution and high cost limit its large scale application. Since the wind is not transportable, the electrical energy can only be generated where the wind blows, which also decrease the flexibility of wind energy.

Water power is another term of alternative power supply and it was used for irrigation, operating machines like watermill even before the development of electrical power. The modern application of water power is to generate electricity by using the gravitational force of falling or flowing water. These days, there are various ways for the water power application. The most traditional method is to store the water in dam and generate electricity by converting the potential energy; pump storage is a different way to utilized water power and can change its output depending on the energy demand by moving water between reservoirs at different elevations. In the low energy demand period, excess energy is used to lift water to the higher level, while in the peak period of energy demand, the water is released back to the lower elevation through water turbine. Water power can also be converted by taking advantage of naturally raise and fall of tide to satisfy the demand of electrical energy consumption [3]. Although the usage of water power can reduce the emission of carbon dioxide and cost, it will destroy the ecosystem because of the large land required for construction. There will be methane emission from the reservoir; the potential failure hazard of dam is also a fatal issue and flow shortage caused by drought may also create serious problem. As result of that, water power technique is not a long-term alternative choice.

Biomass is a renewable energy source used to generate heat or electricity with living or recently living organism such as wood, waste, (hydrogen) gas and alcohol fuels. The biomass energy can 
be converted to electrical energy by thermal method such as combustion, pyrolysis, and gasification. Several specific chemical processes may also be able to convert the biomass energy to other forms. The main problem arise from application of biomass is air pollution which contains carbon monoxide, NOx (nitrogen oxides), VOCs (volatile organic compounds), particulates and other pollutants. And the level of air pollution, to some extent, is even above that of traditional fuel resource. Some other possible issue like transportation and sink of carbon also limit the wide usage of this type of alternative energy [4-5].

Among all the renewable energy sources, solar energy is the most suitable alternative energy for our future life. It is clean, cheap, abundant, without any noise, air pollution, no transportation issue and easy to be obtained anywhere in the earth. Inside the core of the Sun, hydrogen fuses into helium with a rate of $7 \times 10^{11} \mathrm{~kg} / \mathrm{s}$ and generates very powerful nucleation power. This type of nucleation explosion creates ultra-high temperature in the core of the Sun, which reaches approximately 16 million K degrees. Although the Sun is not perfectly black body, it still radiates abundant power with the energy density as $1.6 \times 10^{7}$ watts $/ \mathrm{m}^{2}$ [6-7]. Because of the enough amount of hydrogen underneath the surface of the Sun, the radiation given arise of from the nucleation explosion can continue at least 5 million years with the same rate and strength. The energy reaching the earth is vastly reduced mainly caused by the absorption and spreading of the radiation. It is easily to understand that there are numerous amorphous objects all around the entire universe which can absorb certain portion of the radiation for the Sun. Moreover, the light generated from the spherical object such as the Sun fills all the available space between origins to the destination. Even though the energy will not be lost in the travelling process, due to the long distance between the Sun to the earth, the surface area of the sphere which is formed with the Sun as center and the distance as radius is much larger than that of the earth. As the result of that, only $1340 \mathrm{~W} / \mathrm{m}^{2}$ finally reaches the upmost surface of the earth. Even though the final amount of the received solar energy is very small compared to that is initially radiated from the Sun, the average daily solar radiation falling on one area in the continental United States is equivalent in total energy content to 11 barrels of oil. In summary, the solar energy itself is relatively unlimited, useful, clean and almost unexploited energy and definitely can behave as the promising mean for the future energy supply [8].

There are several different methods to take advantage of the solar energy and all the methods can be distinguished into three group: solar parabolic trough, solar tower and solar dish. Parabolic trough is constructed by silver coated parabolic mirror and there is a Dewar tube going through the length of the mirror and set on the focal point, all the radiation is concentrated on the tube and transfer by heat transfer fluid to the thermal energy storage unit. Solar tower are used to capture solar energy with thousands of mirrors and focus the concentrated sunlight to the top of the tower which is located in the middle of the heliostats. The thermal energy storage medium within the tower was heated to high temperature and transferred to thermal energy storage tank and eventually sent to steam pump. The solar dish is built with a large, reflective parabolic dish which concentrates all the received sunlight to one spot. There is normally a receiver located on the focal point and 
transform the solar energy to other forms of useful energy. The working upper limit temperature of solar parabolic trough system is the lowest among these three systems, normally its maximum working temperature is within the range from $400-500^{\circ} \mathrm{C}$; the solar tower has higher maximum working temperature which ranges from $500-1000^{\circ} \mathrm{C}$; the solar dish has the highest working upper limit temperature which reaches $700-1200^{\circ} \mathrm{C}$ [9].

The energy conversion efficiency is the most concerned parameter in the solar energy storage application and the theoretical and real engineering efficiency are given in Fig 1 as function of temperature. The theoretical conversion efficiency can be up to $80 \%$ while in real application, the value is always less than $70 \%$ regardless of collectors. The actual efficiency increases with temperature in the whole working temperature. As a result of that, the thermal energy storage materials in solar parabolic trough, for instance, should be able to work stably at the upper limit temperature of this type of collection system which is $500^{\circ} \mathrm{C}$ to ensure the highest efficiency $[9,10]$.

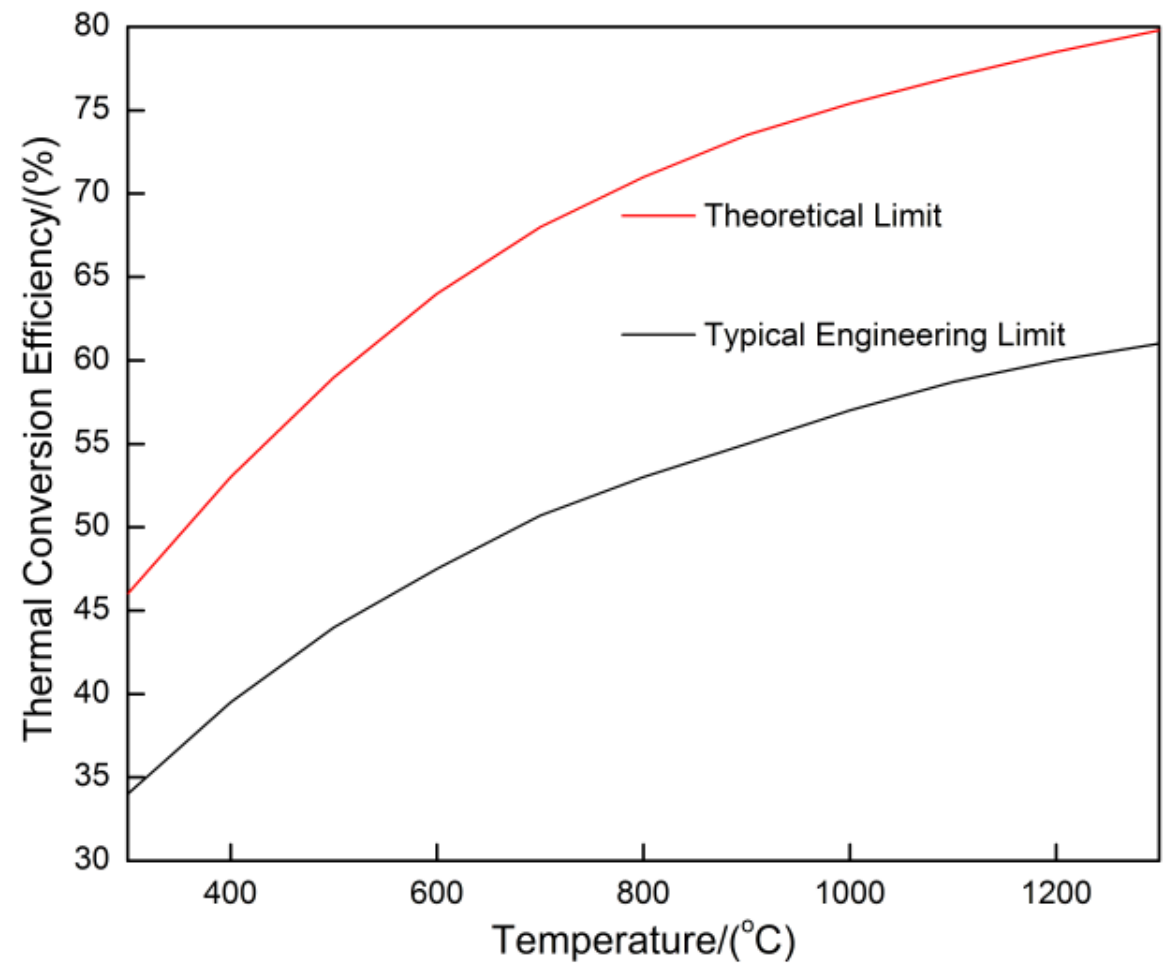

Fig. 1 Theoretical and engineering energy conversion efficiency as function of temperature

Solar energy can be stored in three major forms: sensible heat, latent heat and thermochemical heat. Sensible heat storage was utilized based on the heat capacity and the change as function of temperature of storage materials in the charging and discharging process which correspond to the absorbing and withdrawing energy processes, respectively. The sensible heat stored from the melting point to the maximum working temperature can be expressed by equation 1[9].

$$
Q_{\text {sensible }}=m \int_{T_{L}}^{T_{H}} C_{p}(T) d T
$$


Where $m$ is the mass of storage material, $T_{L}$ and $T_{H}$ are low temperature and high temperature in the same phase, respectively, $\mathrm{Cp}(\mathrm{T})$ is the heat capacity at different temperature. Because the sensible heat storage materials remain in a single phase in the working temperature range, the charging and discharging processes are completely reversible for unlimited cycles.

Latent heat storage is operated by absorbing and withdrawing energy in the charging and discharging processes accompanied with fusion of materials [9]. The latent heat collected throughout the working temperature range can be expressed by equation 2 as following:

$$
Q_{\text {Latent }}=m \int_{T}^{T_{m p}} C_{p}(T) d T+m \Delta H_{\text {fusion }}+m \int_{T_{m p}}^{T_{H}} C_{p}(T) d T
$$

Where $\mathrm{T}$ is temperature in solid state, $\mathrm{T}_{\mathrm{mp}}$ is melting point of storage material, $\mathrm{T}_{\mathrm{H}}$ is the high temperature in liquid state and $\Delta H_{\text {fusion }}$ is enthalpy of fusion.

Thermochemical heat storage is based on the heat capacity and its change as function of temperature accompanied with chemical reaction. The thermochemical heat collected throughout the working temperature range can be expressed by equation 3 .

$$
Q_{\text {thermochemcial }}=m \int_{T_{L}}^{T_{R}} C_{p}(T) d T+m \Delta H_{\text {reaction }}+m \int_{T_{R}}^{T_{H}} C_{p}(T) d T
$$

Where $\mathrm{T}_{\mathrm{R}}$ is the reaction temperature and $\Delta H_{\text {reaction }}$ is the enthalpy of chemical reaction. Because of the destruction of the chemical bonds in the reaction process, the charging and discharging process cannot be completely reversible, which reduces the stability and recyclability of storage operation [10].

Sensible energy storage method is chosen to ensure the efficient usage of solar energy for parabolic trough system of which the maximum working temperature ranges from $400-500^{\circ} \mathrm{C}$. Different from thermochemical heat storage, the sensible heat storage can achieve completely reversible working condition under unlimited cycles. Also, Fig 2 illustrates that the sensible heat storage materials mainly work in the working temperature range for parabolic trough system, and the gravimetric energy storage densities of sensible heat is higher than that of latent heat materials [9 $-11]$. 


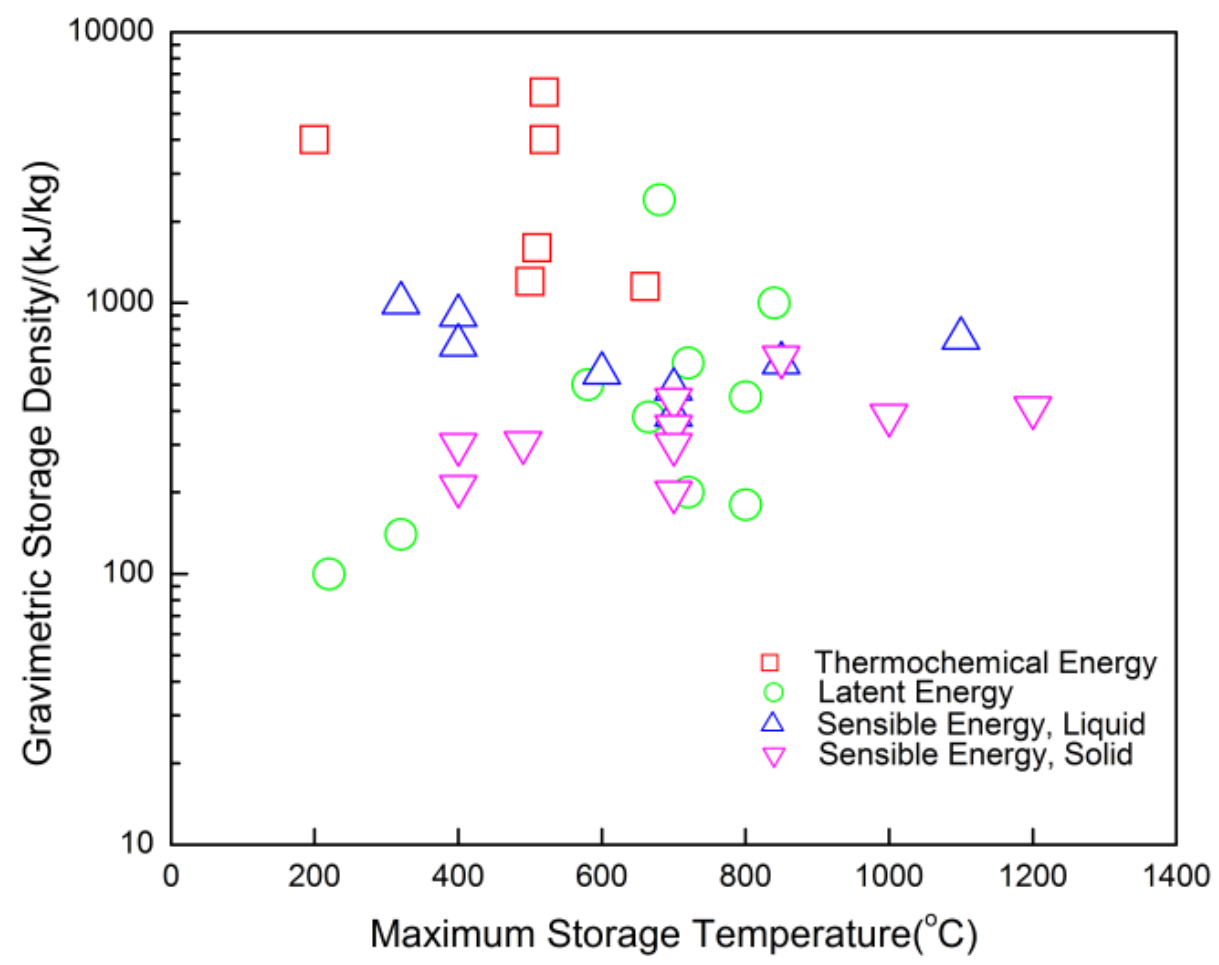

Fig. 2 Gravimetric storage density for different energy storage systems as function of temperature

Various materials are chosen to serve as thermal energy storage fluid for sensible heat such as water, thermal oil, ionic liquid and molten salt [12]. The properties of different heat transfer fluid determine the performance of solar energy heating system. In these days, the efficiency and cost of output of electrical power mainly relies on the parabolic trough solar power plant and the thermal storage fluid [12]. A large investment cost is needed to dispatch 100MW to 200MW energy by consuming the energy transfer fluids. Given by this situation, the development of new thermal storage fluid with higher thermal energy storage density is paramount to lower the expense for generating energy and a lot of effect has been put on design of new systems [13-16].

Water is commonly used as heat transfer and thermal energy storage fluid in industry because of its low cost, high heat capacity and high thermal conductivity. However, the limitation for using this medium is also obvious that the temperature range within which the liquid state can be assured is too small. It is well know that, water can only serve as thermal energy storage liquid above the freezing point $0^{\circ} \mathrm{C}$ and below the boiling temperature $100^{\circ} \mathrm{C}$. In practical experiment, the actual temperature range is even less than $100^{\circ} \mathrm{C}$ because of the large amount of weight loss near the boiling temperature due to the high vapor pressure. Water is possible to work above $100^{\circ} \mathrm{C}$ only if high pressure is also applied to avoid the phase transformation, but the cost will be highly increased. Accordingly, water is only suitable to work in low temperature below $100^{\circ} \mathrm{C}$.

Thermal oils are also being used in the parabolic trough solar power plant and have very low melting point as low as $12^{\circ} \mathrm{C}[17,18]$. However, the application of the oil for the thermal energy storage liquid is limited by some disadvantages from the physic-chemical properties. The upper 
limit for this oil is only $300^{\circ} \mathrm{C}$ and above that the liquid state cannot be maintained. Moreover, the low thermal decomposition temperature, low density and low heat capacity result in limited thermal energy storage capacity. Since the working temperature range is so narrow, the rankie cycle efficiency is reduced when using the synthetic oil and the cost for generating power is considered to be very expensive $[19,20]$.

Ionic liquid is another medium served as thermal energy storage fluid. The liquid temperature range of ionic liquid is large, which is one of the main advantages of this type of material. The high heat capacity and density ensure the efficiency of thermal energy storage of ionic liquid. What's more, the excellent chemical stability and little vapor pressure increase the lifetime [2124]. However, as a result of the very serve corrosion problem to the liquid container and the high cost, the usage of ionic liquid is still limited.

Considering various relative physic-chemical properties of thermal energy storage system, molten salts have been proposed as a suitable group for a wide temperature range application. They are being emphasized in the solar energy applications because of their low melting point and high upper limit which can increase the stable working range. The high heat capacity increases the thermal energy storage density of the heat storage system; excellent thermal stability and negligible vapor pressure ensure the steadiness of cyclic repeating in the lifetime [25]; low viscosity strengths the mobility and efficiency of the thermal storage liquid; low utilization cost reduce the investment and protect the economy. The liquids temperature range of the molten salt varies from $150^{\circ} \mathrm{C}-$ $600^{\circ} \mathrm{C}$, combination of various salts can bring the melting down and further increase the working temperature range. Due to these properties, molten salts can be excellent thermal storage fluid in the solar power generation system.

\section{Background}

\section{(i) Original hypotheses:}

In the thermodynamic modeling, take ternary system as an example in which the integral molar excess Gibbs energy is composed of the summation of the Gibbs energies of three constituent binary systems and one ternary, the expression of the integral excess Gibbs energy is given by Equation4.

$$
G^{x s}=G_{1-2}^{x s}+G_{2-3}^{x s}+G_{1-3}^{x s}+G_{1-2-3}^{x s}
$$

For $\mathrm{LiNO}_{3}-\mathrm{NaNO}_{3}-\mathrm{KNO}_{3}$ ternary system, Gibbs energies of the three constituent binary systems, $\mathrm{LiNO}_{3}-\mathrm{NaNO}_{3}, \mathrm{LiNO}_{3}-\mathrm{KNO}_{3}$, and $\mathrm{NaNO}_{3}-\mathrm{KNO}_{3}$ of the $\mathrm{LiNO}_{3}-\mathrm{NaNO}_{3}-\mathrm{KNO}_{3}$ ternary system are taken from the literature. The Gibbs energies of mixing or the integral excess Gibbs energies of the three constituent binary systems of the $\mathrm{LiNO}_{3}-\mathrm{NaNO}_{3}-\mathrm{KNO}_{3}$ ternary system are given below:

$$
\begin{aligned}
& \mathrm{LiNO}_{3}-\mathrm{NaNO}_{3} \text { Binary System } \\
& G_{\text {LiNO }}^{x S}-\mathrm{NaNO}_{3}=X_{\text {LiNO3 }} X_{\mathrm{NaNO} 3}[-18910-27.51 \mathrm{~T} \ln (\mathrm{T})+205.27 \mathrm{~T}] \mathrm{J} / \mathrm{mol}
\end{aligned}
$$




$$
\begin{aligned}
& \mathrm{LiNO}_{3}-\mathrm{KNO}_{3} \text { Binary System } \\
& G_{\mathrm{LiNO}_{3}-\mathrm{KNO}_{3}}^{x S}=X_{\mathrm{LiNO} 3} X_{\mathrm{KNO} 3}[-5310-6.01 T \ln (\mathrm{T})+30.5 \mathrm{~T}] \mathrm{J} / \mathrm{mol} \\
& \mathrm{NaNO}_{3}-\mathrm{KNO}_{3} \text { Binary System } \\
& \mathrm{G}_{\mathrm{NaNO}_{3}-\mathrm{KNO}_{3}}^{\mathrm{xS}}=\mathrm{X}_{\mathrm{NaNO} 3} \mathrm{X}_{\mathrm{KNO} 3}\left[-1709.2-284.5 \mathrm{X}_{\mathrm{NaNO}_{3}}\right] \mathrm{J} / \mathrm{mol}
\end{aligned}
$$

When assume the integral excess Gibbs energy of $\mathrm{G}_{1-2-3}^{\mathrm{xs}}$ to be zero, the excess Gibbs energy in the ternary system can be expressed by the summation of three constituent binary systems:

$$
G^{x S}=G_{\mathrm{LiNO}_{3}-\mathrm{NaNO}_{3}}^{x S}+G_{\mathrm{NaNO}_{3}-\mathrm{KNO}_{3}}^{x S}+G_{\mathrm{LiNO}_{\mathrm{O}}-\mathrm{KNO}_{3}}^{x S}
$$

The assumption was applied to all the modeling in this project to predict the eutectic point for novel molten salt systems.

\section{(ii) Problems encountered:}

Thermal conductivity of salt mixtures in their liquid state cannot be determined by using inverse method or laser flash method conducted in Oak Ridge national lab due to the severe corrosion and damage to the substrate. As a result of that, the thermal conductivity of molten salt was estimated using the value at melting point which was extrapolated from plot of thermal conductivity in solid state.

\section{Experimental Procedure}

\section{Materials and Preparation}

For LMP system, most components in the mixtures don't require any pre-preparation and can be used as received. The only exception is new developed $\mathrm{MgKN}$ which was composed of $66.67 \mathrm{~mol} \%$ $\mathrm{KNO}_{3}$ and $33.33 \mathrm{~mol} \% \mathrm{Mg}\left(\mathrm{NO}_{3}\right)_{2}$. This unique compound is synthesized from magnesium nitrate hexahydrate (98\%, Alfa Aesar) and potassium nitrate (ACS, 99.0\% min, Alfa Aesar) and added into the mixture as one single component. As received magnesium nitrate hexahydrate is dehydrated before synthesizing MgKN compound. Weighted amount of magnesium nitrate taken in a stainless steel crucible and placed on a hot plate in an argon atmosphere. Temperature of the salt is measured with a thermocouple immersed in the salt. The temperature was held at $523.15 \mathrm{~K}$ for 2 hours. The salt solidifies to a white mass. The temperature of the salt is then raised to 573.15 $\mathrm{K}$ slowly to remove any traces of moisture and to ensure complete dehydration. The complete removal of water is ascertained by weight loss. After dehydration if necessary, each component was weighed to an accuracy of $0.1 \mathrm{mg}$ with the electrical balance and mixed thoroughly in a stainless steel crucible. Later, the mixture is heated up to certain temperature at which the entire salt melts. At this temperature the salt mixture was held for about 30 minutes. The salt mixture is allowed to air cool to ambient temperature. This procedure is repeated 3 to 4 times to get the wellmixed compound. Standard aluminum pan with lid used for DSC measurements are weighed 
before the experiment. Small amount of the synthesized compound is placed carefully in the aluminum pan and closed with the lid. The lid is crimped by a sample press and the pan is weighed. The weight of the sample is determined by removing the weight of the pan and lid. For the determination of melting point and heat capacity $(20-25) \mathrm{mg}$ of the sample was used.

For the high temperature systems, eutectic composition was synthesized by mixing corresponding amounts of fluoride and carbonate salts ( $\geq 99.0 \%$ purity) obtained from Alfa Aesar $®$. All the component salts were dried at approximately $473.15 \mathrm{~K}$ for at least $4 \mathrm{hrs}$ using hot plate. The quantity of each component salt was weighted according to the eutectic composition and mixed inside a ceramic crucible. The salt powders were mechanically mixed inside the crucible for 5 to 10 minutes continuously. Subsequently, the salt mixtures were carefully distributed and sealed in four copper sample pans which were weighted before experiments.

\section{Apparatus and Procedure}

Differential scanning calorimetry (DSC) analysis was performed using Perkin Elmer Diamond DSC instrument. Heat flow and temperature can be recorded in the instrument with an accuracy of $0.0001 \mathrm{~mW}$ and $0.01 \mathrm{~K}$ respectively. The measurements were made under purified nitrogen atmosphere with a flow rate of $20 \mathrm{cc} / \mathrm{min}$ and at a heating rate of $5 \mathrm{~K} / \mathrm{min}$. The crimped ample pan was immediately put inside the sample chamber of DSC after preparation and held at $523.15 \mathrm{~K}$ for 10 hours to remove the trace amount of moisture possibly caught in the process of loading sample and also to ensure a homogeneous mixture. In the experimental procedure, a temperature range from $298.15 \mathrm{~K}$ to $523.15 \mathrm{~K}$ for low temperature systems and $573.15 \mathrm{~K}$ to $773.15 \mathrm{~K}$ for high temperature systems were set with a heating rate of $5 \mathrm{~K} \mathrm{~min}^{-1}$ followed by a cooling cycle at the same rate. This cycle is repeated for at least 6 times to ensure good mixture of the sample and reproducibility of the results.

Density measurement was conducted with two methods: i) standard densitometer with fixed volume marked on the bottle was used to determine the density for LMP. Initial weight of the densitometer is measured and noted. Salt composition, of which the density is measured, is placed in a beaker on a hot place. The densitometer is also placed on the same hot plate. The temperature is set to a fixed value above the melting point of the salt and is measured by a thermocouple. After the salt is melted and when the temperature shows stable reading, the molten salt is poured in to the densitometer up to the set mark on the sensitometer bottle. The weight of the densitometer with the molten salt is measured. The weight difference between this weight and the weight of empty densitometer gives the weight of the molten salt at the fixed set temperature. By knowing the fixed volume in the densitometer, the density of the salt at that temperature can be calculated. This procedure is repeated at least three times to accurately determine the density of the salt. The set temperature is changed to a higher value than before and the same procedure is followed to measure the density of the salt. ii) Archimedean principle was also introduced to measure the density of the salt. Weighted salt mixture was put inside alumina cylindrical crucible covered by insulation material. The crucible was held in the center of a box furnace and the internal temperature of the molten salt was measured with a K-type thermocouple. A protectively coated 
stainless steel rod was immersed in the molten salt and the weight was measured by the electric balance hang over the molten salt container. By getting the actual mass of the stainless steel rod in the air, the density of the molten salt can be calculated based on the buoyancy of the immersed body.

Perkin Elmer® Pyris Diamond TG/DTA was used to study the short-term and long-term thermal stabilities of the eutectic composition in both LMP and HMP molten salt systems. TG/DTA works from ambient temperature to $1500{ }^{\circ} \mathrm{C}$. Weight loss and temperature can be recorded in the instrument with an accuracy of $0.0001 \mathrm{mg}$ and $0.01{ }^{\circ} \mathrm{C}$ respectively. It has two weight balance beams which hold the sample and reference to detect the weight change. The instrument was calibrated with indium, tin and gold corresponding to different working temperature range. All the experiments were conducted under purging gas with a flow rate of 200 $\mathrm{ml} / \mathrm{min}$ and a heating rate of $10^{\circ} \mathrm{C} / \mathrm{min}$.

The thermal conductivity measurements of salt mixtures in the solid state can be made after preparing the cylindrical coupons by the method of casting. The cylindrical coupons of the ternary eutectic salt mixture were prepared by melting the salt component powders and casting into cylinders in a glass mold under a protective environment. Components of the eutectic salt mixture obtained from Alpha Aesar ${ }^{\circledR}$ were at least $98 \%$ pure and were used without further purification. Each solid sample for a given salt mixture was prepared from the component salts whose amounts correspond to the eutectic composition. The dimensions of the cylinders were predicted by using the casting process simulation software package ProCAST ${ }^{\circledR}$. Salt mixture was heated to a temperature $50^{\circ} \mathrm{C}$ higher than its eutectic temperature and cooled to room temperature. This procedure was repeated three to four times to ensure homogeneity of the salt mixture. Four K-type sheathed ungrounded junction thermocouples with $\pm 0.5^{\circ} \mathrm{C}$ accuracy $(1.6 \mathrm{~mm}$ diameter, $300 \mathrm{~mm}$ length) were used to monitor the temperature change at multiple locations along the radius of the cylinder. For each experiment, the salt cylinder was re-melted in the glass mold and the thermocouples were accurately repositioned using a fixture to minimize displacement errors. On solidification of the salt cylinder, the thermocouples were sealed at their positions in the solid sample. Two stainless steel hooks were placed at the edges of the cylindrical mold to help hold the solidified sample. The thermocouples were placed midway along the height of the cylindrical sample. The thermal gradient along the Z-direction is expected to be zero based on an analysis using the casting simulation software package ProCAST ${ }^{\circledR}$.

Corrosivity of SS316 stainless steel coupons in low melting point salts was accomplished by the electrochemical corrosion experiments and also by Dip-test experiments. In the present work, SS 316L rod and coupon were used as testing sample. The testing rod was cut from the stainless steel bar to the dimension of $12 \mathrm{~mm}$ dia. with $30 \mathrm{~mm}$ length and spot-welded to a copper wire with approximately $0.5 \mathrm{~mm}$ diameter. To simplify the analysis afterwards, only the bottom surface of the rod was exposed to the molten salt medium, leaving the side and upper surface warped by Teflon tap and covered by glass tube which has the same inner diameter as the testing rod. We also 
use SS coupons which have the dimension of $1 / 16^{\prime \prime}$ thickness $\times 1 / 2$ " wide $\times 3$ " long to check the reproducibility for the corrosion data. The corrosion test was conducted from 150 to $450{ }^{\circ} \mathrm{C}$ with the interval of $50{ }^{\circ} \mathrm{C}$. In this experiment, the 3-port spherical flask was used as corrosion cell. The working electrode is the stainless steel sample, which goes through the central port of the cell. Two platinum wires of $0.5-\mathrm{mm}$ diameter were used as the counter electrode and reference electrodes and are inserted from two side ports. Before starting the experiment, the flask corrosion cell was cleaned by acetone and dried.

\section{Results and Discussion}

\section{Melting point determination}

Differential scanning calorimetry (DSC) was used to determine the melting point and any solid state phase transitions of the salt mixture. A low scanning rate was chosen to record the heat flow curve as function of temperature in order to improve the sensitivity of detection. It helps to pick up any small endothermic peaks and also avoids the thermal resistance between the internal furnace and sample. Out of tens of tested samples, 10 LMP and HMP systems which have excellent thermal properties were chosen to be present in this dissertation and the eutectic composition is already listed in Table 1.

Table 1 Experimental determined and predicted melting points of molten salt systems

\begin{tabular}{|c|c|c|}
\hline System & $\begin{array}{c}\text { Calc. } \\
\mathrm{T}_{\mathrm{mp}} \\
\left({ }^{\circ} \mathrm{C}\right)\end{array}$ & $\begin{array}{l}\text { Expt. } \\
\text { Tmp } \\
\left({ }^{\circ} \mathrm{C}\right)\end{array}$ \\
\hline $\mathrm{LiNO}_{3}-\mathrm{NaNO}_{3}-\mathrm{KNO}_{3}$ & 116 & 117.4 \\
\hline $\mathrm{LiNO}_{3}-\mathrm{NaNO}_{3}-\mathrm{KNO}_{3}-\mathrm{NaNO}_{2}$ & 98.6 & 99 \\
\hline $\mathrm{LiNO}_{3}-\mathrm{NaNO}_{3}-\mathrm{KNO}_{3}-\mathrm{KNO}_{2}$ & 100 & 96.4 \\
\hline $\mathrm{LiNO}_{3}-\mathrm{KNO}_{3}-\mathrm{NaNO}_{2}-\mathrm{KNO}_{2}$ & 108.1 & 100.3 \\
\hline $\mathrm{LiNO}_{3}-\mathrm{NaNO}_{3}-\mathrm{KNO}_{3}-\mathrm{MgKN}$ & 98.6 & 101.2 \\
\hline $\mathrm{LiNO}_{3}-\mathrm{NaNO}_{3}-\mathrm{KNO}_{3}-\mathrm{NaNO}_{2}-\mathrm{KNO}_{2}$ & 95.7 & 95.6 \\
\hline $\mathrm{Li}_{2} \mathrm{CO}_{3}-\mathrm{Na}_{2} \mathrm{CO}_{3}-\mathrm{K}_{2} \mathrm{CO}_{3}$ & 397 & 397 \\
\hline LiF-NaF-KF & 454 & 456 \\
\hline $\mathrm{MgCl}_{2}-\mathrm{KCl}$ & 425 & 428 \\
\hline $\mathrm{LiF}-\mathrm{NaF}-\mathrm{K}_{2} \mathrm{CO}_{3}$ & 414 & 422 \\
\hline $\mathrm{LiF}-\mathrm{Na}_{2} \mathrm{CO}_{3}-\mathrm{K}_{2} \mathrm{CO}_{3}$ & 403 & 421 \\
\hline $\mathrm{LiF}-\mathrm{NaF}-\mathrm{Na}_{2} \mathrm{CO}_{3}-\mathrm{K}_{2} \mathrm{CO}_{3}$ & 444 & 444 \\
\hline
\end{tabular}


All the selected LMP systems are composed of nitrate and nitrite salts and most of them have three basic components which are lithium, sodium, potassium nitrate or nitrite. All the selected HMP systems are composed of fluoride, carbonate and chloride salt. DSC plots for each system were collected for at least five runs (each run with fresh salt preparation) to ensure the reproducibility as shown in Fig. 3 for $\mathrm{LiNO}_{3}-\mathrm{NaNO}_{3}-\mathrm{KNO}_{3}$ ternary system. By using the similar procedure, all the peak temperatures of melting peaks are determined and tabulated along with the predicted melting point as given in Table.1.

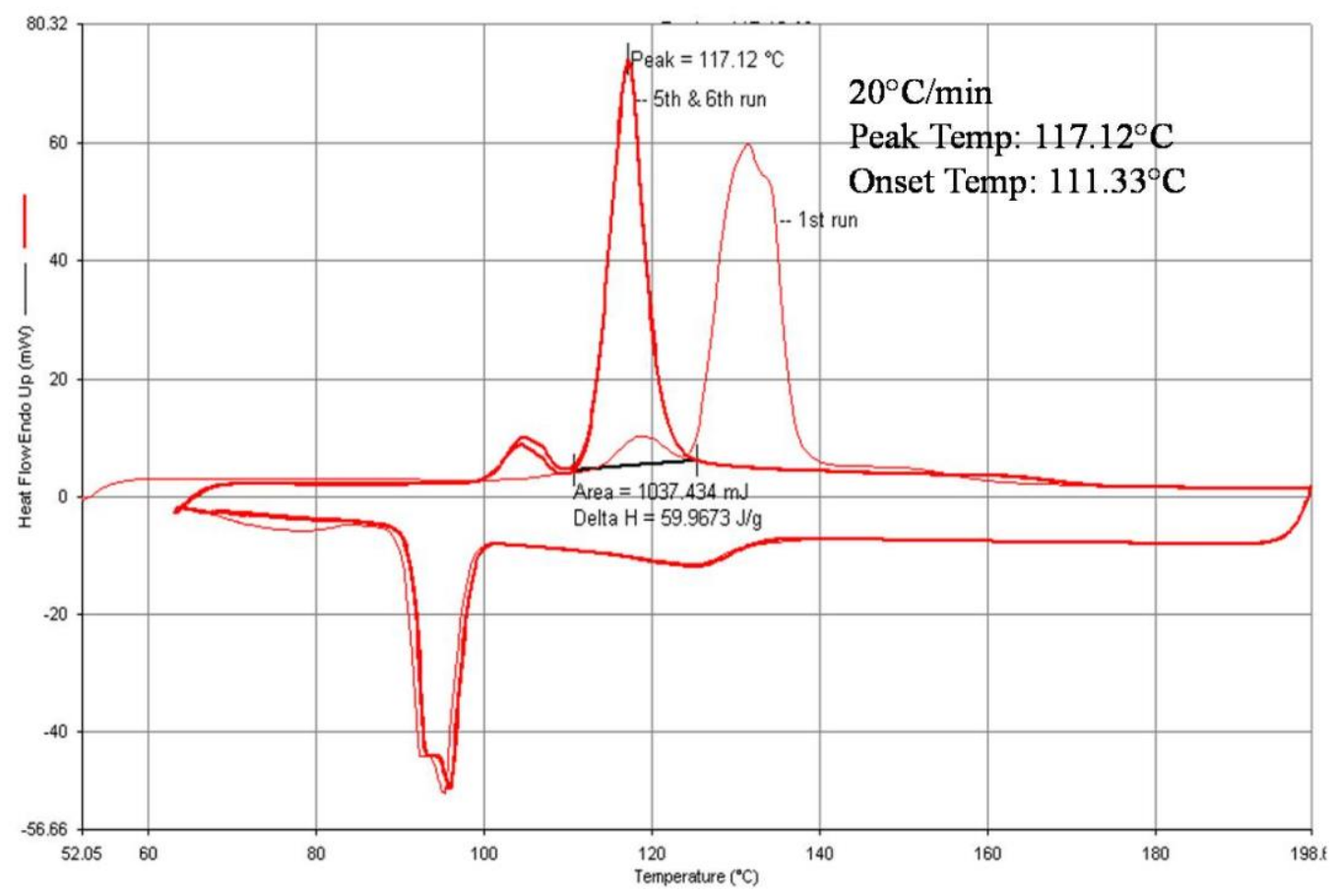

Fig. 3 Melting point determination of LiNO3-NaNO3-KNO3 ternary system

One representative DSC plot for $\mathrm{LiF}-\mathrm{Na}_{2} \mathrm{CO}_{3}-\mathrm{K}_{2} \mathrm{CO}_{3}$ in the heating cycle with scanning rate of 5 $\mathrm{K} / \mathrm{min}$ in argon atmosphere for the melting point determination experiment is given in Fig. 4. Two endothermic peaks were identified where the first peak corresponds to solid state phase transition. After the solid phase transformation peak, the heat absorption started to increase drastically again at approximately $689 \mathrm{~K}$ and this melting peak eventually ended at approximately $703 \mathrm{~K}$. The average peak temperature value of the melting peak was determined to be $695.16 \mathrm{~K}$. The main reason of the wide phase transition temperature range is the low thermal conductivity of salt mixture which is a few orders of magnitude lower than that of metals. As a result, at the onset temperature of endothermic peak, large thermal gradient was present inside the salt mixture and resulted in fluid flow and rapid mixing. This phenomenon is indicated by the rapid increase in endothermic heat after the onset temperature. At the summit temperature of endothermic peak, the last fraction of solid has been transitioned into liquid. Therefore, the peak temperature is emphasized and is considered as the melting point of the eutectic salt mixture. In Fig. 4, the heat flow after the melting peak shows stable reading and no other endothermic peak was detected. 


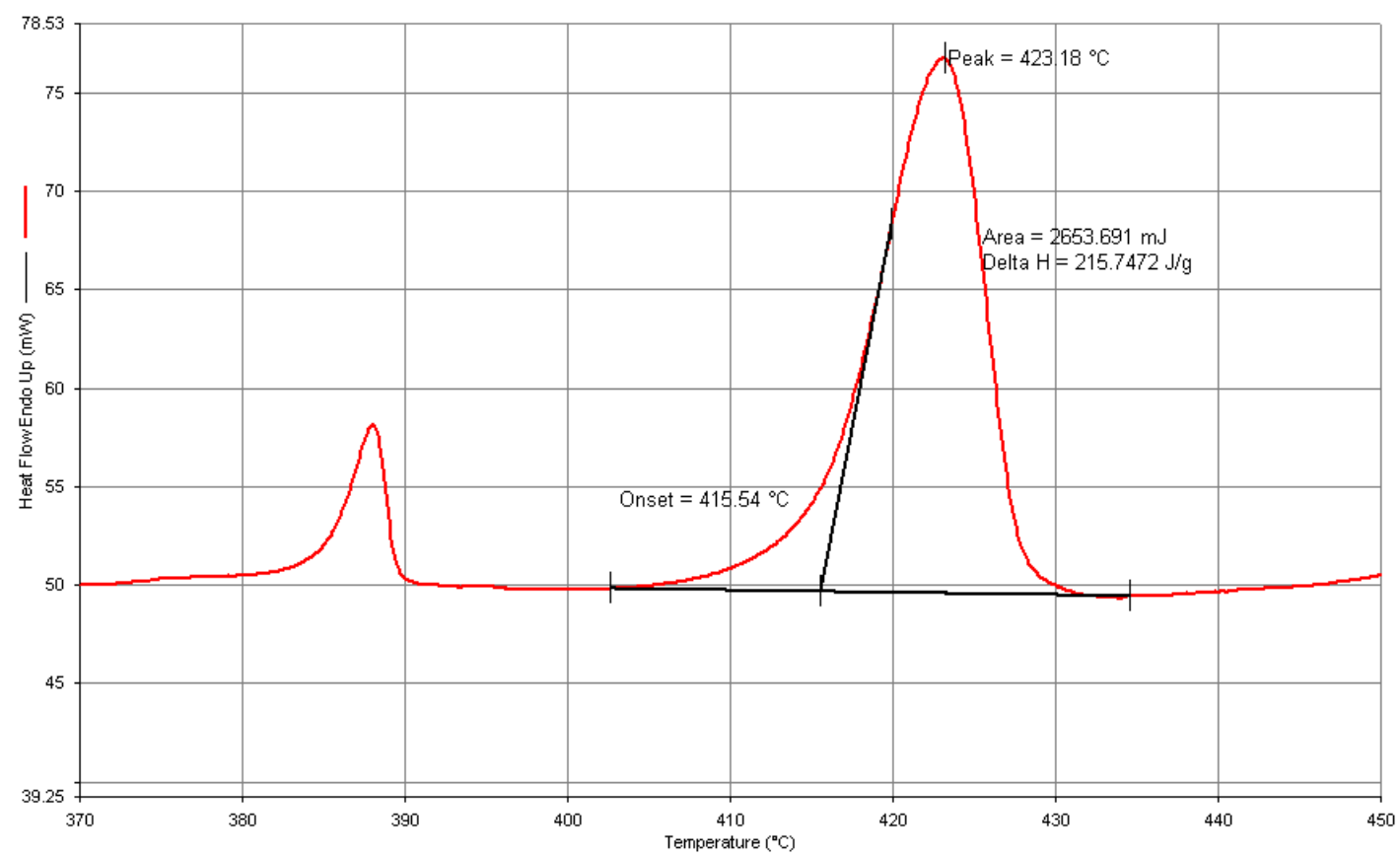

Fig. 4 Representative DSC heat flow curve for the melting point determination of LiF-Na2CO3-K2CO3 eutectic ternary system in argon atmosphere

In the DSC measurement, the scanning rate of the heat flow plays a significant role in determining the melting point. Take $\mathrm{LiF}-\mathrm{Na}_{2} \mathrm{CO}_{3}-\mathrm{K}_{2} \mathrm{CO}_{3}$ as an example, at a high scanning rate of $20 \mathrm{~K} / \mathrm{min}$, the peak is seen shifted slightly to the right as illustrated in Fig 5. As a result, the melting point detected in this case is higher in comparison to that measured at low scanning rate. The higher melting point value is mainly attributed to the large thermal resistance between the testing sample and sample holder under rapid heating which reduces the extent of homogeneous temperature distribution within the sample holder. When the heating rate is lowered to $5 \mathrm{~K} / \mathrm{min}$ or smaller as shown in Fig. 5, the variation of peak temperature is less than $2.7 \mathrm{~K}$. On the basis of values collected at low scanning rates, the average melting point of the eutectic composition in the $\mathrm{LiF}-\mathrm{Na}_{2} \mathrm{CO}_{3}-\mathrm{K}_{2} \mathrm{CO}_{3}$ ternary system was determined to be 694.20 $\mathrm{K}$ with $\pm 0.6 \%$ deviation. 


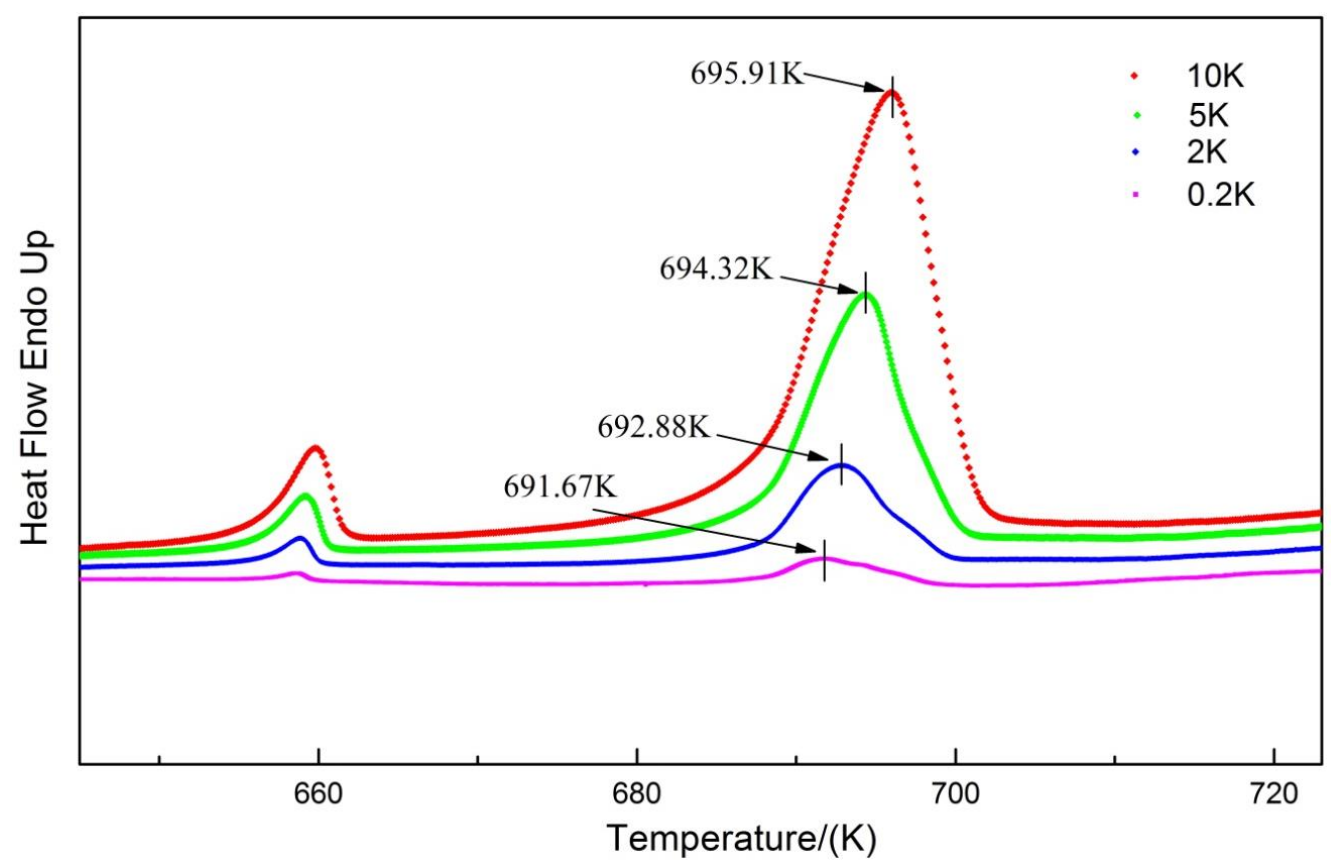

Fig. 5 DSC heat flow curves for the melting point determination of LiF-Na2CO3-K2CO3 eutectic ternary system in different scanning rates

By using the DSC with the procedure described above and lower scanning rate $\left(5^{\circ} \mathrm{C} / \mathrm{min}\right)$, the experimentally determined melting points of LMP and HMP systems are tabulated in the following table.

\section{Heat capacity determination of molten salt mixtures}

In the DSC equipment, the heat flow through the sample is tested as function of temperature. In the heating process, the temperature profile can be expressed as:

$$
T_{t}=T_{o}+\beta t
$$

where $T_{o}$ is the initial temperature in $K, \beta$ is the set heating rate $(\mathrm{K} / \mathrm{min})$ and $T_{t}$ is the temperature in $\mathrm{K}$ at a certain time $\mathrm{t}(\mathrm{min})$. Based on the thermodynamic definition, heat capacity is the amount of heat required to change a body's temperature by a given amount. Combined with the equation above, the expression for $\mathrm{Cp}$ can be shown as follows:

$$
C p=\frac{1}{m}\left(\frac{d H}{d T}\right)=\frac{1}{m}\left(\frac{\frac{d H}{d t}}{\frac{d T}{d t}}\right)=\frac{1}{m}\left(\frac{\Delta P}{\beta}\right)
$$

where the $\triangle \mathrm{P}$ is the actual DSC heat flow signal which has the unit as $\mathrm{mW}, \mathrm{m}$ is the mass for the sample of interest. This way the heat capacity with the DSC heat flow data is calculated. 
Heat capacity of Low melting point (LMP) molten salt systems

The materials used in the heat capacity measurements of LMP systems are the same as those in the melting point experiments. Specific heat capacities of the all LMP systems were measured by the DSC equipment from room temperature to $623.15 \mathrm{~K}$. Because the heat capacity measurement in the heating process corresponds to collecting the value of required heat flow at each temperature, all the heat capacity plots have the same shape with that of heat flow in the melting point measurements. Take the heat capacity plot of $\mathrm{LiNO}_{3}-\mathrm{NaNO}_{3}-\mathrm{KNO}_{3}$ ternary system as an example which is shown in Fig. 6, the heat capacity curve also has two different peaks. The first little peaks corresponds to one occurs at $390.27 \mathrm{~K}$ which was observed in Fig. 3, the second large and sharp peak happened right after the small one is prevalent to the endothermic peak with the peak temperature as $390.27 \mathrm{~K}$. Similarly, after the phase transformation, the heat capacity in liquid state becomes very stable and increase with temperature linearly with little slope.

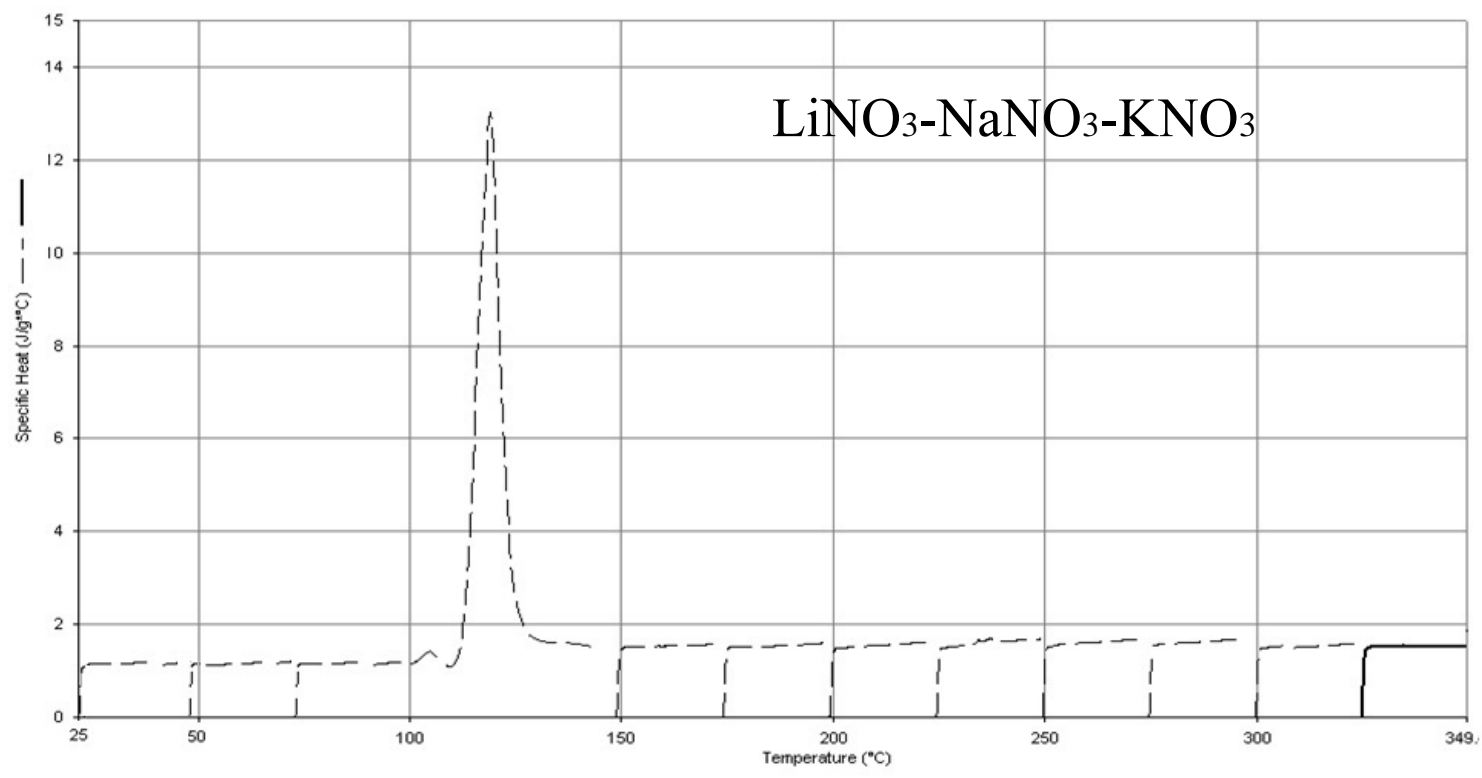

Fig. 6 Heat capacity data plot of LiNO3-NaNO3-KNO3 ternary system as function of temperature

Based on the linear increasing trend of heat capacity for LMP system in the liquid state, any value in the liquid can be extrapolated. On the basis of that, the extrapolated heat capacities of LMP molten salt systems are listed in Table 2 .

Table 2 Heat capacities of molten LMP systems

\begin{tabular}{lc}
\hline \multicolumn{1}{c}{ System } & Extrapolated(773.15K) \\
\cline { 2 - 2 } & $\mathrm{C}_{\mathrm{p}}, \mathrm{J} / \mathrm{g} \cdot \mathrm{K}$ \\
\hline $\mathrm{LiNO}_{3}-\mathrm{NaNO}_{3}-\mathrm{KNO}_{3}$ & 1.63 \\
$\mathrm{LiNO}_{3}-\mathrm{NaNO}_{3}-\mathrm{KNO}_{3}-\mathrm{NaNO}_{2}$ & 1.66 \\
$\mathrm{LiNO}_{3}-\mathrm{NaNO}_{3}-\mathrm{KNO}_{3}-\mathrm{KNO}_{2}$ & 1.63 \\
$\mathrm{LiNO}_{3}-\mathrm{KNO}_{3}-\mathrm{NaNO}_{2}-\mathrm{KNO}_{2}$ & 1.70
\end{tabular}




\begin{tabular}{ll}
$\mathrm{LiNO}_{3}-\mathrm{NaNO}_{3}-\mathrm{KNO}_{3}-\mathrm{MgKN}$ & 1.67 \\
$\mathrm{LiNO}_{3}-\mathrm{NaNO}_{3}-\mathrm{KNO}_{3}-\mathrm{NaNO}_{2}-\mathrm{KNO}_{2}$ & 1.58 \\
\hline
\end{tabular}

Heat capacity of High melting point (HMP) molten salt systems

As shown in Fig. 7, the specific heat capacity of the $\mathrm{LiF}-\mathrm{Na}_{2} \mathrm{CO}_{3}-\mathrm{K}_{2} \mathrm{CO}_{3}$ eutectic salt mixture was measured by the DSC equipment from $623.15 \mathrm{~K}$ to $748.15 \mathrm{~K}$ and the dependence of heat capacity on the temperature is a typical example among the HMP molten salt systems. In the measurement, the heat flow is also recorded as a function of temperature in "iso-scan-iso" steps at intervals of $25 \mathrm{~K}$. Fig. 7 shows the heat capacity of the $\mathrm{LiF}-\mathrm{Na}_{2} \mathrm{CO}_{3}-\mathrm{K}_{2} \mathrm{CO}_{3}$ eutectic salt mixture measured as function of temperature in the studied temperature range. Since the heat capacity measurement is equivalent to the heat flow collection against time, the shape of the smoothed heat capacity curve is identical to that in the melting point determination process as illustrated in Fig. 6

The heat capacity data of the $\mathrm{LiF}-\mathrm{Na}_{2} \mathrm{CO}_{3}-\mathrm{K}_{2} \mathrm{CO}_{3}$ can be divided into three sections; (i) solid state $\alpha(623.15-648.15 \mathrm{~K})$ (ii) solid state $\beta(671.15-678.15 \mathrm{~K})$ (iii) liquid state $(718.15-748.15 \mathrm{~K})$. Accordingly, the heat capacity data are fit to three separate equations corresponding to the phases of the eutectic salt mixture.

Heat capacity of solid state $\alpha: 623.15-648.15 \mathrm{~K}$

The heat capacity data for the $\mathrm{LiF}-\mathrm{Na}_{2} \mathrm{CO}_{3}-\mathrm{K}_{2} \mathrm{CO}_{3}$ eutectic salt mixture in the solid state $\alpha$ in the temperature range of 623.15 to $648.15 \mathrm{~K}$ can be fit to a second order polynomial equation. Equation [11] gives the polynomial equation along with the least square fit parameter $\left(\mathrm{R}^{2}\right)$ in the temperature range for the solid state $\alpha$ of the eutectic salt mixture.

$C p($ solid state $\alpha)\left(\frac{J}{g \cdot K}\right)=1.057 \times 10^{-4} T^{2}-1.247 \times 10^{-1} T+38.046$

$(623.15-648.15 \mathrm{~K})$

$\mathrm{R}^{2}=0.9378$

Heat capacity of solid state $\beta$ : $671.15-678.15 \mathrm{~K}$

The heat capacity data for the $\mathrm{LiF}-\mathrm{Na}_{2} \mathrm{CO}_{3}-\mathrm{K}_{2} \mathrm{CO}_{3}$ eutectic salt mixture in the solid state $\beta$ in the temperature range of 671.15 to $678.15 \mathrm{~K}$ can be fit to a second order polynomial equation. Equation [12] gives the polynomial equation along with the least square fit parameter $\left(R^{2}\right)$ in the temperature range for the solid state $\beta$ of the eutectic salt mixture.

Cp $($ solid state $\beta)\left(\frac{\mathrm{J}}{\mathrm{g} \cdot \mathrm{K}}\right)=4.702 \times 10^{-3} T^{2}-6.263 T+2087.545$

$(671.15-678.15 \mathrm{~K})$

$\mathrm{R}^{2}=0.9766$ 
Heat capacity of liquid state: $718.15-748.15 \mathrm{~K}$

The heat capacity data for LiF- $\mathrm{Na}_{2} \mathrm{CO}_{3}-\mathrm{K}_{2} \mathrm{CO}_{3}$ eutectic salt mixture in the liquid state doesn't vary much as function of temperature. Consequently, the value can be assumed to be constant throughout the liquid state and expressed as Equation [13]. The deviation range includes all the liquid state heat capacity values throughout all the four measurements.

Cp (liquid state $)\left(\frac{J}{g \cdot K}\right)=1.90 \pm 0.16$

$(718.15-748.15 \mathrm{~K})$

Similar to the LiF- $\mathrm{Na}_{2} \mathrm{CO}_{3}-\mathrm{K}_{2} \mathrm{CO}_{3}$, the variation of heat capacity in liquid state of the other HMP systems is also negligible. As a result of that, the heat capacity of molten HMP systems can be assumed to be constant and shown in Table 3. Compared to the LMP systems, the larger heat capacity of HMP systems still demonstrate their great capability of thermal energy storage, although the higher melting point leads to more initial energy consumption.

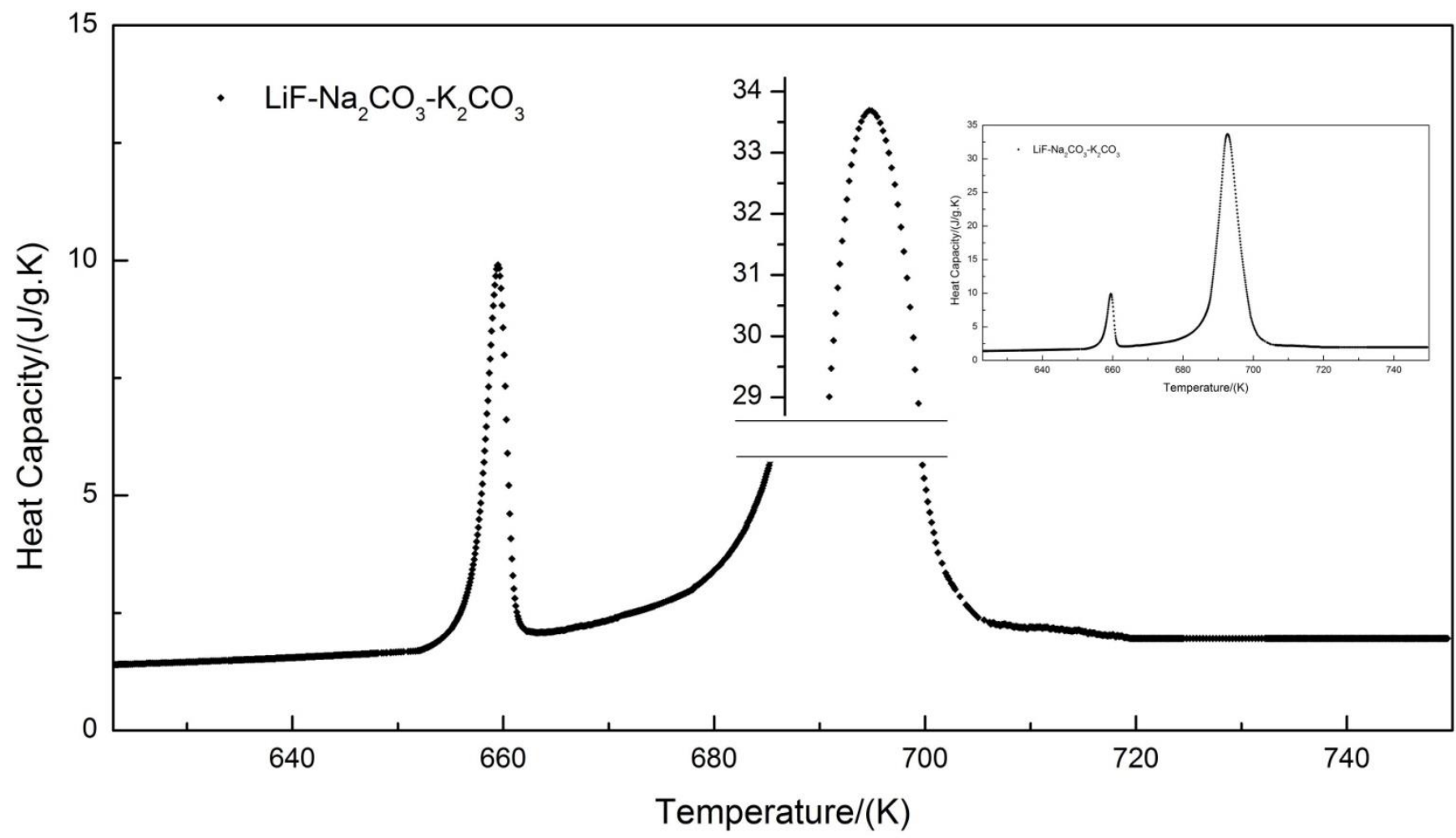

Fig. 7 Heat capacity of LiF-Na2CO3-K2CO3 eutectic ternary system as function of temperature 
Table 3 Heat capacities of molten HMP systems

\begin{tabular}{|c|c|}
\hline System & $\begin{array}{c}\text { Heat Capacity } \\
\text { J/g.K }\end{array}$ \\
\hline $\mathrm{Li}_{2} \mathrm{CO}_{3}-\mathrm{Na}_{2} \mathrm{CO}_{3}-\mathrm{K}_{2} \mathrm{CO}_{3}$ & 1.75 \\
\hline LiF-NaF-KF & 1.85 \\
\hline $\mathrm{MgCl}_{2}-\mathrm{KCl}$ & 1.67 \\
\hline $\mathrm{LiF}-\mathrm{NaF}-\mathrm{K}_{2} \mathrm{CO}_{3}$ & 1.81 \\
\hline $\mathrm{LiF}-\mathrm{Na}_{2} \mathrm{CO}_{3}-\mathrm{K}_{2} \mathrm{CO}_{3}$ & 1.90 \\
\hline $\mathrm{LiF}-\mathrm{NaF}-\mathrm{Na}_{2} \mathrm{CO}_{3}-\mathrm{K}_{2} \mathrm{CO}_{3}$ & 1.83 \\
\hline
\end{tabular}

\section{Density determination of molten salts}

The density result of the LMP system as indicates that the temperature dependence of density above the melting point is different from that in solid state. As known, in solid state, the density of salt has an exponential relation with temperature, while in these liquid cases the density values have linearly dependence with temperature. The stable variation as function of temperature allows the extrapolation of density at even higher temperature. The regression analysis is performed to get the coefficient used for describing Equation 14 and the results for the coefficients are shown in Table.4. It is observed that the change of composition is implied on the coefficient A which indicates the initial point at $0^{\circ} \mathrm{C}$. The temperature dependence coefficient $\mathrm{B}$ doesn't change much with composition, which may be mainly affected by the group of anion and cation.

Table 4 Coefficient A and B for density determination of LMP salt systems

\begin{tabular}{clcc}
\hline $\begin{array}{c}\text { Salt } \\
\text { No. }\end{array}$ & \multicolumn{1}{c}{ System } & $\begin{array}{c}\mathrm{A} \\
\left(\mathrm{g} / \mathrm{cm}^{3}\right)\end{array}$ & $\begin{array}{c}\mathrm{B} \times 10^{3} \\
\left(\mathrm{~g} / \mathrm{cm}^{3 \cdot}{ }^{\circ} \mathrm{C}\right)\end{array}$ \\
\hline 1 & $\mathrm{LiNO}_{3}-\mathrm{NaNO}_{3}-\mathrm{KNO}_{3}$ & 2.032 & 0.493 \\
2 & $\mathrm{LiNO}_{3}-\mathrm{NaNO}_{3}-\mathrm{KNO}_{3}-\mathrm{NaNO}_{2}$ & 2.055 & 0.526 \\
3 & $\mathrm{LiNO}_{3}-\mathrm{NaNO}_{3}-\mathrm{KNO}_{3}-\mathrm{KNO}_{2}$ & 2.060 & 0.554 \\
4 & $\mathrm{LiNO}_{3}-\mathrm{KNO}_{3}-\mathrm{NaNO}_{2}-\mathrm{KNO}_{2}$ & 2.048 & 0.554 \\
5 & $\mathrm{LiNO}_{3}-\mathrm{NaNO}_{3}-\mathrm{KNO}_{3}-\mathrm{MgKN}$ & 2.033 & 0.52 \\
6 & $\mathrm{LiNO}_{3}-\mathrm{NaNO}_{3}-\mathrm{NaNO}_{2}-\mathrm{KNO}_{3}-\mathrm{KNO}_{2}$ & 2.018 & 0.445 \\
\hline
\end{tabular}

All the density values are clustered around $1.98 \mathrm{~g} / \mathrm{cm}^{3}$ at $150^{\circ} \mathrm{C}$ to $1.86 \mathrm{~g} / \mathrm{cm}^{3}$ at high temperature end and the deviation of density between all the mixtures is within in $0.047 \mathrm{~g} / \mathrm{cm}^{3}$. 
Among all the salt mixtures, the $\mathrm{LiNO}_{3}-\mathrm{NaNO}_{3}-\mathrm{KNO}_{3}-\mathrm{KNO}_{2}$ system demonstrates the highest density value throughout the studied temperature range and $\mathrm{LiNO}_{3}-\mathrm{NaNO}_{3}-\mathrm{KNO}_{3}$ ternary system, $\mathrm{LiNO}_{3}-\mathrm{NaNO}_{3}-\mathrm{KNO}_{3}-\mathrm{NaNO}_{2}$ quaternary system and $\mathrm{LiNO}_{3}-\mathrm{NaNO}_{3}-\mathrm{KNO}_{3}-\mathrm{NaNO}_{2}-\mathrm{KNO}_{2}$ quinary system show lower densities. For $\mathrm{LiNO}_{3}-\mathrm{NaNO}_{3}-\mathrm{KNO}_{3}-\mathrm{KNO}_{2}$, which contains least amount of lithium nitrate, the density at every selected temperature spot is obviously higher than that of other salts which have large amount of lithium nitrate. This comparison illustrates that the addition of lithium nitrate has an offsetting effect on density for molten salt and it is consistent with previous literature reports.

For HMP molten salt system, the density determination is still in progress by using Archimedes method as described above.

\section{Thermal stability determination of molten salts}

\section{Short-term thermal stability of Low melting point (LMP) system in argon atmosphere}

Short-term thermal stabilities of the LMP systems were evaluated experimentally by using TG/DTA instrument, and the results are given below in terms of weight loss vs. temperature for 5 cycles. The salts were heated through 5 cycles at $10^{\circ} \mathrm{C} / \mathrm{min}$ from $75^{\circ} \mathrm{C}$ to $500{ }^{\circ} \mathrm{C}$ and cooled down. The weight used in the short-term thermogravimetric analysis is $15-20 \mathrm{mg}$. Take the eutectic composition in $\mathrm{LiNO}_{3}-\mathrm{NaNO}_{3}-\mathrm{KNO}_{3}$ ternary system as an example, the weight loss curve collected from TG/DTA under argon atmosphere purged at 200 $\mathrm{ml} / \mathrm{min}$ was plotted as function of temperature and shown in Fig. 8. The obvious weight loss was observed in the first heating process. The initial weight of sample was $23.30 \mathrm{mg}$ and a weight loss of $1.76 \mathrm{mg}$ was observed after the first cycle. In the following four thermal cycles, the weight loss was negligible compared to the first cycle. On the basis of that, it can be easily concluded that the system reached stable condition after the first cycle. In the ternary system, the mass fraction of lithium nitrate is over $25 \%$ and this component is prone to moisture pickup. Hence, the major weight change in the first heating cycle is attributed to the presence of lithium nitrate which picks up moisture from the atmosphere in the process of sample loading. The shape of weight change curve of the first cycle also demonstrates the water removal process. The salt mixture went through a drastic weight loss after about $100{ }^{\circ} \mathrm{C}$ up to about $150{ }^{\circ} \mathrm{C}$. Most of the moisture gets removed during this drastic weight loss period followed by a slow weight loss where the small amount of residual water was removed. Since the weight loss in the first cycle is mostly due to the moisture removal, the total weight loss listed in Table 5 at $500{ }^{\circ} \mathrm{C}$ is calculated using the last four cycles for the salt mixture. Total weight after four cycles was less than $1 \%$ which is considered to be very good and which confirms the recyclability of the system in its whole lifetime for thermal energy storage application.

The short-term reliability at high temperature was also determined using the Differential Scanning Calorimetry (DSC) technique. By conducting the thermal cycling on a repeated basis in the temperature range from $50{ }^{\circ} \mathrm{C}$ to the upper limit temperature of the instrument which is 350 
${ }^{\circ} \mathrm{C}$, the reliability of the eutectic mixture can be determined. The reliability of the salt mixture can be identified by the reproducibility of the heat flow curve and the endothermic peak temperature. The heat flow curves of twenty repeated cycles on the eutectic salt mixture are shown in Fig. 9. Except for the first cycle which involves the water removal, the remaining cycles show identical curves including the endothermic peak temperature which is comparable with the data obtained in a previous study. The repeating curves throughout the measurement re-verify the substantial thermal stability in the short-term application.

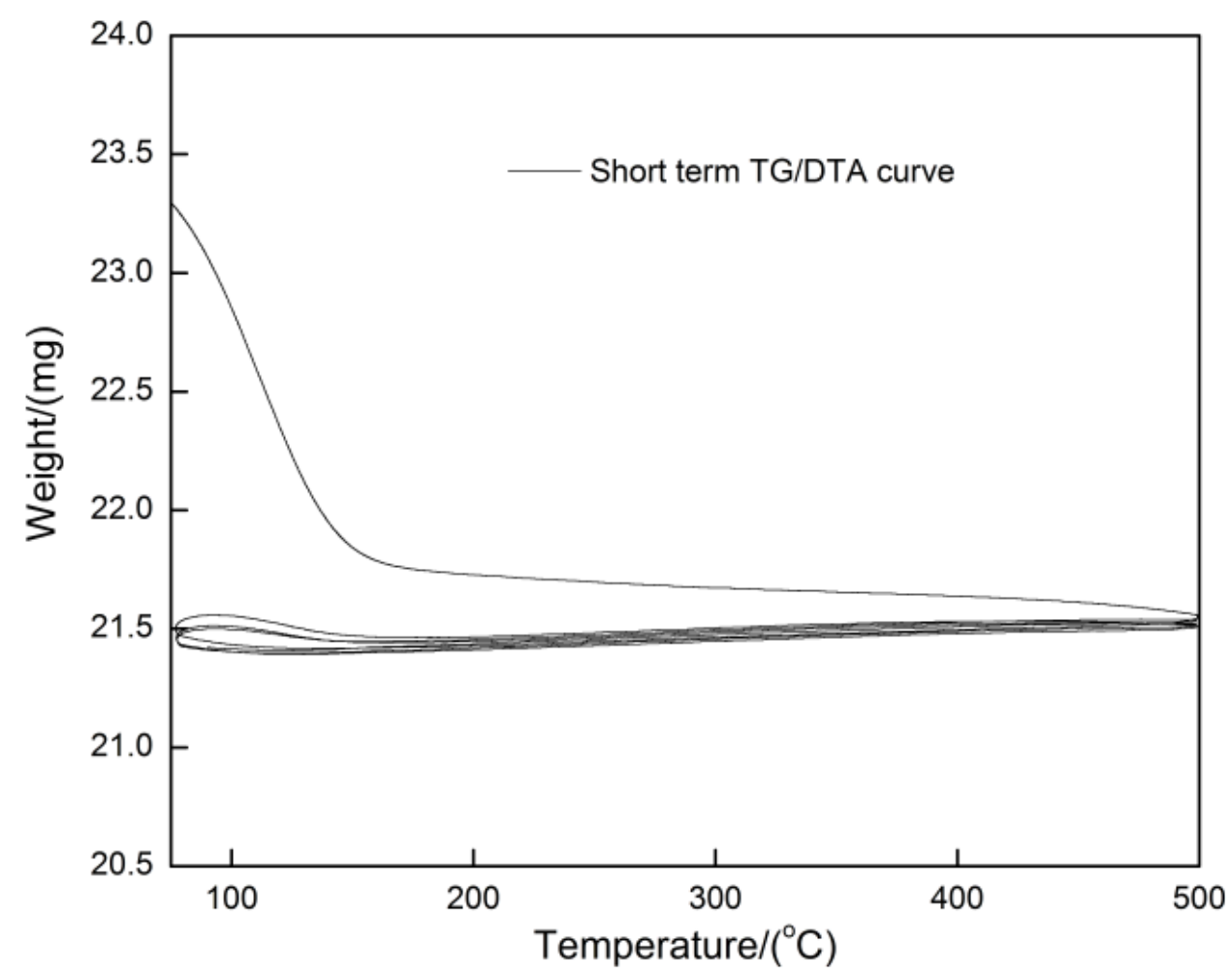

Fig. 8 Weight loss of the eutectic mixture of LiNO3-NaNO3-KNO3 ternary system as function of temperature in cyclic short-term thermal stability experiment.

Table 5 Weight loss of the eutectic mixture of LiNO3-NaNO3-KNO3 ternary system at different cycles during short-term thermal stability measurement 


\begin{tabular}{cl}
\hline Cycle \# & $\begin{array}{l}\text { Weight } \\
\text { loss }(\mathrm{mg})\end{array}$ \\
\hline 1 & 1.740 \\
2 & 0.054 \\
3 & 0.030 \\
4 & 0.010 \\
5 & 0.005
\end{tabular}

Total weight loss, wt $\% \quad 0.43$

Average weight loss, wt $\% \quad 0.11$

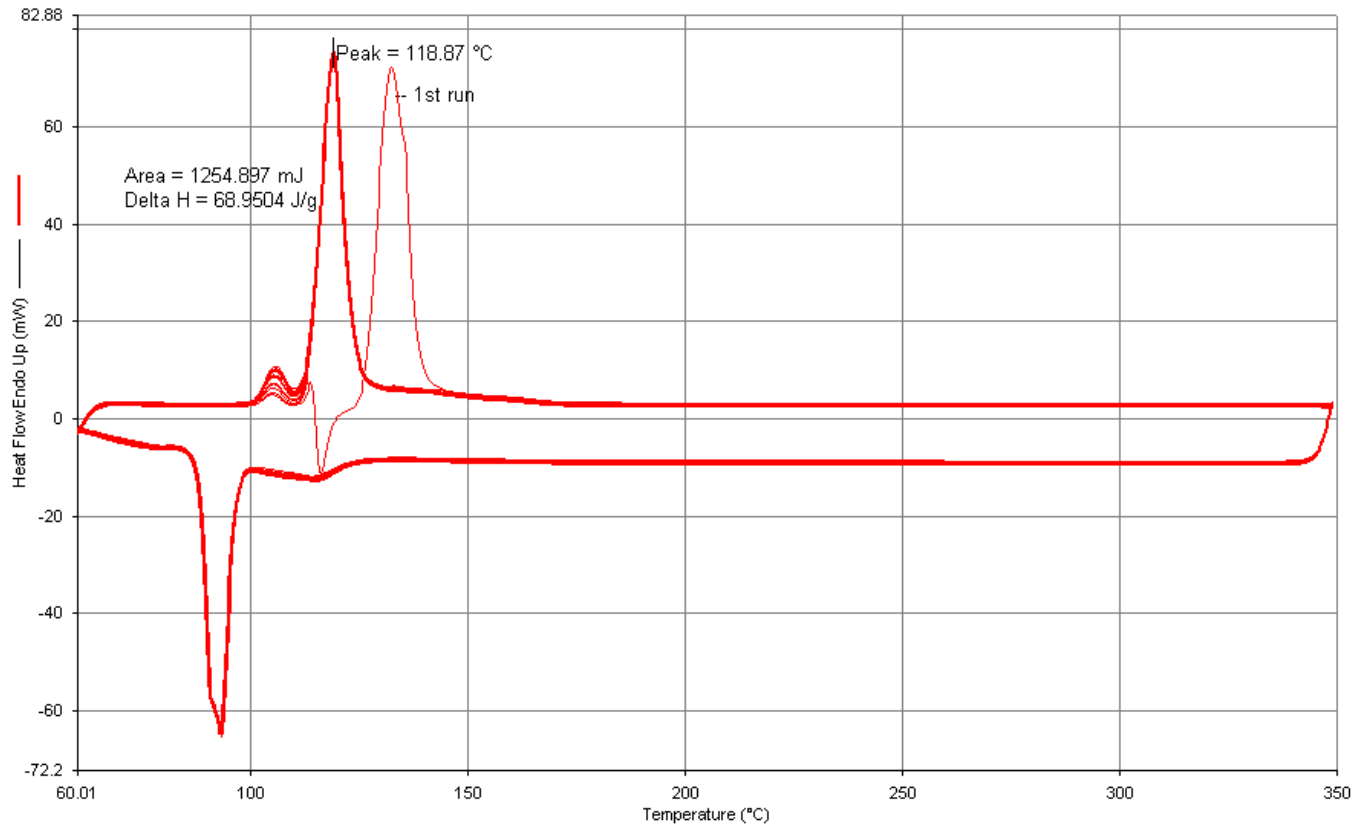

Fig. 9 Heat flow curves using DSC for 20-cycle thermal reliability measurement of the eutectic mixture of LiNO3-NaNO3-KNO3 ternary system.

By using the short-term method, the thermal stability of cyclic operation for all the LMP molten salt systems have been determined and listed in Table 6. The small amount of weight loss for all the LMP systems indicates their excellent thermal stabilities for short-term utilization. 
Table 6 Short-term thermal stability of LMP molten salt systems

\begin{tabular}{lc}
\hline \multicolumn{1}{c}{ System } & $\begin{array}{c}\text { Total weight } \\
\text { loss, wt } \%\end{array}$ \\
\hline $\mathrm{LiNO}_{3}-\mathrm{NaNO}_{3}-\mathrm{KNO}_{3}$ & 0.49 \\
$\mathrm{LiNO}_{3}-\mathrm{NaNO}_{3}-\mathrm{KNO}_{3}-\mathrm{NaNO}_{2}$ & 0.71 \\
$\mathrm{LiNO}_{3}-\mathrm{NaNO}_{3}-\mathrm{KNO}_{3}-\mathrm{KNO}_{2}$ & 0.88 \\
$\mathrm{LiNO}_{3}-\mathrm{KNO}_{3}-\mathrm{NaNO}_{2}-\mathrm{KNO}_{2}$ & 0.76 \\
$\mathrm{LiNO}_{3}-\mathrm{NaNO}_{3}-\mathrm{KNO}_{3}-\mathrm{MgKN}$ & 0.66 \\
$\mathrm{LiNO}_{3}-\mathrm{NaNO}_{3}-\mathrm{KNO}_{3}-\mathrm{NaNO}_{2}-\mathrm{KNO}_{2}$ & 0.58 \\
\hline
\end{tabular}

Long-term thermal stability and upper limit determination of LMP system in argon atmosphere

The operation of the long-term thermal stability measurement is similar to the short term study. However, instead of heating and cooling sample continuously, the long-term thermal stability study was performed isothermally at constant temperature for 20 hours. The experiment was carried out at each temperature of $150{ }^{\circ} \mathrm{C}$ interval in the range from $200{ }^{\circ} \mathrm{C}$ to $500{ }^{\circ} \mathrm{C}$. At the very beginning, the synthesized sample was left inside the furnace chamber of the TG/DTA at $150{ }^{\circ} \mathrm{C}$ for 1 hour to remove moisture absorbed in the process of loading sample. Besides, there is no cooling step in the long-term study, after the isothermally holding steps, the furnace was turned off and the weight loss detection was finished.

Long-term thermal stability of LMP molten salt systems were studied by using the TG/DTA isothermal weight change up to $500{ }^{\circ} \mathrm{C}$ carried out in four stages spanning a period of 60 hours. Take $\mathrm{LiNO}_{3}-\mathrm{NaNO}_{3}-\mathrm{KNO}_{3}$ system as an example, the long term thermal stability study as function of time was given in Fig. 10. 


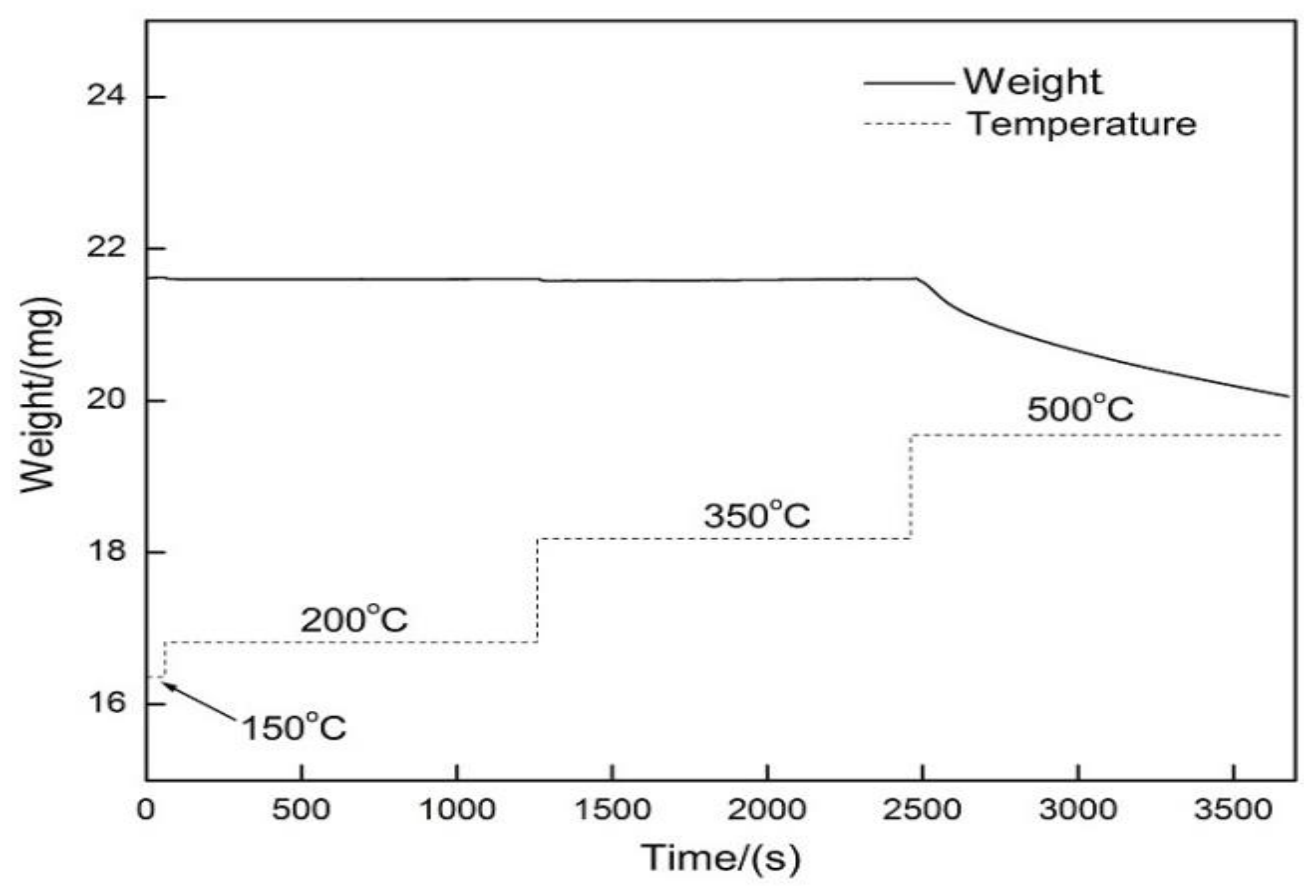

Fig. 10 60hrs long-term thermal stability measurement of LiNO3-NaNO3-KNO3

The total weight loss at $500{ }^{\circ} \mathrm{C}$ after the measurement was determined to be $8.57 \mathrm{wt} \%$. A small amount of the eutectic mixture was heated in four stages, namely: (i) One hour at $150{ }^{\circ} \mathrm{C}$, (ii) 20 hours at $200{ }^{\circ} \mathrm{C}$, (iii) 20 hours at $350{ }^{\circ} \mathrm{C}$ and (iv) 20 hours at $500{ }^{\circ} \mathrm{C}$. The small amount of weight loss in the one-hour isothermal period at $150{ }^{\circ} \mathrm{C}$ mainly results from the moisture removal which was also observed in the short-term thermal stability studies. The weight change was found to be zero in the following 20 hours at $200{ }^{\circ} \mathrm{C}$ as well as at $350{ }^{\circ} \mathrm{C}$. However, the stable state was disturbed once the temperature was increased to $500{ }^{\circ} \mathrm{C}$. A concave polynomial curve implies that the salt may asymptotically reach an equilibrium state again after being exposed at $500{ }^{\circ} \mathrm{C}$ for certain amount of time. Although Fig. 10 illustrates that the thermal stability is weakened only when temperature reaches the last isothermal step, the actual onset temperature for the weight loss needs further investigation. The isothermal TG/DTA thermal stability studies were conducted for each temperature from $350{ }^{\circ} \mathrm{C}$ to $500{ }^{\circ} \mathrm{C}$ at intervals of $25^{\circ} \mathrm{C}$ over a period of 20 hours. Among these measurements, no weight loss was detected in the temperature range from $350{ }^{\circ} \mathrm{C}$ to $425^{\circ} \mathrm{C}$.

In this series of measurements, Fig. 11 shows the isothermal thermal stability study of the eutectic salt mixture at $450{ }^{\circ} \mathrm{C}$. A steady weight loss with time was observed at this temperature. In order to determine the accurate upper limit of the working temperature of the salt mixture, the narrowed temperature range which involves the onset temperature for thermal instability was further examined by decreasing the temperature interval from 25 to $5{ }^{\circ} \mathrm{C}$. Trace amount of weight loss detected at $435^{\circ} \mathrm{C}$ demonstrates the onset temperature of thermal instability, which serves as a useful limiting parameter for the practical application. 


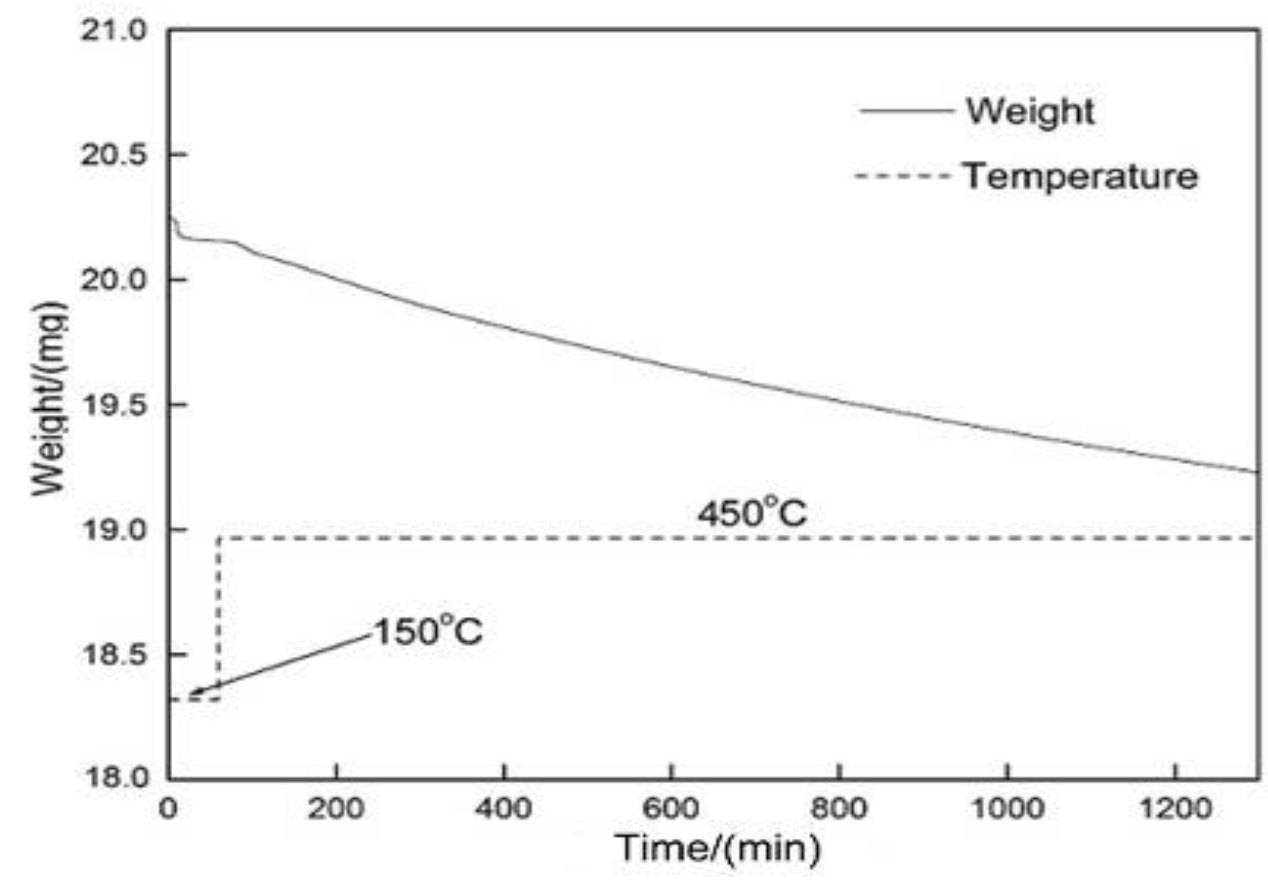

Fig. 11 Isothermal thermal stability study of LiNO3-NaNO3-KNO3 at $450^{\circ} \mathrm{C}$

All the weight loss values for the studied temperatures along with their upper limit temperature of thermal stability are listed in Table 7. Since the salt mixture is held at high temperature for a longer period in long-term experiment than that in the short-term experiment, the weight loss percentage is significantly higher in the former case. However, the total weight loss at the highest temperature of measurement is still acceptable for the realistic utility of the eutectic salt mixture as a potential candidate for thermal energy storage applications.

Table 7 Upper limit of thermal stability and weight loss of LMP molten salt systems at $500^{\circ} \mathrm{C}$ after $20 \mathrm{hrs}$

\begin{tabular}{lcc}
\hline \multicolumn{1}{c}{ System } & Total weight & Upper limit temperature \\
& loss, $\%$ & $\left({ }^{\circ} \mathrm{C}\right)$ \\
\hline $\mathrm{LiNO}_{3}-\mathrm{NaNO}_{3}-\mathrm{KNO}_{3}$ & 8.9 & 435 \\
$\mathrm{LiNO}_{3}-\mathrm{NaNO}_{3}-\mathrm{KNO}_{3}-\mathrm{NaNO}_{2}$ & 7.6 & 425 \\
$\mathrm{LiNO}_{3}-\mathrm{NaNO}_{3}-\mathrm{KNO}_{3}-\mathrm{KNO}_{2}$ & 9.1 & 440 \\
$\mathrm{LiNO}_{3}-\mathrm{NaNO}_{3}-\mathrm{KNO}_{3}-\mathrm{MgKN}$ & 5.4 & 385 \\
$\mathrm{LiNO}_{3}-\mathrm{NaNO}_{3}-\mathrm{KNO}_{3}-\mathrm{NaNO}_{2}-$ & & 435 \\
$\mathrm{KNO}_{2}$ & 6.4 & \\
\hline
\end{tabular}




\section{Upper limit determination of High melting point (HMP) system thermal stability}

In order to determine the accurate upper limit of the working temperature of the HMP molten salt systems, each salt mixture was heated continuously from $773.15 \mathrm{~K}$ to $1223.15 \mathrm{~K}$ with $10 \mathrm{~K} / \mathrm{min}$ heating rate in argon atmosphere. The measurements were repeated at least three times with fresh prepared samples to ensure the accuracy and reproducibility. As a typical case for upper limit thermal stability determination, the collected weight change curve as function of temperature of LiF- $\mathrm{Na}_{2} \mathrm{CO}_{3}-\mathrm{K}_{2} \mathrm{CO}_{3}$ is illustrated in Fig. 12 along with the rate of weight loss dTG. The temperature with approximately $0.01 \mathrm{mg} / \mathrm{min}$ of dTG trace is defined to be the upper limit of thermally stable working temperature. For $\mathrm{LiF}-\mathrm{Na}_{2} \mathrm{CO}_{3}-\mathrm{K}_{2} \mathrm{CO}_{3}$ salt, the average value was measured to be $1070.15 \pm 35 \mathrm{~K}$ under argon atmosphere.

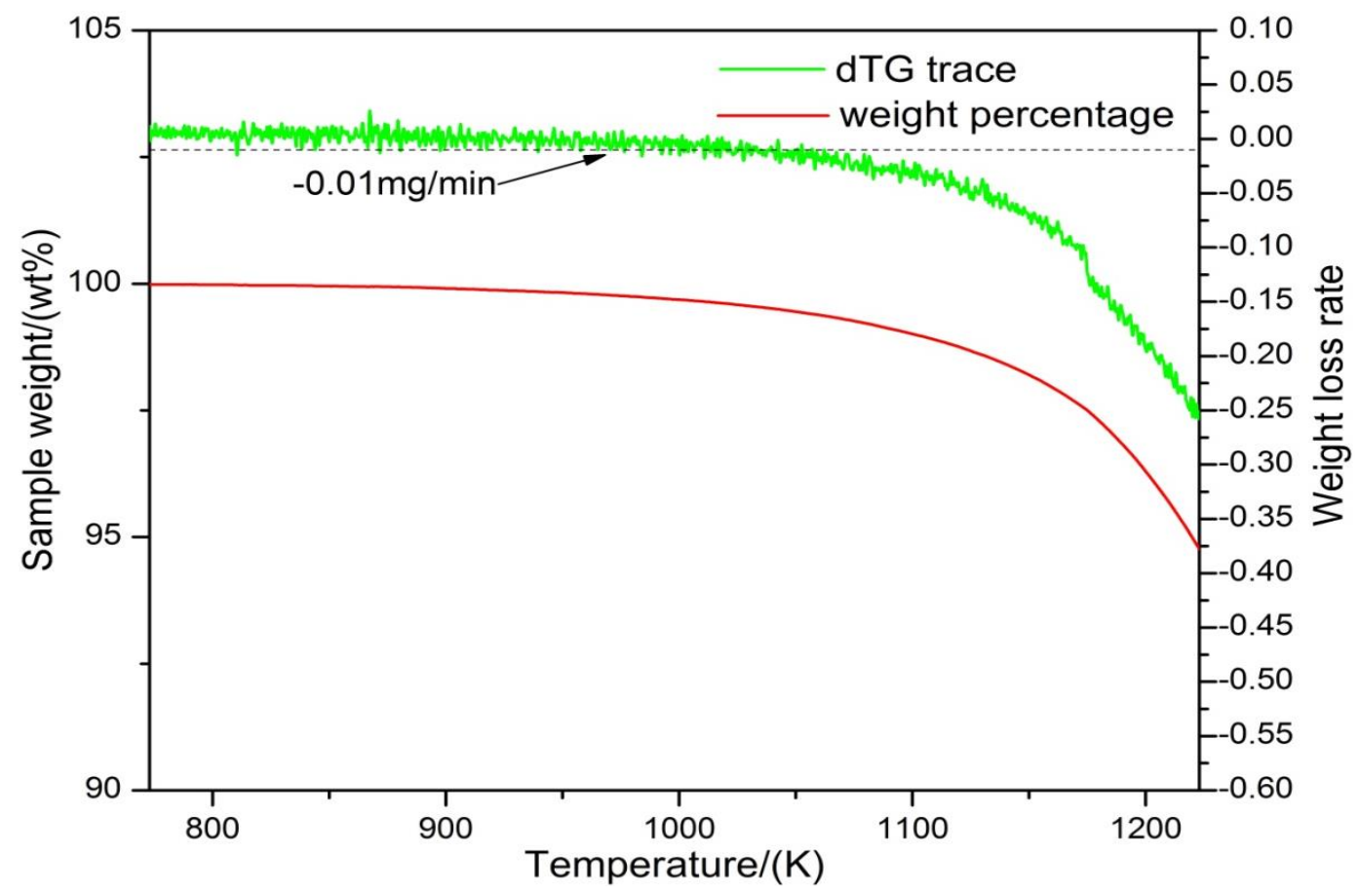

Fig. 12 Weight change of LiF-Na2CO3-K2CO3 system as function of temperature in argon atmosphere

The HMP systems were then heated continuously to determine the upper limit of the working temperatures in carbon dioxide atmosphere and the weight change curve as function of temperature of the LiF- $\mathrm{Na}_{2} \mathrm{CO}_{3}-\mathrm{K}_{2} \mathrm{CO}_{3}$ ternary system is illustrated in Fig. 13 which demonstrates significant improvement of thermal stability compared to that detected in argon atmosphere. The upper limit of thermally stable working temperature of the $\mathrm{LiF}-\mathrm{Na}_{2} \mathrm{CO}_{3}-\mathrm{K}_{2} \mathrm{CO}_{3}$ salt was measured to be $1194.15 \pm 40 \mathrm{~K}$ in this case. At $1273.15 \mathrm{~K}$, relatively small amount of weight losses $(<1.5 \mathrm{wt} \%)$ were observed with approximately $0.06 \mathrm{mg} / \mathrm{min}$ dTG trace. It is notable that the upper limit of thermally stable working temperature measured in the carbonate dioxide atmosphere is approximately $124 \mathrm{~K}$ higher than that detected in argon atmosphere. What's more, the rate of weight loss detected at high temperature with carbonate dioxide purge gas is lower than that measured in argon atmosphere. The phenomenon is most likely attributed to the presence of carbon 
dioxide suppresses the decomposition of carbonate salts. Therefore, the extent of weight loss at working temperature was diminished. Similar to the $\mathrm{LiF}-\mathrm{Na}_{2} \mathrm{CO}_{3}-\mathrm{K}_{2} \mathrm{CO}_{3}$ system, the upper limit of thermal stability of other HMP systems have been tabulated in Table 8 .

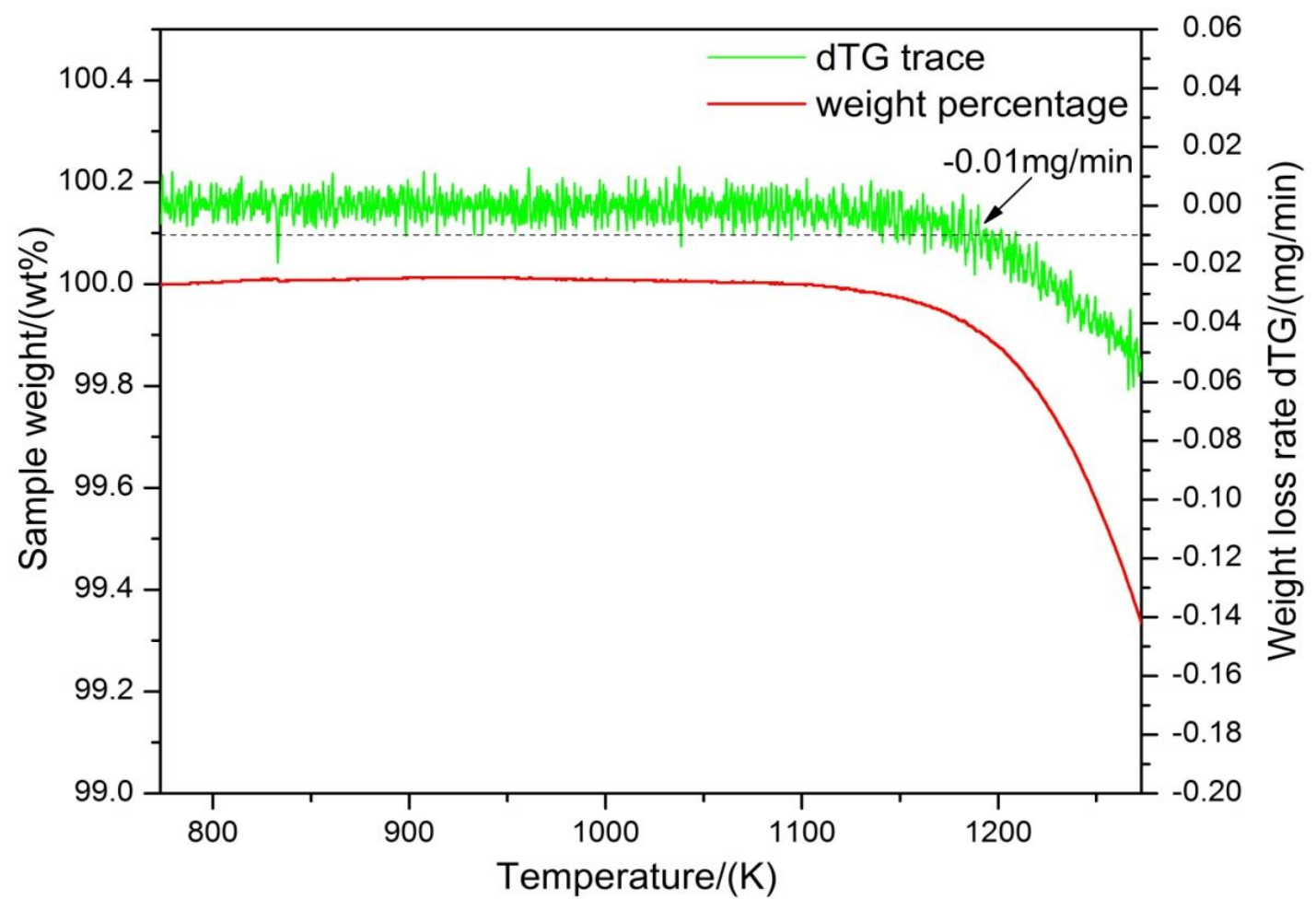

Fig. 13 Weight change of LiF-Na2CO3-K2CO3 system as function of temperature in carbon dioxide atmosphere

Table 8 Upper limit temperature of thermal stability under carbon dioxide atmosphere

\begin{tabular}{|c|c|}
\hline System & $\begin{array}{c}\text { Upper limit } \\
\text { temperature } \\
\left({ }^{\circ} \mathrm{C}\right)\end{array}$ \\
\hline $\mathrm{Li}_{2} \mathrm{CO}_{3}-\mathrm{Na}_{2} \mathrm{CO}_{3}-\mathrm{K}_{2} \mathrm{CO}_{3}$ & 857 \\
\hline $\mathrm{LiF}-\mathrm{Na}_{2} \mathrm{CO}_{3}-\mathrm{K}_{2} \mathrm{CO}_{3}$ & 921 \\
\hline LiF-NaF-K ${ }_{2} \mathrm{CO}_{3}$ & 951 \\
\hline
\end{tabular}

On the basis of the experimentally measured upper limit of stable temperature and the thermal weight loss rate dTG, it can be concluded that HMP system can be operated more stably in carbon dioxide atmosphere than other inert gas at high temperature. Consequently, a large working temperature range is achieved given the great thermal stability. 


\section{Thermal conductivity determination of salt mixtures in solid state}

Theoretical analysis

The thermophysical properties of solid salts are strongly dependent on temperature. In this work, the thermal conductivity of a ternary eutectic salt mixture was determined in the solid state. Fourier's second law for unsteady state conditions was applied to calculate the thermal conductivity as a function of temperature. The governing equation for heat conduction in cartesian coordinates is expressed as:

$\rho C_{p} \frac{\partial T}{\partial t}=\lambda \Delta T+q_{v}$

where $\Delta$ is the Laplace operator $\Delta=\frac{\partial^{2}}{\partial \mathrm{X}^{2}}+\frac{\partial^{2}}{\partial \mathrm{Y}^{2}}+\frac{\partial^{2}}{\partial \mathrm{Z}^{2}}, \rho$ is the density of the solid, $C_{p}$ is specific heat capacity, $\lambda$ is thermal conductivity, $t$ is time, and $q_{v}$ is heat generation per unit volume during phase transition. The conduction equation in cylindrical coordinates has the following form:

$\rho C_{p} \frac{\partial T}{\partial t}=\frac{1}{r} \frac{\partial}{\partial r}\left(\lambda r \frac{\partial T}{\partial r}\right)+\frac{1}{r^{2}} \frac{\partial}{\partial \varphi}\left(\lambda \frac{\partial T}{\partial \varphi}\right)+\frac{\partial}{\partial Z}\left(\lambda \frac{\partial T}{\partial Z}\right)+q_{v}$

where $r$ is the radial distance, $\varphi$ is the angular coordinate, and $Z$ is axial position. Since measurements were conducted in the solid state in the absence of phase transitions, the heat generation per unit volume $\left(q_{v}\right)$ is zero. Since the thermal conductivity of salts is isotropic, heat transfer may be considered to be axi-symmetric. Consequently, Equation [16] can be simplified to a two-dimensional axi-symmetric form as following:

$\rho C_{p} \frac{\partial T}{\partial t}=\frac{1}{r} \frac{\partial}{\partial r}\left(\lambda r \frac{\partial T}{\partial r}\right)+\frac{\partial}{\partial Z}\left(\lambda \frac{\partial T}{\partial Z}\right)$

Since thermal conductivity is only a function of temperature, Equation [17] can be expanded as follows:

$\rho C_{p} \frac{\partial T}{\partial t}=\frac{\lambda}{r} \frac{\partial T}{\partial r}+\lambda \frac{\partial^{2} T}{\partial r^{2}}+\lambda \frac{\partial^{2} T}{\partial Z^{2}}$ 
Rearranging Equation [18] yields

$\lambda=\rho C_{p} \frac{\partial T}{\partial t} /\left(\frac{1}{r} \frac{\partial T}{\partial r}+\frac{\partial^{2} T}{\partial r^{2}}+\frac{\partial^{2} T}{\partial Z^{2}}\right)$

Now, Equation [19] can be further simplified as:

$\lambda=\rho \cdot C_{p} \cdot\left(\frac{\partial T}{\partial t}\right) /\left(\frac{1}{r} \frac{\partial T}{\partial r}+\frac{\partial^{2} T}{\partial r^{2}}\right)$

Using Equation [20], the thermal conductivity can be calculated by substituting the values of heating or cooling rate, temperature gradient, density and specific heat capacity of the solid salt into the equation.

\section{Determination of sample dimensions}

The simulation software package ProCAST ${ }^{\circledR}$ was used to determine suitable sample dimensions for the thermal conductivity measurement of the eutectic salt mixture in this study. The criterion of the sample size determination is to maintain sufficient isothermal range in the $\mathrm{Z}$ direction. ProCAST simulation predicts the temperature profile for any given sample whose density, heat capacity and thermal conductivity are known. Literature data of density, heat capacity, and thermal conductivity of nitrate group salts were used in the ProCAST simulation to study the temperature profile along the Z-direction of the cylindrical eutectic salt samples. Based on the predicted temperature profiles, suitable sample dimensions are chosen to cast the cylindrical samples for the ternary eutectic salt mixture of this study. The simulation was conducted on a chosen eutectic salt mixture with arbitrary dimensions of $50 \mathrm{~mm}$ in diameter and $50 \mathrm{~mm}$ in length. Starting from some initial temperature lower than the melting point of the salt mixture, the temperature profile was collected after certain time along the $\mathrm{Z}$ axis. The isothermal range in the $\mathrm{Z}$ axis is less than $4 \mathrm{~mm}$ when the length is set as $50 \mathrm{~mm}$ for the cylindrical sample. When the length of the cylindrical sample was increased to $75 \mathrm{~mm}$, the isothermal range was $9 \mathrm{~mm}$.

The isothermal temperature range did not change much when the cylindrical length of the sample was increased beyond $75 \mathrm{~mm}$. On the basis of the observation, the length of the cylindrical sample was set as $75 \mathrm{~mm}$ for the thermal conductivity measurements of the eutectic salt mixture in this study. The heat conduction conditions for different materials were also predicted using the ProCAST simulation and the isothermal ranges with the same sample length are listed in Table 9.

Table 9 Isothermal range along Z-axis of different solid samples with $75 \mathrm{~mm}$ cylinder length 


\begin{tabular}{lc}
\hline Solid sample & Zero gradient zone $(\mathrm{mm})$ \\
\hline Alumina & $36-42$ \\
SS-Austenitic & $36-42$ \\
AL-3004 & $36-39$ \\
Solid salt & $33-42$ \\
Zinc & $36-40$ \\
\hline
\end{tabular}

The thermal gradient along the radial direction is the determining parameter in the calculation of thermal conductivity of solid samples in 1-Dimensional inverse method. Therefore, sufficient temperature difference between the selected spots along the radial direction of the cylindrical sample is necessary to ensure the accuracy of the calculated thermal conductivity using Equation [20]. Since the thermal conductivity of salts in solid state is very low, the thermal gradient along the radial direction can be expected to be maintained. For the cylinder with $75 \mathrm{~mm}$ length and 50 $\mathrm{mm}$ diameter, the temperature distribution along the radius after certain time in the simulation process is given in Fig. 14. It is observed that the temperature difference between the outer and inner surfaces of the sample was over $60^{\circ} \mathrm{C}$. Since the thermal gradient within the solid sample is so large that the thermocouple error $\left( \pm 0.5^{\circ} \mathrm{C}\right)$ can be neglected in these measurements. Thermal gradient measurements for the cylindrical sample cast for each eutectic salt mixture were repeated at least three times to ensure reproducibility. Based on the temperature distribution as seen from Fig. 14, a cylindrical sample with a diameter of $50 \mathrm{~mm}$ was considered to be large enough for this study. 


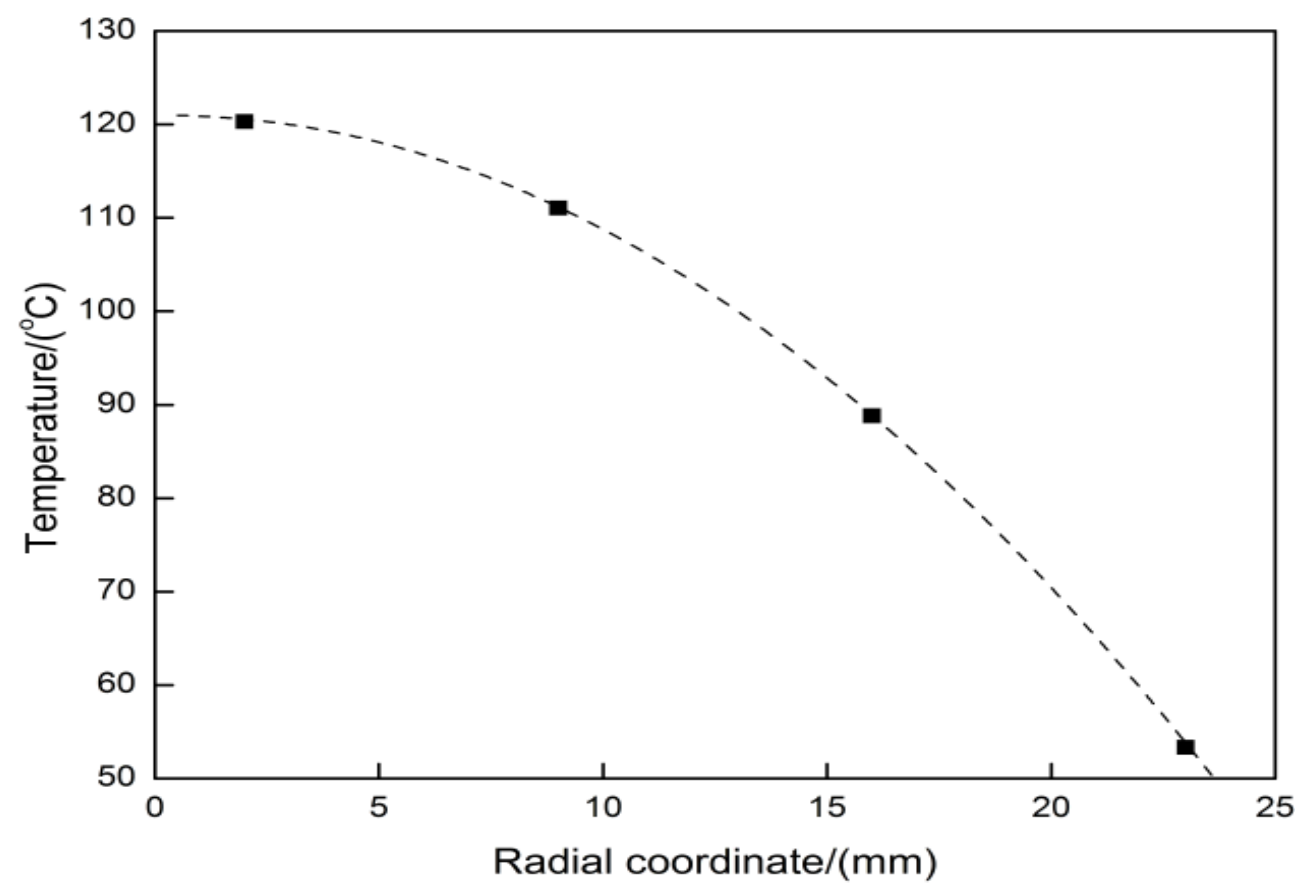

Fig. 14 Thermal gradient of cylindrical sample along the radial direction

Thermal conductivity calibration

The thermal conductivity of a commercially available HITEC ${ }^{\circledR}$ heat transfer salt was determined in this study using the simplified inverse heat conduction equation. For the poorly conducting solid salts, the thermal gradient inside the sample body can be established either by heating process or air-cooling process. Unlike in the case of highly conductive metals/alloys, the starting temperature of the measurement is significant for solid salts mixtures. This is because all the selected spots for thermocouples must have same starting temperature to ensure the initial condition and the accuracy of the temperature plot as function of radial coordinate. If the cooling process is chosen for solid salts, it would be difficult to bring all the points inside the sample to reach the same expected temperature which is above the room temperature. Alternately, this can be easily achieved in a heating process from the room temperature.

In the experiment, at least three sets of measurements were made to check the reproducibility of the data. Fig. 15 shows the thermal conductivity data for the HITEC ${ }^{\circledR}$ salt as function of temperature along with those available in the literature for the salt. Thermal conductivity calculated for HITEC $^{\circledR}$ salt in the present study varies non-linearly with temperature. The experimental data of Turnbull for the HITEC ${ }^{\circledR}$ salt were measured by the transient hot wire method. The results from this work were $20 \%$ higher than those from the literature at $30{ }^{\circ} \mathrm{C}$, and the deviation is still acceptable for the conductivity measurement of salt. It is also observed from Fig. 15 that the difference was lower at higher temperatures. The thermal conductivity data obtained for HITEC $^{\circledR}$ salt by this method shows relatively large deviation from that available in the literature at temperatures lower than $60{ }^{\circ} \mathrm{C}$. In salt mixtures, especially in binary and higher 
order mixtures, the thermal gradients are much lower than those expected in metals or alloys, particularly at low temperatures. Small errors in the measurement of temperature at low temperature for salt mixtures can lead to significant errors in the calculated thermal conductivity values. However, at higher temperatures, the thermal gradients are higher which reduces the errors in measurement. It can be concluded that the presented inverse method is a reliable method for the determination of thermal conductivities of salt mixtures at high temperatures than at low temperatures due to low thermal gradients.

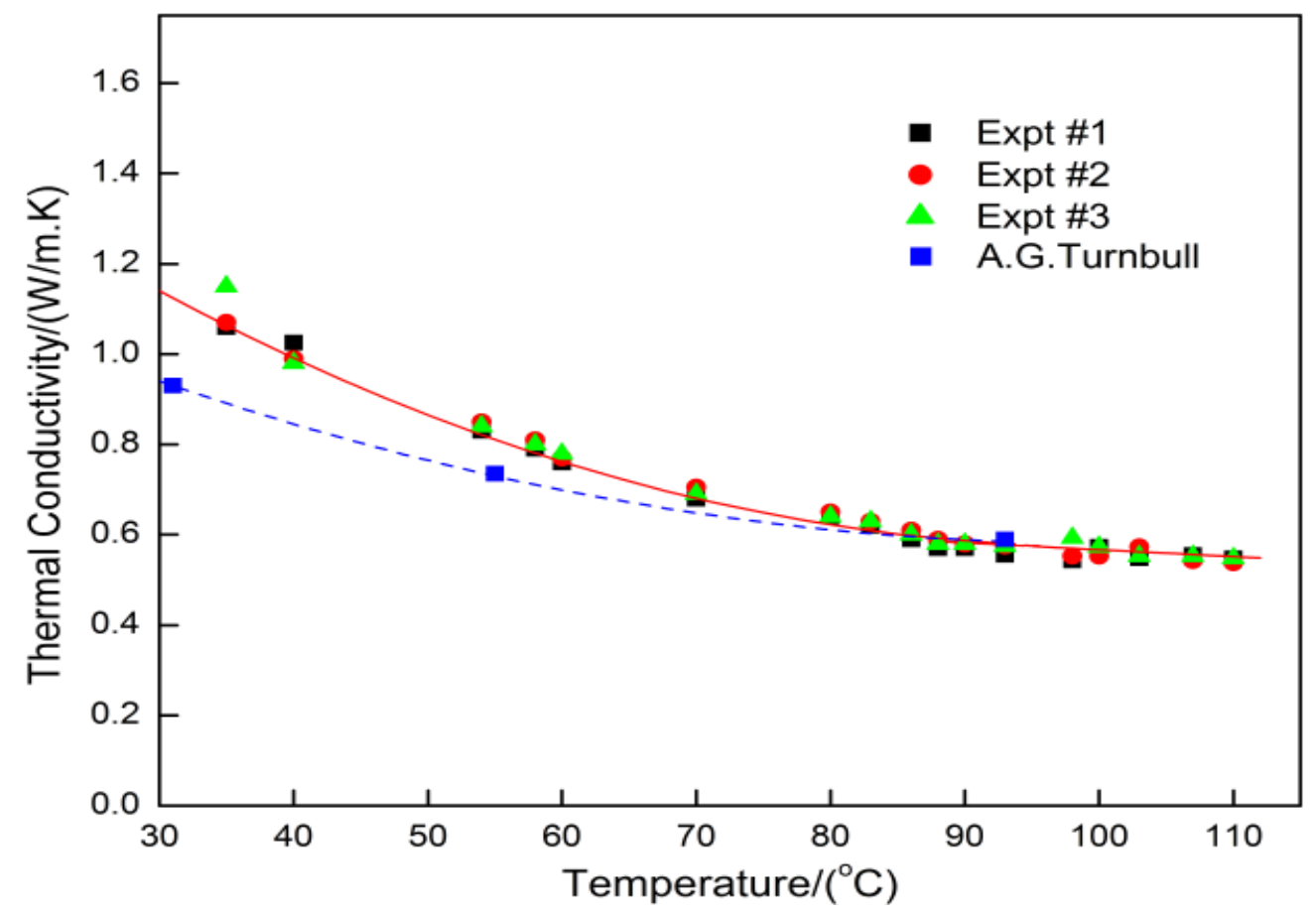

Fig. 15 Thermal conductivity of HITEC $\AA$ salt measured as a function of temperature

Fig. 16 (a) shows the experimental thermal conductivity data for the HITEC ${ }^{\circledR}$ salt as function of temperature up to $110^{\circ} \mathrm{C}$ along with the literature data available for the salt at its melting point $\left(142{ }^{\circ} \mathrm{C}\right)$. The thermal conductivity values of the salt decreases with increase in temperature. However, the variations of the thermal conductivities become very small beyond $90{ }^{\circ} \mathrm{C}$ as can be seen from Fig. 16(b). Therefore, the thermal conductivity data variation from $90{ }^{\circ} \mathrm{C}$ to $110{ }^{\circ} \mathrm{C}$ can be assumed to be linear. As a result of this trend, the thermal conductivity data beyond $90{ }^{\circ} \mathrm{C}$ can be extrapolated to the salt melting point $\left(142^{\circ} \mathrm{C}\right)$ using a linear fit as shown in Fig. 16 (c). At 142 ${ }^{\circ} \mathrm{C}$, the extrapolated data is $2 \%$ higher than literature data and the excellent agreement of thermal conductivity beyond the studied temperature range verifies the feasibility of application of 1Dimensional inverse method. 

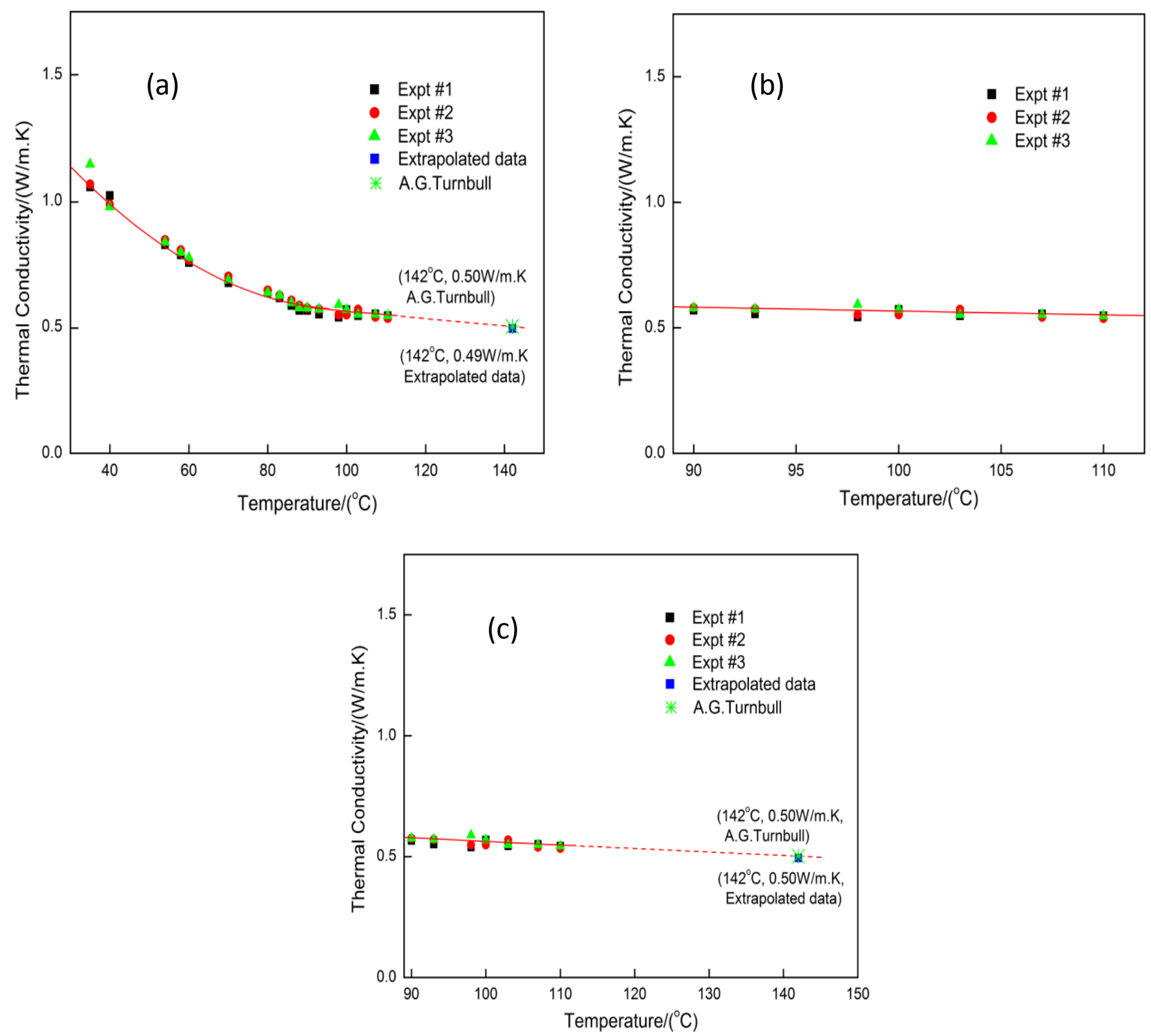

Fig. 16 (a) Comparison of extrapolated and literature data of thermal conductivity of HITEC® salt near melting point, (b) linear variation of experimental thermal conductivity in the temperature range of 90 $110{ }^{\circ} \mathrm{C}$ (c) extrapolated linear variation of thermal

Thermal conductivity of Low melting point (LMP) and High melting point (HMP) salt mixtures

Thermal conductivity in the solid state was determined for the both low melting point and high melting point ternary eutectic mixture. Take $\mathrm{LiNO}_{3}-\mathrm{NaNO}_{3}-\mathrm{KNO}_{3}$ salt mixture as an example, the salt mixture was prepared into cylindrical sample based on its eutectic composition as mentioned above. The temperature data was collected at least three times for each salt sample and 
the results are shown in Fig. 17. Since all the experiments were conducted under identical conditions and the samples were homogeneous, there is excellent reproducibility of the data (within 3\% variation). Similar to that in the case of HITEC $^{\circledR}$ salt, the thermal conductivity values of ternary salt mixture decreased as function of temperature. The similarities of the temperature dependence of thermal conductivity are likely due to the identical thermal conduction mechanism and similar groups of constituent ions. In the solid state, heat transfer in salt is mainly controlled by phonon vibrations. Unlike metals, heat conduction due to free electrons is negligible due to ionic bonding in salts. Thermal conductivity in this condition is highly depended on the mean free path of phonons within the studied temperature range. As the temperature increases, the random vibration inside the crystal is enhanced, which increases the chance of collision of neighboring phonons. As a consequence, the mean free path decreases and so does the thermal conductivity.

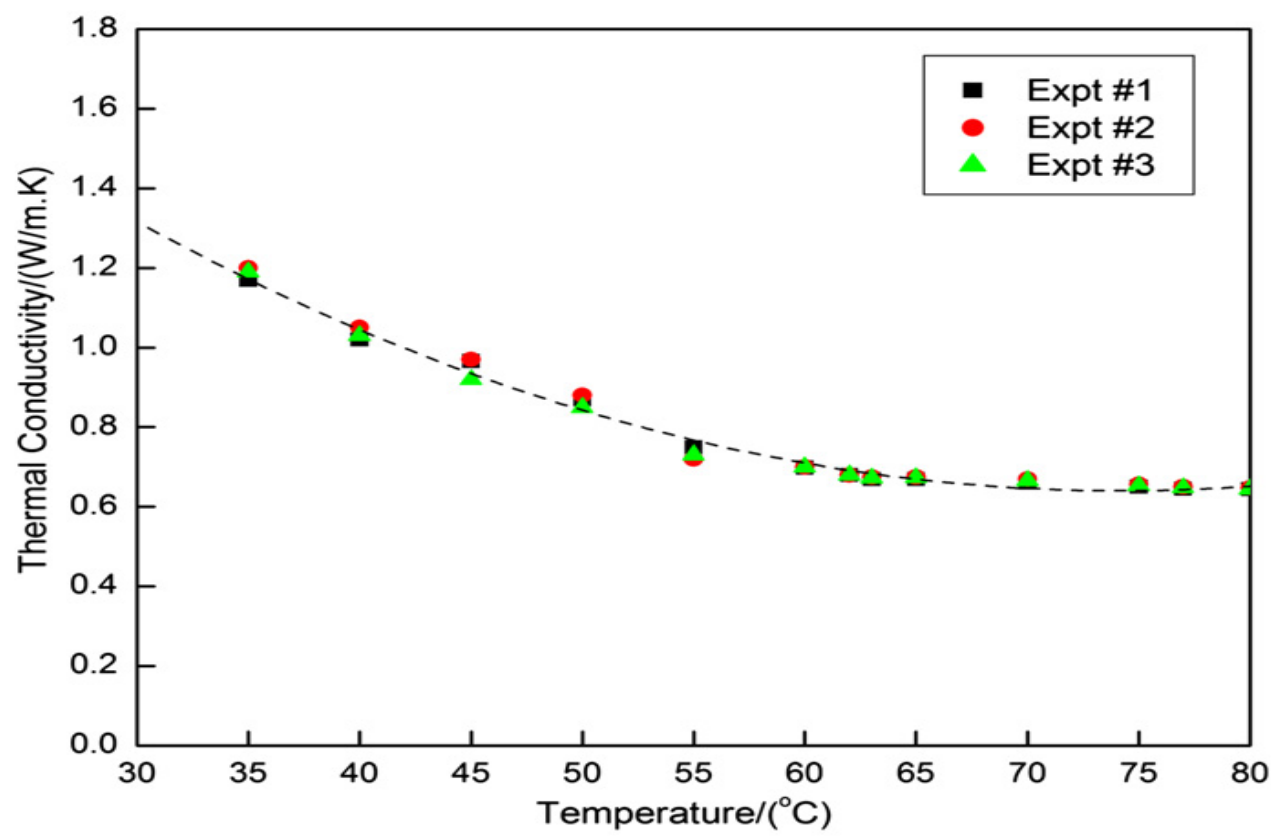

Fig. 17 Thermal conductivity of LiNO3-NaNO3-KNO3 ternary system.

For nitrate mixture, at lower temperatures the thermal conductivity decreases non-linearly with temperature. As the temperature approaches the melting point, the decrease in thermal conductivity becomes linear and significantly smaller. The thermal conductivity of $\mathrm{LiNO}_{3}-\mathrm{NaNO}_{3}-\mathrm{KNO}_{3}$ salt mixture given in Fig. 17 can be expressed as follows:

$\lambda(\mathrm{W} / \mathrm{m} \cdot \mathrm{K})=2.68-5.59 \times 10^{-2} \mathrm{~T}+3.83 \times 10^{-4} \mathrm{~T}^{2}$

where the coefficients $\mathrm{A}, \mathrm{B}$, and $\mathrm{C}$ are $2.68,-0.0559$, and 0.000383 respectively. The $\mathrm{R}^{2}$ value for the least square fit between the calculated and experimental data is 0.985 .

Similar to the $\mathrm{LiNO}_{3}-\mathrm{NaNO}_{3}-\mathrm{KNO}_{3}$ system, the thermal conductivity of other systems expect $\mathrm{LiF}-\mathrm{NaF}-\mathrm{KF}$ and $\mathrm{MgCl}_{2}-\mathrm{KCl}$ system have also been experimentally determined. The moderate hygroscopic property of $\mathrm{LiF}-\mathrm{NaF}-\mathrm{KF}$ and $\mathrm{MgCl}_{2}-\mathrm{KCl}$ makes it difficult to prepare the cylindrical 
sample coupon at room temperature. As illustrated in Fig. 18 and 19, the thermal conductivity of HMP molten salt systems have very similar dependence on temperature as LMP systems. As the sample is heated up to the temperature close to its melting point, the thermal conductivity tends to reach a constant value. Even though the thermal conductivities in the liquid state of salt mixtures cannot be determined directly from inverse method, it can still be roughly estimated based on the values at melting point which are listed in Table 10.

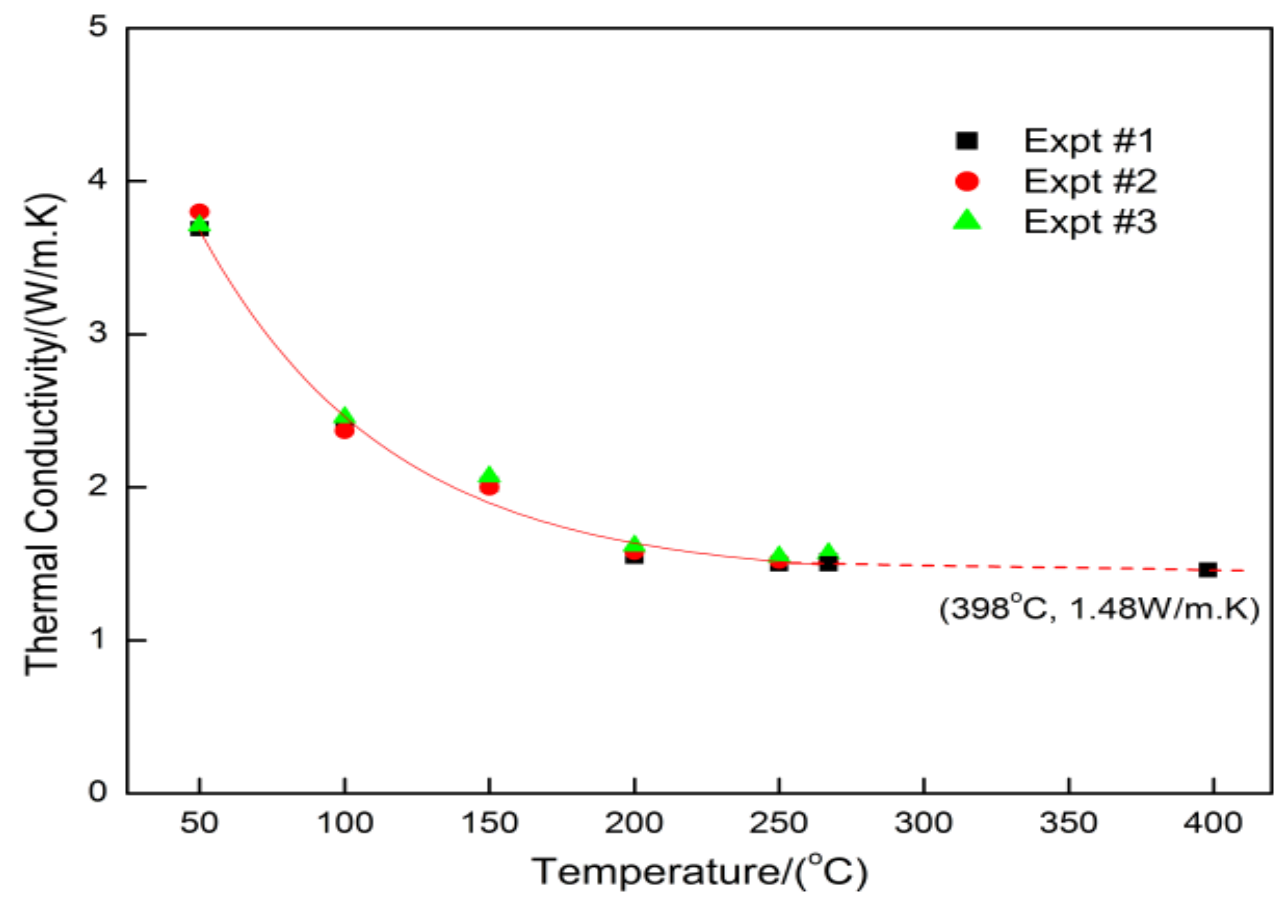

Fig. 18 Thermal conductivity of Li2CO3-Na2CO3-K2CO3 ternary system. 


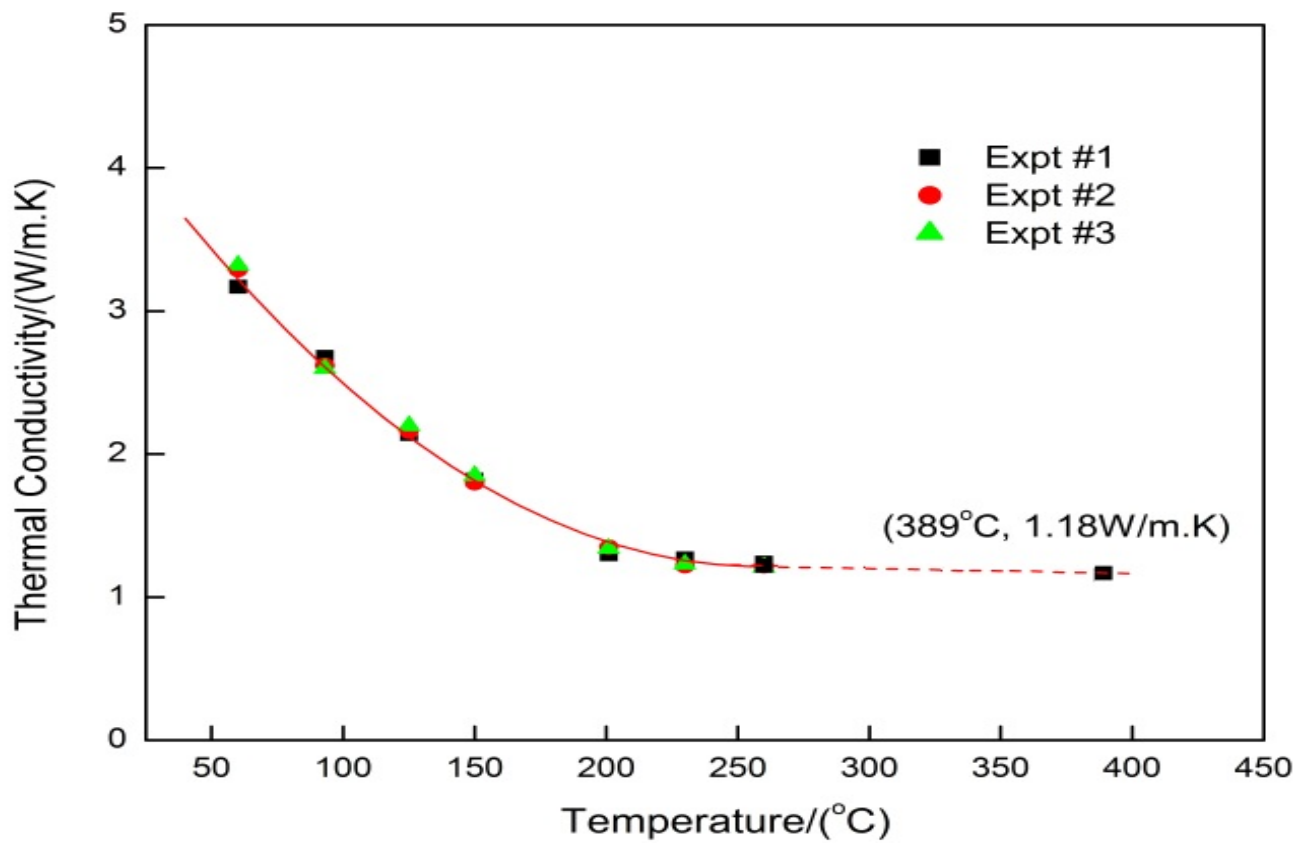

Fig. 19 Thermal conductivity of LiF-Na2CO3-K2CO3 ternary system.

Table 10 Thermal conductivity of LMP and HMP molten salt systems at melting point

\section{Thermal Conductivity}

System

$(\mathbf{W} / \mathbf{m} . \mathbf{K})$

at melting point

\begin{tabular}{ll}
\hline $\mathrm{LiNO}_{3}-\mathrm{NaNO}_{3}-\mathrm{KNO}_{3}$ & 0.60 \\
$\mathrm{LiNO}_{3}-\mathrm{NaNO}_{3}-\mathrm{KNO}_{3}-\mathrm{NaNO}_{2}$ & 0.55 \\
$\mathrm{LiNO}_{3}-\mathrm{NaNO}_{3}-\mathrm{KNO}_{3}-\mathrm{KNO}_{2}$ & 0.63 \\
$\mathrm{LiNO}_{3}-\mathrm{NaNO}_{3}-\mathrm{KNO}_{3}-\mathrm{MgKN}$ & 0.53 \\
$\mathrm{LiNO}_{3}-\mathrm{NaNO}_{3}-\mathrm{KNO}_{3}-\mathrm{NaNO}_{2}-\mathrm{KNO}_{2}$ & 0.54 \\
\hline $\mathrm{Li}_{2} \mathrm{CO}_{3}-\mathrm{Na}_{2} \mathrm{CO}_{3}-\mathrm{K}_{2} \mathrm{CO}_{3}$ & 1.48 \\
$\mathrm{LiF}_{-} \mathrm{Na}_{2} \mathrm{CO}_{3}-\mathrm{K}_{2} \mathrm{CO}_{3}$ & 1.18 \\
\hline
\end{tabular}




\section{Determination of corrositivity of Low melting point (LMP) molten salts}

All electrochemical experiments were monitored by PAR Potentiostat \& Galvanistat instrument model $273 \mathrm{~A}$ which is connected and controlled by a dedicated computer. Temperature inside the molten salt was measured by thermocouple and read from the software named Chartview 2006. Once the testing sample was immersed in the electrolyte, the potential in the experimental process is continuously detected and collected. The potential scanning range for the potentiostat instrument is from $-0.25 \mathrm{~V}$ to $0.25 \mathrm{~V}$ with respect to the corrosion potential, $\mathrm{E}_{\text {corr }}$, and the scanning rate is fixed to $10 \mathrm{mV} / \mathrm{min}$. After getting the polarization curve, the corrosion current density Icorr was calculated from the intersection of the extrapolated straight Tafel line of anodic and cathodic curves. The calculation is done automatically by the software from the console window of the program. A representative plot of the polarization curve for $\mathrm{LiNO}_{3}-\mathrm{NaNO}_{3}-\mathrm{KNO}_{3}$, at $450{ }^{\circ} \mathrm{C}$ is shown in Fig. 19.

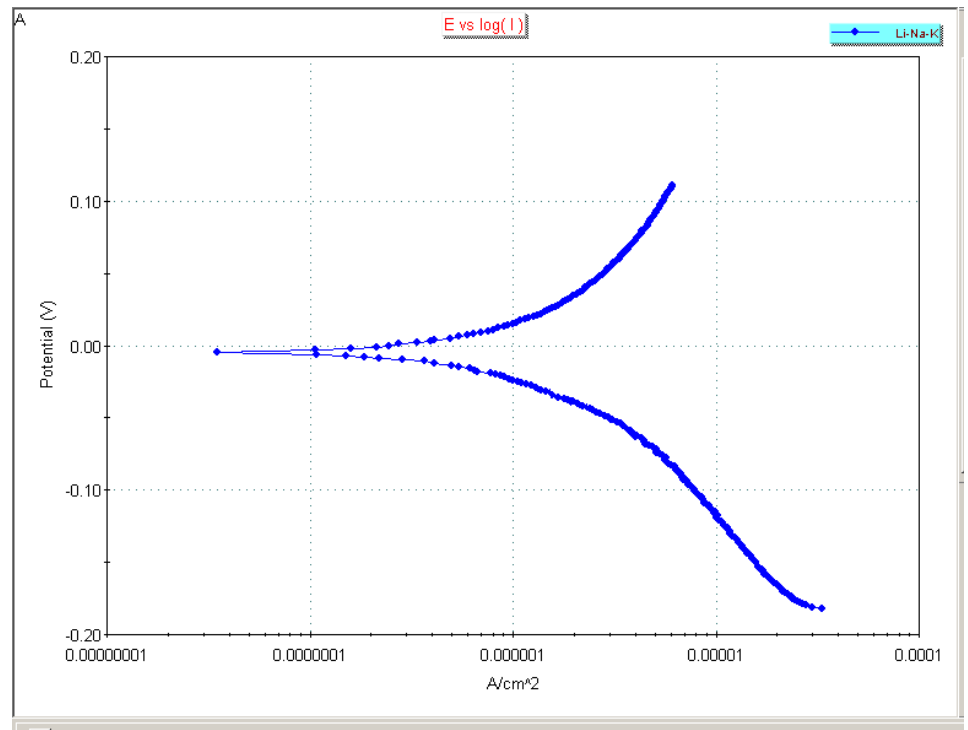

Fig. 19 Polarization curve for LiNO3-NaNO3-KNO3 at $450{ }^{\circ} \mathrm{C}$.

The corrosion rates are calculated from the electrochemical experimental results as follows:

$$
\mathrm{r}=\frac{3.27 \mathrm{i}_{\text {corr }} \mathrm{W}_{\mathrm{i}}}{\rho}
$$

where $\mathrm{r}$ is corrosion rate in micrometers per year, Wi is equivalent weight of the alloy, $\rho$ is density of the alloy $(\mathrm{g} / \mathrm{cc})$ and icorr is corrosion current density $(\mu \mathrm{A} / \mathrm{cm} 2)$ collected from the polarization curve. As shown in Fig. 20-23, when immersed in low melting point systems, the corrosion rate of SS 316L increases linearly as function of temperature. 


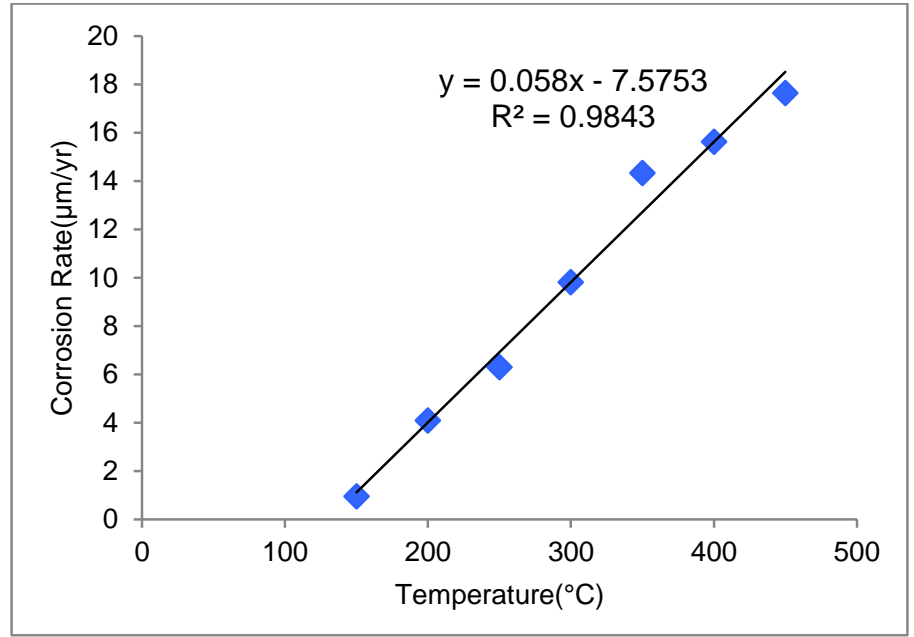

Fig. 20 Variation of corrosion rate as a function of temperature for LiNO3-NaNO3-KNO3 salt.

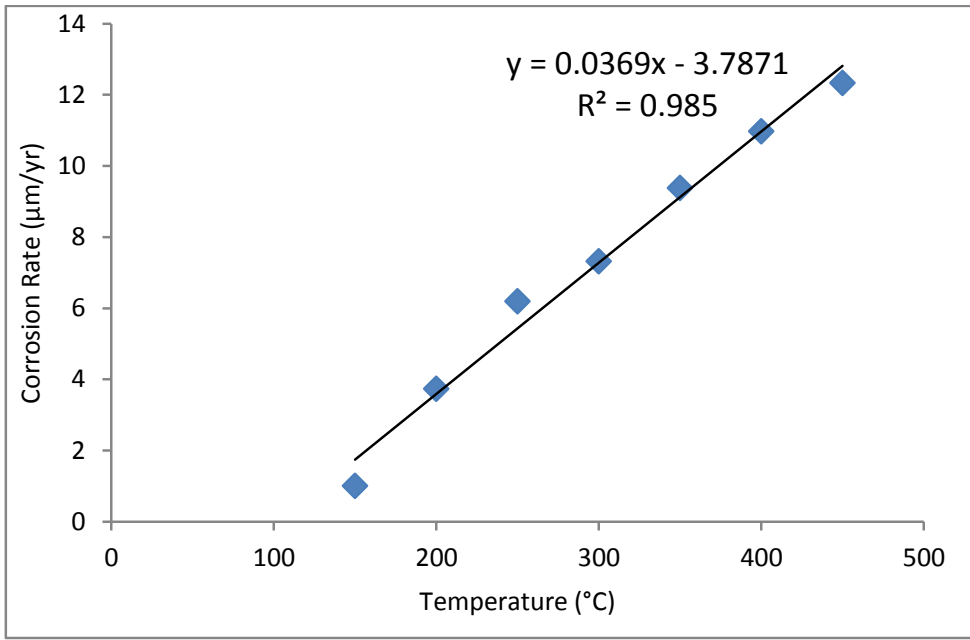

Fig. 21 Variation of corrosion rate as a function of temperature for Salt \# LiNO3-NaNO3-KNO3-MgKN 


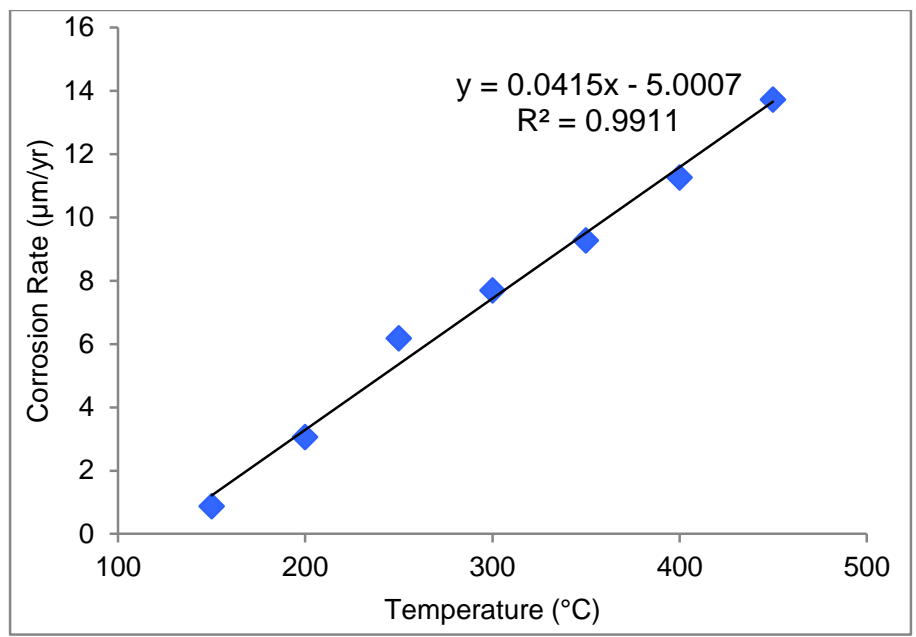

Fig. 22 Variation of corrosion rate as a function of temperature for Salt \# LiNO3-NaNO3-KNO3-NaNO2

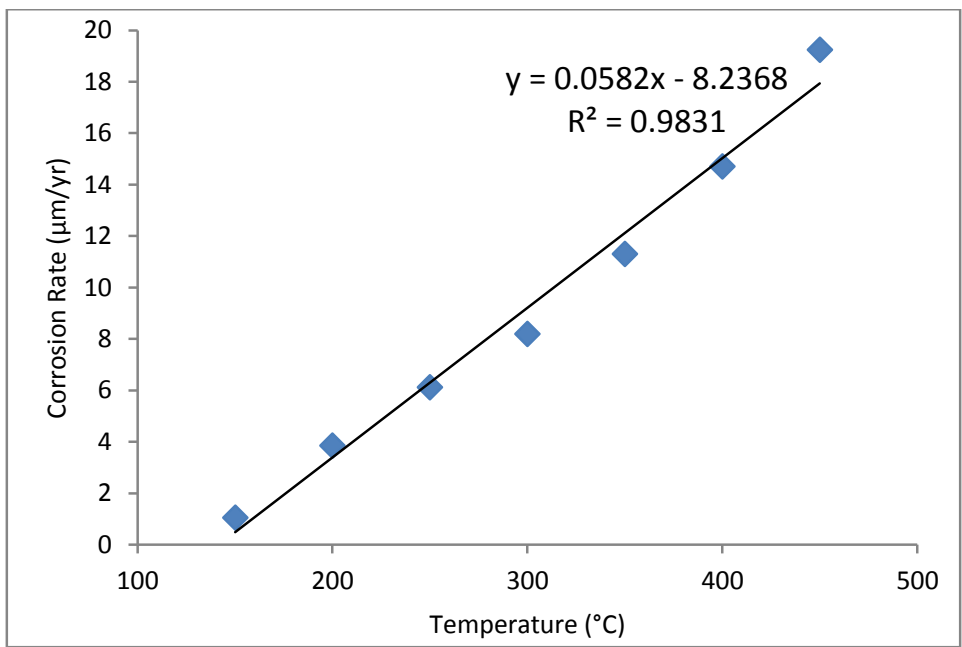

Fig. 23 Variation of corrosion rate as a function of temperature for LiNO3-NaNO3-KNO3-NaNO2$\mathrm{KNO} 2$

The corrosion rates of SS 316 stainless steel coupons in low melting point molten salts at $500^{\circ} \mathrm{C}$ were tabulated in Table 11. In all cases, the corrosion rate at $500{ }^{\circ} \mathrm{C}$ is $<22 \mu \mathrm{m} / \mathrm{yr}$. This would imply less than $450 \mu \mathrm{m} / \mathrm{yr}$ corrosion over a 20 year lifetime, well within practical equipment limits for design purposes. 
Table 11 Corrosion rate of LMP molten salts at 500oC

\begin{tabular}{lc}
\hline \multicolumn{1}{c}{ System } & $\begin{array}{c}\text { Corrosion Rate } \\
\mu \mathrm{m} / \mathrm{yr}\end{array}$ \\
\hline $\mathrm{LiNO}_{3}-\mathrm{NaNO}_{3}-\mathrm{KNO}_{3}$ & 21.42 \\
$\mathrm{LiNO}_{3}-\mathrm{NaNO}_{3}-\mathrm{KNO}_{3}-\mathrm{NaNO}_{2}$ & 15.75 \\
$\mathrm{LiNO}_{3}-\mathrm{NaNO}_{3}-\mathrm{KNO}_{3}-\mathrm{KNO}_{2}$ & 18.70 \\
$\mathrm{LiNO}_{3}-\mathrm{KNO}_{3}-\mathrm{NaNO}_{2}-\mathrm{KNO}_{2}$ & 16.12 \\
$\mathrm{LiNO}_{3}-\mathrm{NaNO}_{3}-\mathrm{KNO}_{3}-\mathrm{MgKN}$ & 14.66 \\
$\mathrm{LiNO}_{3}-\mathrm{NaNO}_{3}-\mathrm{KNO}_{3}-\mathrm{NaNO}_{2}-\mathrm{KNO}_{2}$ & 20.86 \\
\hline
\end{tabular}

\section{TES Cost Analysis}

To enable a comparison of cost models with the original RPC cost goal of $\$ 15 / \mathrm{kWh}$-th and the Phase I work reported for 2009, an additional set of cost calculations was completed. This cost model used the EPRI system as a baseline, which was also the case in calculations for the project's Phase I report.

\section{System Comparisons}

The EPRI system design is a 50 MWe power plant with 6 hour TES storage, similar to Andasol 1. The system was designed to utilize solar salt as the storage material (and the heat transfer media) and had a thermal storage capacity of $880 \mathrm{MWh}$-thermal, a required salt volumetric inventory (effectively a $34 \%$ overall off-hours efficiency) with $11,855 \mathrm{~m}^{3}$ of salt plus one hot and one cold tank. Tanks were 25.1 meters diameter and 12.2 meters tall.

In contrast, the SAM baseline system is designed for 6 hours storage for a 100 MWe powerplant. The basic design as defined in supporting documents is for an oil-driven "indirect" system, and includes 2 hot and 2 cold tanks for salt storage. The thermal storage capacity is $1750 \mathrm{MWh}$-th (a little over double the half sized EPRI design). The reference TES design includes 6 oil-to-salt heat exchangers (unneeded in a direct system) and 12 circulation VFD driven pumps. Required $6 \mathrm{hr}$ salt volumetric inventory is $\sim 26250 \mathrm{~m}^{3}$ (calculated), is more than double that in the EPRI design. It is clear that the complexity and therefore equipment cost as a \% of total cost for the SAM system is higher than the EPRI system. 
Baseline system Cost comparison as shown in the table below:

Table 12 Cost Model Baseline Cost Comparisons

\begin{tabular}{|c|c|c|c|c|}
\cline { 2 - 5 } \multicolumn{1}{c|}{} & \multicolumn{2}{c|}{ EPRI } & \multicolumn{2}{c|}{ SAM } \\
\hline Basic TES Cost & $\$ 32.5 / \mathrm{kWh}-\mathrm{th}$ & $100 \%$ & $\$ 81 / \mathrm{kWh}-\mathrm{th}$ & $100 \%$ \\
\hline Material & $\$ 17.00$ & $52.3 \%$ & $\$ 35.40$ & $43.7 \%$ \\
\hline Tanks & $\$ 8.00$ & $24.6 \%$ & $\$ 24.38$ & $30.1 \%$ \\
\hline BOP & $\$ 7.50$ & $23.1 \%$ & $\$ 21.22$ & $26.2 \%$ \\
\hline
\end{tabular}

EPRI System Cost Estimates

Cost projections utilizing the EPRI system as a baseline are tabulated in Table 13 below and illustrated in Fig. 24. 2009 calculations used linear equipment scaling and are based on available energy capacity considering the full temperature spread from $500^{\circ} \mathrm{C}$ to the salt mixture melt point (as assumed in the earlier Phase I annual report). 2010 calculations are somewhat more conservative, utilizing the energy availability based upon a useful temperature range from $500^{\circ} \mathrm{C}$ down to only $200^{\circ} \mathrm{C}$. This smaller range was defined by 2010 modeling, and results in higher material requirements and therefore material costs. Also, 2010 calculations utilized 0.7 power law equipment and BOP cost scaling, again raising relative hardware costs vs. 2009 cost model assumptions.

Table 13 TES cost estimates based upon EPRI System as a baseline

\begin{tabular}{|c|c|c|c|c|c|c|}
\hline & \multicolumn{3}{|c|}{ EPRI Basis - 2009 Calculation } & \multicolumn{3}{|c|}{ EPRI Basis - 2010 Calaulation } \\
\hline & $\begin{array}{c}\text { Tank+BOP } \\
\text { cost }\end{array}$ & Salt Material & TES Total & \begin{tabular}{|c} 
Tank+BOP \\
cost \\
\end{tabular} & \begin{tabular}{|c|} 
Salt \\
Material \\
\end{tabular} & TES Total \\
\hline & $\$ / \mathrm{kWh}$-th & $\$ / k W h-t h$ & $\$ / \mathrm{kWh}$-th & $\$ / \mathrm{kWh}$-th & $\$ / \mathrm{kWh}$-th & $\$ / \mathrm{kWh}$-th \\
\hline Solar Salt Baseline & 15.50 & 15.71 & $\$ 31.21$ & 15.50 & 15.71 & $\$ 31.21$ \\
\hline LiNO3-NaNO3-KNOB & 8.18 & 13.28 & $\$ 21.46$ & 11.44 & 16.96 & $\$ 28.40$ \\
\hline LiNO3-NaNO3-KNOB-NaNO2 & 7.85 & 10.42 & $\$ 18.27$ & 11.59 & 14.10 & $\$ 25.68$ \\
\hline LiNO3-NaNO3-KNO3-MaK & 7.41 & 8.74 & $\$ 16.15$ & 11.82 & 12.45 & $\$ 24.27$ \\
\hline LiNO3-NaNO3-KNO3-KNO2 & 8.07 & 8.47 & $\$ 16.54$ & 12.09 & 11.41 & $\$ 23.49$ \\
\hline LiNO3-KNO3-NaNO2-KNO2 & 7.59 & 10.59 & $\$ 18.18$ & 11.50 & 14.12 & $\$ 25.62$ \\
\hline LiNO3-NaNO3-NaNC2-KNO3-KNO2 & 7.88 & 10.35 & $\$ 18.23$ & 11.54 & 14.00 & $\$ 25.54$ \\
\hline
\end{tabular}




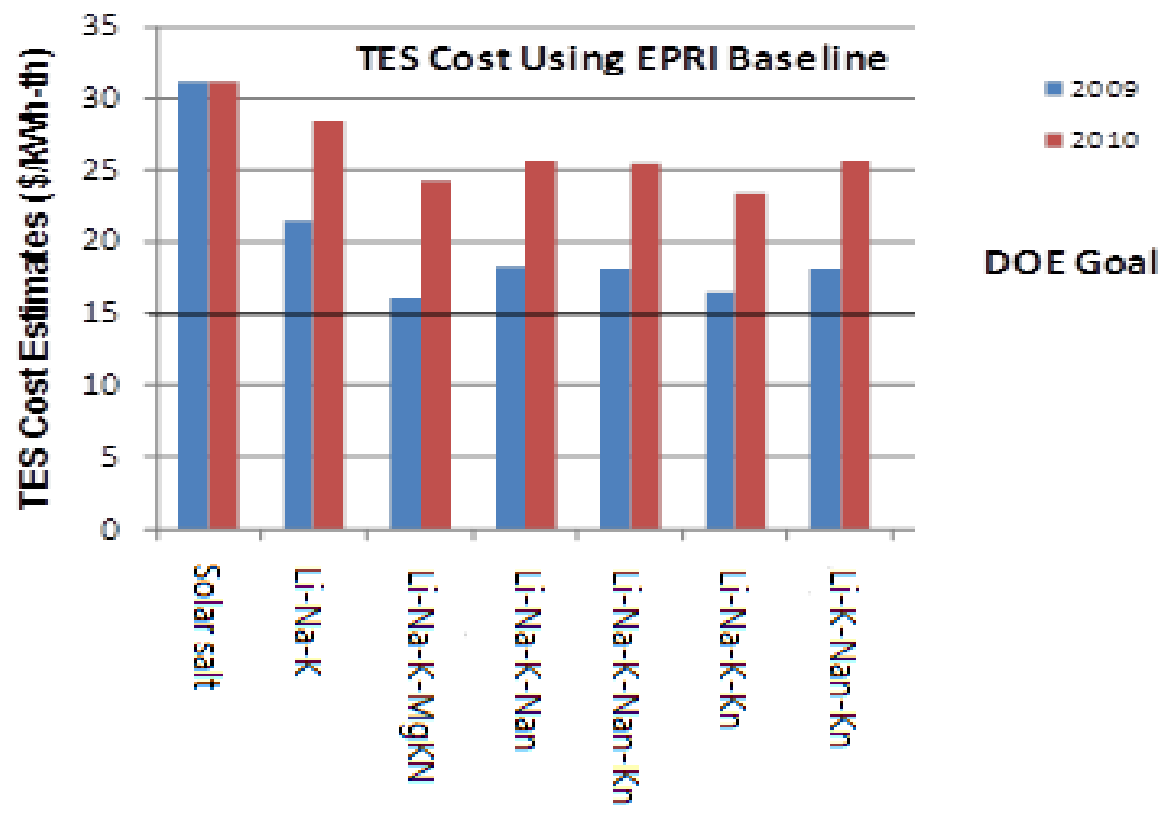

Fig. 24 TES Calculations using 2009 EPRI Baseline (from Phase I report). Blue bars assume full delta T and linear equipment scaling; red bars assume average properties at $350^{\circ} \mathrm{C}$ and 0.7 power scaling.

All estimated costs are significantly below the baseline system that used solar salt. These lower melt point salts offer significantly higher energy density per volume than solar salt - and therefore attractively smaller inventory and equipment costs.

\section{Other Considerations Beyond the Choice of "Optimized Salt and TES geometry"}

To fully consider the use of the molten salt as a heat transfer fluid in a solar trough collection field, other concerns regarding solar collector field size, and parasitic pump energy need to be evaluated. These elements would all be part of the overall assessment of LCOE for the options proposed. Preliminary consideration of these factors is described below.

Potential solar field expansion needs to be examined because we are collecting and using a slightly higher amount of solar energy for some cases of the 200C - 500C salt based system. Table 14 below shows the results of the preliminary analysis. The cases illustrated are Case 1 where oil is used as the HTF, Case 2 using salt 5 as the HTF but no feedwater heating, and Case 5 for salt as the HTF and using it to preheat all feedwater heaters.

In the table below, solar input required is the MWth needed to produce a MWe during daytime hours. The collection rate column calculates the MWth needed from the field during the day assuming that extra heat is collected during each of 10 hours of on-sun operation to transfer to the storage fluid for an additional 6 hours of off-sun operation. An estimate of 200 parabolic trough loops in the field is made (conservative - SAM model uses 230 loops), and the Oil HTF case is used to calculate the heat/loop. This $2145 \mathrm{kWth} /$ loop is assumed to be the limiting collector heat 
availability per loop for the molten salt HTF fluid cases as well - also a very conservative assumption. Salt flow rates are calculated using the energy $/ \mathrm{m}^{3}$ needed by the salt in each case. And finally a pressure drop / loop is calculated assuming a $70 \mathrm{~mm}$ inner collector diameter, a $400 \mathrm{~m}$ length, and fluid densities and viscosities at mid-field temperature (350C).

Table 14 . Oil vs. Salt - Solar Field Size, HTF Flow Rates and Comparative Pressure Drops

\begin{tabular}{|c|c|c|c|c|c|c|c|c|c|c|c|}
\hline Case \# & Plant Outpu & Efficiency & $\begin{array}{c}\text { Solar Input } \\
\text { Required }\end{array}$ & $\begin{array}{l}\text { Collection } \\
\text { Rate } \\
\text { MWth }\end{array}$ & $\begin{array}{c}\text { Collection } \\
\text { per loop } \\
\text { assume } \\
200 \text { loops }\end{array}$ & $\begin{array}{c}\text { Loops } \\
\text { needed }\end{array}$ & $\begin{array}{c}\text { HTF } \\
\text { Energy } \\
\text { Density* } \\
\text { to collect }\end{array}$ & $\begin{array}{c}\text { HTF flow } \\
\text { daytime }\end{array}$ & $\begin{array}{c}\text { HTF flow } \\
\text { daytime }\end{array}$ & $\begin{array}{c}\text { Velocity } \\
\text { in each } \\
\text { loop }\end{array}$ & $\begin{array}{c}\text { Pressure } \\
\text { Drop / } \\
400 \mathrm{~m} \\
\text { loop }\end{array}$ \\
\hline & & & MWth & $\begin{array}{c}10 \mathrm{~h} \text { collect } \\
16 \mathrm{hr} \text { operate }\end{array}$ & kW/loop & & $\begin{array}{c}\mathrm{kW} / \mathrm{m}^{3} \\
/ \text { pass }\end{array}$ & $\mathrm{m}^{3} / \mathrm{sec}$ & $\mathrm{m}^{3} / \mathrm{hr}$ & $\mathrm{m} / \mathrm{sec}$ & bar \\
\hline 1-Oil HTF & $100 \mathrm{MW}$ & $37.3 \%$ & 268.1 & 429.0 & 2145 & 200 & 51.8 & 0.0115 & 41.40431 & 2.989 & 2.34 \\
\hline 2-Salt HTF & $100 \mathrm{MW}$ & $39.2 \%$ & 255.1 & 408.2 & 2145 & 190 & 188.4 & 0.0032 & 11.38535 & 0.822 & 0.89 \\
\hline 5-Salt HTF & $100 \mathrm{MW}$ & $36.0 \%$ & 277.8 & 444.4 & 2145 & 207 & 226.1 & 0.0026 & \begin{tabular}{|l|}
9.487792 \\
\end{tabular} & 0.685 & 0.65 \\
\hline
\end{tabular}

From the calculation of "Loops needed", it can be seen that the Case 5 (recommended TES geometry and salt) solar field would be only $3.5 \%$ larger than the baseline Case 1 (oil HTF) field, and in fact Case 2 would result in a smaller field. The (volumetric) flow rates and flow velocities for the salt are much smaller than for oil, and the calculated pressure drops/loop are also lower, indicating there would potentially be a reduction in parasitic pumping power from the salt as HTF cases.

\section{System Integration Modeling}

\section{$\underline{\text { Salt as a Heat Transfer Fluid }}$}

By going from a system where oil is used as the heat transfer fluid to the use of molten salt as the HTF, several advantages are available for the solar trough electrical generation system. First, use of salt enables raising Rankine cycle temperature to $490^{\circ} \mathrm{C}$ from $390^{\circ} \mathrm{C}$ - adding nearly $2 \%$ efficiency improvement to the power block. Secondly, because the higher steam temperature results in a reduction of steam flow to achieve the same electrical output, power block equipment size and cost reductions are potentially available. And finally, the TES system can now be run as a two tank, "direct" storage system rather than a two tank "indirect" system. This eliminates a costly and efficiency reducing step of transferring heat to the salt storage media and the retransferring heat back to the oil during off-sun hours.

Visual comparison of the two systems can be seen in process schematics below; Fig. 25 for the baseline-line oil HTF system (using a two tank indirect thermal storage system) and Fig. 26 depicting the salt based HTF system that enables operation as a two tank "direct" TES system. 


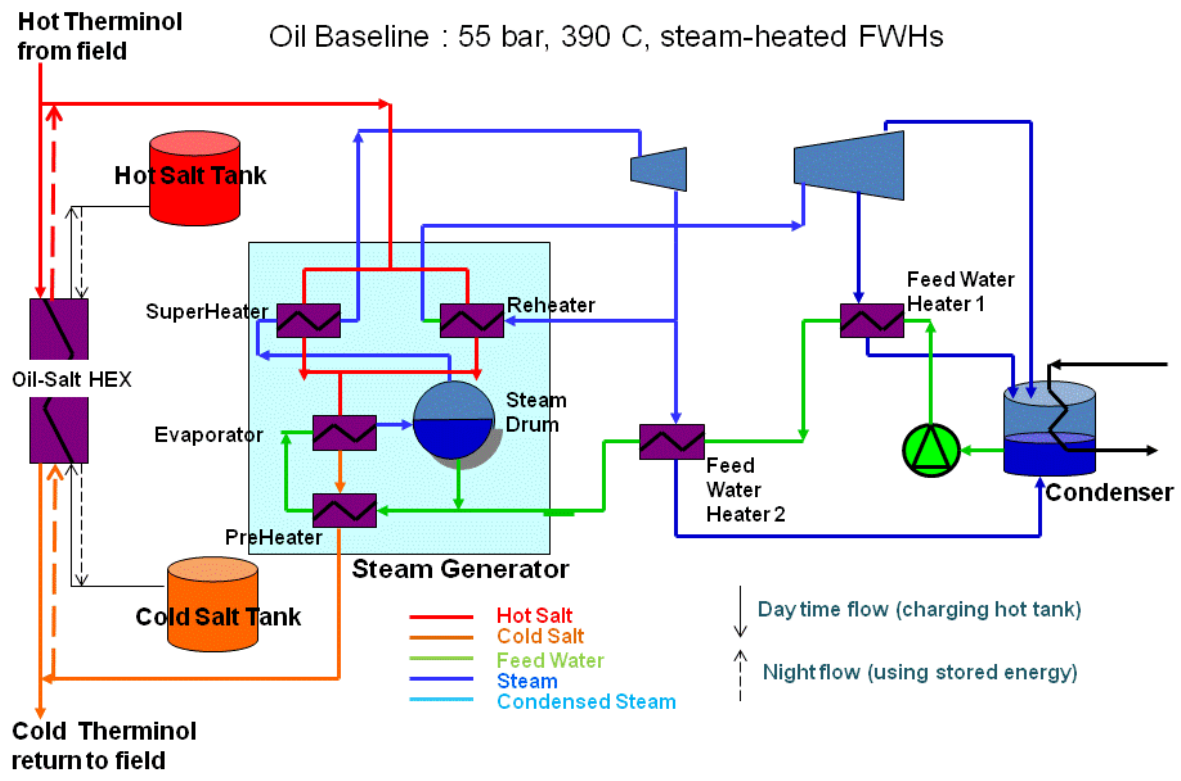

Fig. 25 Oil based HTF system - 2 Tank "Indirect" TES - Baseline Case 1

Note: additional feedwater heaters and steam extraction lines from the low pressure turbine have been inserted in Fig. 26 below to provide better modeling fidelity for the actual power block configuration.

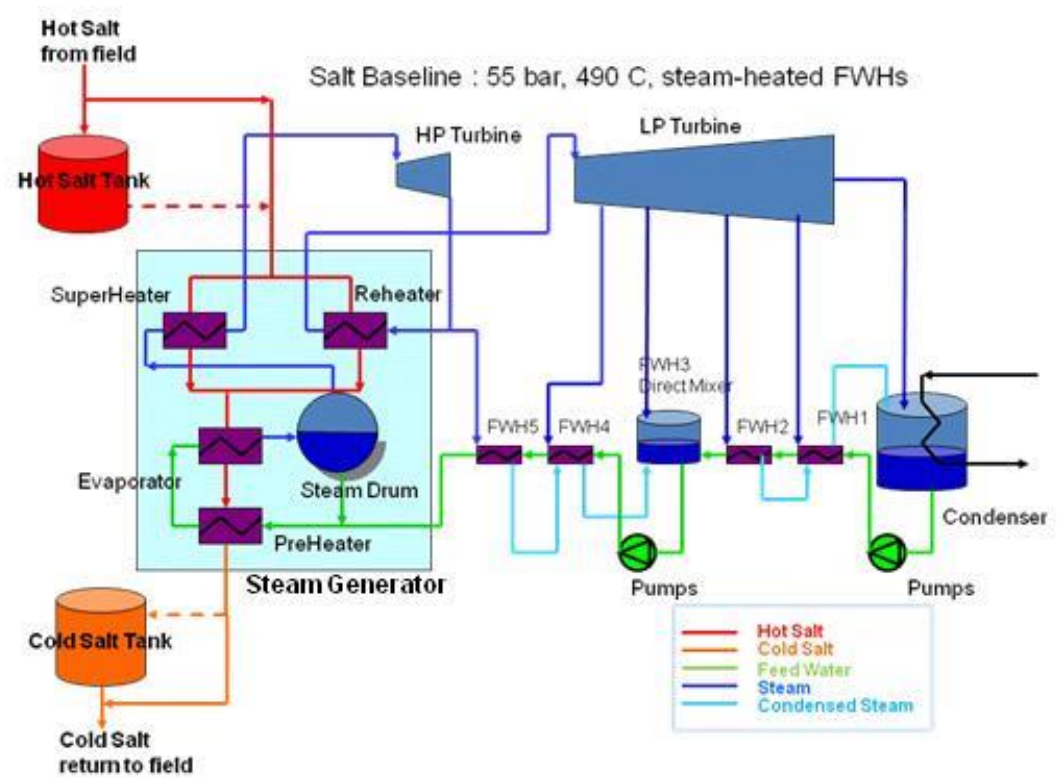

Fig. 26 Molten Salt based HTF system - 2 Tank "Direct" TES - Case 2

\section{$\underline{\text { Preheating Condensate Feedwater with Salt vs. Steam }}$}

Preheating of the condensed feedwater was evaluated to make greater use of the low temperature sensible heat from the salt HTF. We increasingly replaced steam lines that were extracting heat 
from various turbine sections and instead, used salt in each case to preheat the feedwater. In the end, the maximum heat and value was contributed by applying the salt stream exiting the Steam Generator subsystem to counter-currently heat all sensible feedwater heaters (FWH 5, 4, 2 and 1) as shown in Fig. 27.

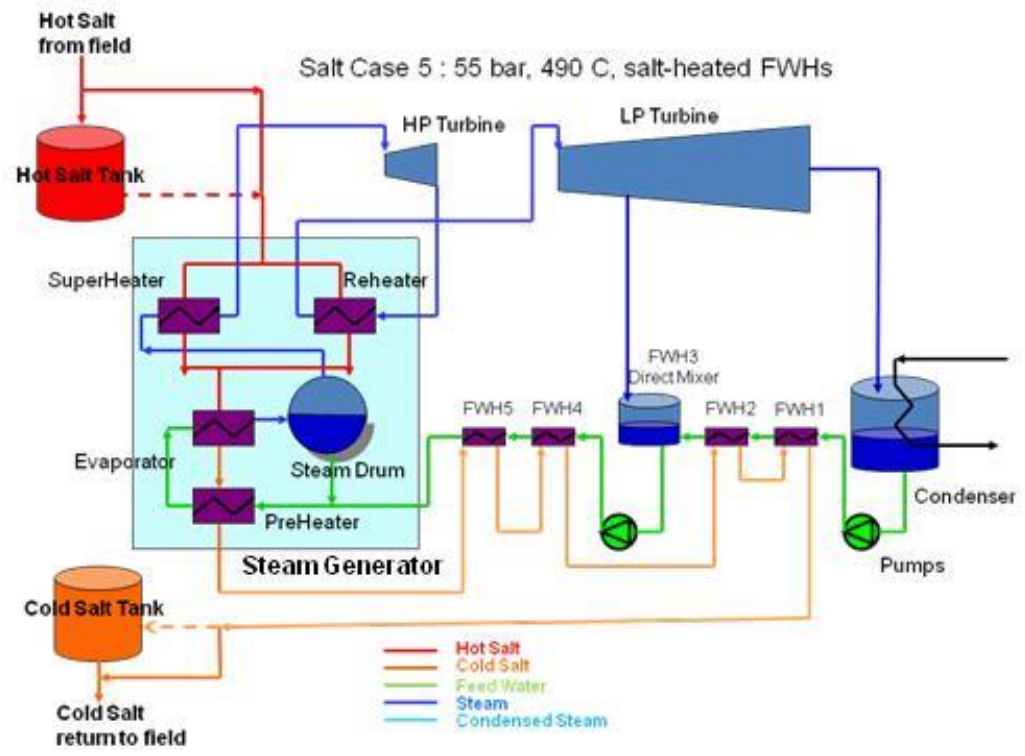

Fig. 27 Molten Salt based HTF system - 2 Tank "Direct" TES with salt heating all FWH (except FWH3 which is a deaerator) - Case 5

\section{Analysis of Novel Thermal Storage Configuration Concepts}

One set of modeling results for the multiple system configurations studied are presented in Table 15. The configuration row shows the baseline oil-"indirect" TES case 1 which uses solar salt, the use of $\mathrm{LiNO}_{3}-\mathrm{NaNO}_{3}-\mathrm{KNO}_{3}$ as a HTF with 2 tank "direct" TES in case 2 and then in cases 3-5 where $\mathrm{LiNO}_{3}-\mathrm{NaNO}_{3}-\mathrm{KNO}_{3}$ salt is increasingly used to preheat the feedwater.

Note: Additional data for solar power plants with no storage are shown in cases $A$ and $B$ for reference only.

Table 15 Modeling Results from Expanded Molten Salt Energy Use - Cases Using $\mathrm{LiNO}_{3}$ -

\begin{tabular}{|c|c|c|c|c|c|c|c|c|c|c|c|c|c|c|}
\hline & & \multicolumn{5}{|c|}{ Power } & \multicolumn{3}{|c|}{ Feed Water Heating } & \multicolumn{3}{|c|}{ Plus Low Pressure Superheater } & \multicolumn{2}{|c|}{ TES Elements } \\
\hline & & $\begin{array}{c}\text { HTF temp } \\
\text { to Steam } \\
\text { Gen }\end{array}$ & Efficiency & $\begin{array}{c}\text { Steam } \\
\text { Flow Rate }\end{array}$ & $\begin{array}{c}\text { Steam } \\
\text { Pressure }\end{array}$ & $\begin{array}{c}\text { Salt } \\
\text { Flow Rate }\end{array}$ & $\begin{array}{l}\text { Salt in } \\
\text { Temp }\end{array}$ & $\begin{array}{l}\text { Salt out } \\
\text { Temp }\end{array}$ & $\begin{array}{c}\text { Total Low } \\
\text { Temp Q } \\
\text { from Salt }\end{array}$ & $\begin{array}{l}\text { Salt in } \\
\text { Temp }\end{array}$ & $\begin{array}{l}\text { Salt out } \\
\text { temp }\end{array}$ & $\begin{array}{c}\text { Total Low } \\
\text { Temp Q } \\
\text { from Salt }\end{array}$ & $\begin{array}{c}6 \mathrm{hr} \text { active } \\
\text { salt inventory }\end{array}$ & $\begin{array}{c}\text { Individual } \\
\text { Tank } \\
\text { Volume }\end{array}$ \\
\hline \multirow[t]{2}{*}{ Case: } & Configuration & C & $\%$ & $\mathrm{~kg} / \mathrm{sec}$ & bar & $\mathrm{kg} / \mathrm{sec}$ & C & C & $\mathrm{kJ}$ & C & C & $\mathrm{kJ}$ & Metric tonnes & $\mathrm{m}^{3}$ \\
\hline & With 6 hrs Storage & & & & & & & & & & & & & \\
\hline 1 & Baseline: 2 Tank Indirect Parabolic Trough ${ }^{\star}$ & $390 / 373$ & 37.3 & 108.6 & 91 & - & 294 & & & & & & 45502 & 31500 \\
\hline 2 & \begin{tabular}{|l|} 
U-A Salt 2 Tank Direct Parabolic Trough \\
\end{tabular} & 490 & 39.2 & 91.8 & 55 & 765 & & & & & & & 19815 & 10648 \\
\hline 3 & w/salt heating FWH5,4 & 490 & 38.4 & 85.6 & 55 & 612 & 250.1 & 227.4 & 21589 & & & & 15869 & 8527 \\
\hline 4 & w/ salt heating FWH 5,4,and 2 & 490 & 37.4 & 84 & 55 & 602 & 250.1 & 215.3 & 32664 & & & & 15591 & 8378 \\
\hline \multirow[t]{2}{*}{5} & w/ salt heating all FHW & 490 & 36 & 82.6 & 55 & 591 & 250.1 & 198.6 & 47476 & & & & 15326 & 8235 \\
\hline & With No Storage & & & & & & & & & & & & & \\
\hline A & Parabolic Trough ${ }^{\star}$ & 393 & 37.9 & 112.8 & 101 & & & & & & & & & \\
\hline B & Power Tower ${ }^{\star \star}$ & 550 & 42.1 & 85.5 & 120 & 616 & & & & & & & & \\
\hline & & & & & & & & & & & & & & \\
\hline ** Bas & seline data from Dasgupta original flowsheet - & reviewed & y PW_Rock & dyne & & & & & & & & & & \\
\hline
\end{tabular}


All plant configurations are for 100MW net power blocks with $6 \mathrm{hrs}$ storage similar to the plant described in a 2010 NREL subcontractor Report. Tank size has been calculated to include a $10 \%$ salt heel and a $10 \%$ headspace beyond the salt volume needed for 6 hours of steam generation.

\section{Case Comparisons}

Case 1 to Case 2 - by changing from oil to low melt point salt as the heat transfer fluid, the temperature of the $\mathrm{HTF}$ can now reach $500 \mathrm{C}$ in the solar field, resulting in a steam temp of $490^{\circ} \mathrm{C}$ $-100^{\circ} \mathrm{C}$ higher than when using oil HTF. As mentioned earlier, this provides nearly a 2 point efficiency gain in the power block and a $10 \%$ reduction in steam flow rate that potentially can turn into smaller power block heat exchange equipment. There may be additional gains available by going to 100 psi steam pressure from the 55 psi used throughout cases in this analysis.

Cases 3-5 look at increasing the use of salt to preheat the feedwater. Salt exits the preheater in the steam generator subsystem at 250C. Cases 3-5 evaluate using the sensible heat in that stream to preheat the condensed feedwater, thereby reducing the number and amount of steam lines pulling heat from various low pressure turbine sections. As more salt heat is utilized, the overall system efficiency goes down by several points (it is an artifact of calculation: efficiency $=\mathrm{MWe} / \mathrm{MWth}$ energy from field). However, it also results in a reduced steam flow (slightly) and commensurately smaller salt flow rate, which will further lower heat exchange and TES component size (see active salt inventory and individual tank volume) and subsequent capital costs.

Key metrics for the full set of system configurations, exploring each case with each salt, are listed in Table 16 below.

Table 16 Key Metric Comparison for All Cases and All Salts

\begin{tabular}{l|ccccc}
\hline & \multicolumn{2}{|c}{$\begin{array}{c}\text { Steam Flow } \\
\mathrm{kg} / \mathrm{sec}\end{array}$} & \multicolumn{5}{c}{$\begin{array}{c}\text { Active Salt Inventory for 6 Hours Storage } \\
\text { 000 Metric Tons }\end{array}$} \\
& All cases & Li-Na-K & Li-Na-K-MgKN & Li-Na-K-Nan & Li-Na-K-Nan-Kn \\
\hline Case 1 & 108.6 & 45.5 & & & \\
Case 2 & 91.8 & 19.8 & 20.6 & 20.1 & 20.1 \\
Case 3 & 85.6 & 15.9 & 16.5 & 16.1 & 16.1 \\
Case 4 & 84 & 15.6 & 16.2 & 15.8 & 15.8 \\
Case 5 & 82.6 & 15.3 & 15.9 & 15.5 & 15.5 \\
\hline
\end{tabular}

The most dramatic change in the TES system is shown going from the baseline case 1 to case 2 . The volume of active salt inventory required to achieve the 6 hour storage - illustrated in the data above - goes from 45.5 tonnes (Case 1-Oil HTF-Indirect salt storage) to 19.8 tonnes (Case 2 -salt HTF - direct storage), a $2 / 3$ inventory reduction. This is most easily understood by considering that the sensible heat in the stored salt is being provided over a 300C range in the proposed system 
(500C down to $200 \mathrm{C}$ ) rather than only a 100C range in the baseline "indirect" TES oil based system (390 down to 290C).

Differences in active salt inventory for each specific case across the mixtures $1-6$ are primarily due to differences in each salt's energy density $\left(\mathrm{kW} / \mathrm{m}^{3}-{ }^{\circ} \mathrm{K}=\mathrm{Cp} * \rho\right)$. Reductions in inventory requirements down the cases for a particular salt are driven by increasingly smaller steam and salt flow rates. As more salt feedwater heating is done, less steam is withdrawn from the turbines for water preheating. Therefore, a greater $\%$ of the steam is used to make electricity, thus the total steam flow requirement goes down, and salt flow rates, which are a function of steam flow, also get smaller. From this analysis (no costs yet included), it would appear that the $\mathrm{LiNO}_{3}-\mathrm{NaNO}_{3}$ $\mathrm{KNO}_{3}$ has the smallest 6 hour inventory, and Case 5 is the preferred TEX system configuration.

\section{Accomplishments}

Table 17 Comparison of the actual accomplishments with the goals and objectives of the project

\section{Sl. No. Goals and objectives}

1

Development of novel low
point molten salt systems

2 Determination of melting point

3 Determination of heat capacity.

$4 \quad$ Determination of density

5 Determination of thermal stability

6

\section{Actual accomplishments}

Many novel low melting point molten salt systems were developed using thermodynamic modeling method

Successful determined the melting points of novel molten salt systems and the values have excellent agreement with predicted values.

Heat capacities of novel salt systems were successfully determined using DSC. The heat capacities were also extrapolated to the maximum operation temperature of molten salts.

Densities were successfully determined and compared using two different methods. The offsetting effect of lithium nitrate is consistent with findings in previous literatures.

The short-term, long-term and upper limit of thermal stability have been successfully determined using TG-DTA \& DSC.

The corrosion behavior and corrosion rate of molten salts to stainless steel have 
$7 \quad$ System Integration modeling

been determined using electrochemical and dipping methods.

Five different cases of system integration based on oil HTF and molten salt HTF have been analyzed and compared. A new TES system geometry has been recommended.

\section{Summary}

Concentrating solar power (CSP) technologies are seen as the Solar Program's most attractive option for meeting utility-scale needs in the U.S. southwest. The Department of Energy (DOE) is conducting research and development activities that will reduce the cost of CSP plants and facilitate their implementation. Two key opportunities for cost reduction are the development of improved heat transfer fluids and improved methods for thermal storage. As part of this direction, DOE has issued contract DE-FG36-08GO18153 to the University of Alabama (UA).

The explicit UA program objective is to develop low melting point (LMP) molten salt thermal energy storage media with high thermal energy storage density for sensible heat storage systems. The novel Low Melting Point (LMP) molten salts are targeted to have the following characteristics:

1. Lower melting point (MP) compared to current salts $\left(<222^{\circ} \mathrm{C}\right)$

2. Higher energy density compared to current salts $\left(>300 \mathrm{MJ} / \mathrm{m}^{3}\right)$

3. Lower power generation cost compared to current salt

In terms of lower power costs, the program target the DOE's Solar Energy Technologies Program year 2020 goal to create systems that have the potential to reduce the cost of Thermal Energy Storage (TES) to less than $\$ 15 / \mathrm{kWh}$-th and achieve round trip efficiencies greater than $93 \%$.

The project has completed the experimental investigations to determine the thermo-physical, long term thermal stability properties of the LMP molten salts and also corrosion studies of stainless steel in the candidate LMP molten salts. Heat transfer and fluid dynamics modeling have been conducted to identify heat transfer geometry and relative costs for TES systems that would utilize the primary LMP molten salt candidates. The project also proposes heat transfer geometry with relevant modifications to suit the usage of our molten salts as thermal energy storage and heat transfer fluids.

The essential properties of the down-selected novel LMP molten salts to be considered for thermal storage in solar energy applications were experimentally determined, including melting point, heat capacity, thermal stability, density, viscosity, thermal conductivity, vapor pressure, and corrosion resistance of SS 316. The thermodynamic modeling was conducted to determine potential high temperature stable molten salt mixtures that have thermal stability up to $1000{ }^{\circ} \mathrm{C}$. The thermophysical properties of select potential high temperature stable (HMP) molten salt mixtures were also experimentally determined. 
All the salt mixtures align with the go/no-go goals stipulated by the DOE for this project. Energy densities of all salt mixtures were higher than that of the current solar salt. The salt mixtures costs have been estimated and TES system costs for a 2 tank, direct approach have been estimated for each of these materials. All estimated costs are significantly below the baseline system that used solar salt. These lower melt point salts offer significantly higher energy density per volume than solar salt - and therefore attractively smaller inventory and equipment costs. Moreover, a new TES system geometry has been recommended

A variety of approaches were evaluated to use the low melting point molten salt. Two novel changes are recommended that 1) use the salt as a HTF through the solar trough field, and 2) use the salt to not only create steam but also to preheat the condensed feedwater for Rankine cycle. The two changes enable the powerblock to operate at $500^{\circ} \mathrm{C}$, rather than the current $400^{\circ} \mathrm{C}$ obtainable using oil as the HTF. Secondly, the use of salt to preheat the feedwater eliminates the need to extract steam from the low pressure turbine for that purpose.

Together, these changes result in a dramatic $63 \%$ reduction required for 6 hour salt inventory, a $72 \%$ reduction in storage volume, and a $24 \%$ reduction in steam flow rate in the power block. Round trip efficiency for the Case 5 - 2 tank "direct" system is estimated at $>97 \%$, with only small losses from time under storage and heat exchange, and meeting RFP goals. This attractive efficiency is available because the major heat loss experienced in a 2 tank "indirect" system losses by transferring the thermal energy from oil HTF to the salt storage material and back to oil to run the steam generator at night - is not present for the 2 tank direct system. The higher heat capacity values for both LMP and HMP systems enable larger storage capacities for concentrating solar power.

\section{Products developed and technology transfer activities:}

a. publications:

Research Papers:

Tao Wang, Divakar Mantha, Ramana G. Reddy, Thermal stability of the eutectic composition in LiNO3NaNO3-KNO3 ternary system used for thermal energy storage, Solar Energy Materials and Solar Cells, 100 (2012) 162-168.

Divakar Mantha, Tao Wang, Ramana G. Reddy, Thermodynamic Modeling of Eutectic Point in the LiNO3-NaNO3-KNO3 Ternary System, Journal of Phase Equilibria and Diffusion, 33 (2012) 110-114.

Ramana G. Reddy, Tao Wang, Divakar Mantha, Determination of thermodynamic properties of 2KNO3·Mg(NO3)2, Thermochimica Acta, 531 (2012) 6-11.

Tao Wang, Srinath Viswanathan, Divakar Mantha, Ramana G. Reddy, Thermal conductivity of eutectic salt mixtures in solid state using inverse method, Solar Energy Materials and Solar Cells, 102 (2012) 201-207.

Tao Wang, Divakar Mantha, Ramana G. Reddy, High Thermal Energy Storage Density LiNO3-NaNO3KNO3-KNO2 quaternary Molten Salt for Parabolic Trough Solar Power Generation, Energy Technology 
2012: Carbon Dioxide Management and Other Technologies, TMS, Warrendale, PA, USA, pp. 73-84, 2012.

Tao Wang, Divakar Mantha, Ramana G. Reddy, Novel low melting point quaternary eutectic system for solar thermal energy storage, Applied Energy, 102 (2013) 1422-1429.

Tao Wang, Divakar Mantha, Ramana G. Reddy, Thermodynamic properties of LiNO3-NaNO3-KNO32KNO3.Mg(NO3)2, Thermochimica Acta, 551 (2013) 92-98.

Divakar Mantha, Tao Wang, Ramana G. Reddy, Thermodynamic modeling of eutectic point in the LiNO3-NaNO3-KNO3-NaNO2 quaternary system, Solar Energy Materials and Solar Cells, 118 (2013) $18-21$.

Tao Wang, Ramana G. Reddy, Novel LiNO3-NaNO3-KNO3-NaNO2 Molten Salts for Solar Thermal Energy Storage Applications, Energy Technology 2014 (In press).

Tao Wang, Divakar Mantha, Ramana G. Reddy, The corrosion behavior of SS316L in the LiNO3NaNO3-KNO3-NaNO2 quaternary eutectic molten salt system, Corrosion Science 2013 (Submitted).

Tao Wang, Divakar Mantha, Ramana G. Reddy, Melting Point, Heat Capacity, Thermal Stability and Corrosion Behavior of LiF-Na2CO3-K2CO3 Eutectic Ternary System for Thermal Energy Storage, Applied Energy 2013 (Submitted).

M.S. Thesis:

Thermal and physical properties of low melting point molten salts for solar thermal energy storage Tao Wang, MS Thesis, The University of Alabama, Tuscaloosa, AL, 2011.

b. Website:

http://www1.eere.energy.gov/solar/review meeting/pdfs/prm2010 ualabama.pdf http://www1.eere.energy.gov/solar/sunshot/pdfs/csp_review_meeting_042413_reddy.pdf

c. Networks or collaborations fostered:

United Technologies Research Center

d. Technologies/Techniques:

N/A

e. Inventions/Patent Applications, licensing agreements:

N/A

f. Other products:

N/A 


\section{References}

[1] J.F. Manwell, J.G. McGowan, A.L. Rogers, Wind Energy Explained - Theory, Design and Application, second edition, John Wiley and sons Ltd., UK, 2009.

[2] M.J. Pasqualetti, Morality, space and the power of wind-energy landscapes. Geographical Review, 90, 2000, 381-394.

[3] D.G. Fink, H.W. Beaty, Standard Handbook for Electrical Engineers, Eleventh Edition, McGraw-Hill, New York, 1978.

[4] T.A. Volk, L.P. Abrahamson, E.H. White, E. Neuhauser, E. Gray, C. Demeter, C. Lindsey, J. Jarnefeld, D.J. Aneshansley, R. Pellerin and S. Edick, Developing a Willow Biomass Crop Enterprise for Bioenergy and Bioproducts in the United States, Proceedings of Bioenergy 2000, October 15-19, 2000, Buffalo, New York, USA

[5] J. Edmunds, R. Richets; M. Wise, Future Fossil Fuel Carbon Emissions without Policy Intervention: A Review, The carbon cycle, edited by T. M. L. Wigley and David Steven Schimel, Cambridge University Press, 2000, pp.171-189.

[6] M. Asplund, N. Grevesse, A.J. Sauval, The new solar abundances - Part I: the observations, Communications in Asteroseismology, 147, 2006, 76-79.

[7] D.R.Williams, Sun Fact Sheet, NASA, 2004, http://nssdc.gsfc.nasa.gov/planetary/factsheet/sunfact.html

[8] U. Herrmann, Survey of Thermal Energy Storage for Parabolic Trough Power Plants, Journal of Solar Energy Engineering, 124, 2002, 145 - 152

[9] Rocket Research Company, Chemical energy storage for solar thermal conversion, SAND798198, Livermore, Sandia National Laboratories, 1979.

[10] A. Steinfeld, R. Palumbo, Solar thermochemical process technology, Encyclopedia of Physical Science and Technology, 2001, 237-256

[11] E.A. Fletcher, Solarthermal processing: a review, Journal of Solar Energy Engineering, 2001, 63-74

[12]. R. W. Bradshaw and Nathan P. Siegel, Molten Nitrate Salt Development for Thermal Energy Storage in Parabolic Trough Solar Power Systems, of the Energy Sustainability 2008 Conference, August 10-14, 2008, Jacksonville, Florida USA

[13] B. Kelly, H. Price, D. Brosseau, D. Kearney, Adopting Nitrate/Nitrite Salt Mixtures as the Heat Transport Fluid in Parabolic Trough Power Plants, Proceedings of the Energy Sustainability 2007 Conference, June 27-30, 2007, Long Beach, CA.

[14] H. Reilly, G. Kolb, Evaluation of Molten Salt Power Tower Technology Based on Experience at Solar Two, SAND2001-3674, Sandia National Laboratories, 2001. 
[15] T. Wendelin, "Parabolic Trough VSHOT Optical Characterization in 2005-2006," NREL, www.nrel.gov/docs/fy06osti/40024.pdf.

[16] R.B. Diver, C. Andraka, S. Rawlinson, V. Goldberg, G. Thomas, 2001, "The Advanced Dish Development System Project," ASME Proceedings of Solar Forum 2001, Washington, D.C

[17] S. D. Odeh, G. L. Morrison, M. Behnia, Modelling of parabolic trough direct steam generation solar collectors, Solar Energy, 62, 1998, 396 - 406

[18] V. Heinzel, H. Kungle, M. Simon, Simulation of a parabolic trough collector, ISES Solar World Congress, Harare, Zimbabwe, 1-10

[19] S. D. Odeh, G. L. Morrison, M. Behnia, Modeling of Parabolic Trough Direct Generation Solar Collectors, Solar Energy, 62, 1998, 395-406

[20] Ezzat, Optimum Working Fluids for Solar Powered Rankine Cycle Cooling of Buildings, Solar energy, 25, 1980, 235-241

[21] R. G. Reddy, Ionic Liquids: How well do we know them, editorial, Journal of Phase Equilibria and Diffusion, 27, 2006, 210-211.

[22] M. Zhang, R. G. Reddy, Application of [C4min][Tf2N] Ionic Liquid as Thermal Storage and Heat Transfer Fluids, editor J. Weidner, ECS Transactions, 2 (28), 2007, 27-32.

[23] M. Zhang, R. G. Reddy, Evaluation of Ionic Liquids as Heat Transfer Materials in Thermal Storage Systems, Energy: Energy Materials, editors: F. Dogan, M. Awano, D. Singh and B. Tuttle, ASM International, Materials Park, Ohio, USA MS\&T’07, 2007, 151-160.

[24] R. G. Reddy, Novel Applications of Ionic Liquids in Materials Processing, Advanced Structural and Functional Materials Design 2008, Journal of Physics: Conference Series (JPCS), 165, 2009, 1-6.

[25] R.W. Bradshaw, D.E. Meeker, High-temperature stability of ternary nitrate molten salts for solar thermal energy systems, Solar Energy Materials, 21, 1990, 51-60 